\title{
From banks' strategies to financial (in)stability
}

October 17, 2016

\begin{abstract}
This paper aims to shed light on the emergence of systemic risk in credit systems. By developing an interbank market with heterogeneous financial institutions granting loans on different network structures, we investigate which market architecture is more resilient to liquidity shocks and how the risk spreads over the modeled system. In our model, credit linkages evolve endogenously via a fitness measure based on different banks' strategies. Each financial institution, in fact, applies a strategy based on a low interest rate, a high supply of liquidity or a combination of them. Interestingly, the choice of the strategy influences both the banks' performance and the network topology. In this way, we are able to identify the most effective tactics adapt to contain contagion and the corresponding network topology. Our analysis shows that, when financial institutions combine the two strategies, the interbank network does not condense and this generates the most efficient scenario in case of shocks.

JEL codes: G01; G02; D85

Keywords: Interbank market; dynamic network; fitness model; network resilience; bank strategy.
\end{abstract}

\section{Introduction}

The role of the financial sector and the effects of financial development on the economic system have been extensively debated (Schumpeter 1911; Robinson 1952). Specifically, the development of the financial sector has traditionally been indicated as a key ingredient of the economic growth (Rajan and Zingales 1998; Levine 2005), as an instrument to foster entrepreneurship (Black and Strahan 2002) and increase firms' productivity (Herrera and Minetti 2007, Dabla Norris et al. 2012). However, recent evidence has suggested that the rapid flourishing of the finance industry could have a negative effect on the economic system (Arcand et al. 2011). The fast expansion of the financial sector in the last decades, therefore, has been associated with an increased economic instability and fragility and with a higher systemic vulnerability (Wray 2009; Tridico 2012). In this respect, the European Central Bank (ECB) itself is worried about the fact the tools 
currently available to monitor financial systems are insufficient (see Trichet 2010). Such inadequacy is also among the major concerns of the European Commission, which has just created the European Systemic Risk Board.

A general discontent over the ability of our current theoretical frameworks to fully understand economic systems and evaluate their systemic properties has led scholars to analyze them in a dynamic way. Specifically, the present situation is ripe for a change of approach. ECB has officially called for (1) more integrated systems, (2) a systemic approach that takes into account the network of financial exposures, and (3) new appropriate systemic risk indicators (Issing 2009).

Following this line of thought, in this paper, we present a stylized interbank market and analyze the endogenous source of instability in the credit system. By combining network theory and heterogeneous agents approach we investigate, in an evolutionary framework, the dynamics which are detrimental to the financial stability. Specifically, we emphasize the effect of different banks' strategies and different network architectures on the resiliency and robustness of the credit system. Indeed, as the economic literature on contagion has highlighted, the financial market structure and its interconnectedness are key ingredients to explain systemic failure propagation. The common idea is that two opposite effects interact in credit networks: risk sharing, which decreases with the network connectivity and systemic risk that, in contrast, increases with linkages (see, for instance, Allen and Gale 2000, Thurner et al. 2003, Iori et al. 2006, Battiston et al. 2007, Battiston et al. 2012a,b, Tedeschi et al. 2012).

In confirmation of the results of many of the above mentioned studies, this work shows that the relationship between connectivity and systemic risk is not linear but involves different forces. Specifically, agents' heterogeneity and their financial fragility seem to be a leading force in generating propagation of systematic failure. On the one hand, in fact, the possible emergence of contagion depends crucially on the degree of heterogeneity. Indeed, when the agents' balance sheets are heterogeneous, banks are not uniformly exposed to their counter-party. Therefore, if contagion is triggered by the failure of a big bank, which represents the highest source of exposure for its creditors, the situation is certainly worse than when agents are homogeneous (see Iori et al. 2006; Caccioli et al. 2012; Lenzu and Tedeschi 2012; Tedeschi et al. 2012). On the other hand, the probability of default in credit markets is strictly linked to the presence of highly leveraged agents (see Gonzalez 2013; Gonzalez and Gonzalez 2014). Indeed, when variations in the level of financial robustness of institutions tend to persist in time or to get amplified, financial linkages among financially fragile banks represent a propagation channel for contagion and a source of systemic risk (see Lorenz and Battiston 2008; Battiston et al. 2012a). Moreover, our analysis shows that another force plays a crucial role in causing financial distress, namely the interest rate. When a lender accords a loan to an over-leveraged agent it 
applies, via the financial accelerator (see Bernanke and Gertler 1989, 1990; Grilli et al. 2014, a,b) higher interest rate. This, in turn, worsens the financial condition of the borrower itself pushing it towards the bankruptcy state. If one or more borrowers are not able to pay back their loans, even the lenders' equity is affected by bad debts. Therefore, lenders reduce their credit supply and increase the borrowers' rationing. In this way, the profit margin of borrowers decreases and a new round of failures may occur.

The problems arising from financial market interconnectedness have also been highlighted by empirical studies, which have analyzed the properties of credit networks during different phases of the economic cycle (Cocco et al. 2009; Hale 2011; Schiavo et al 2010; Minoiu and Reyes 2011; Chinazzi et al. 2012; Memmel and Sachs 2013; Tonzar 2015) and defined new analytical tools able to better identify and monitor systemic risk and crisis transmission (Sornette and Von der Becke 2011; Kaushik and Battiston 2012; Catullo et al. 2015).

The originality of this work in respect to previous mentioned models on interbank networks is in the credit linkages evolution. In our framework financial connections might change over time via a preferential attachment evolving procedure (see Barabasi and Albert 1999; Tedeschi et al. 2014; Grilli et al. 2014b) such that each financial institution can enter into a lending relationship with others with a probability proportional to a fitness measure. Specifically, we implement a compound fitness parameter, which is a combination between banks' supply of liquidity and their interest rate. Banks can attract their customers by offering a higher supply of liquidity or a lower interest rate. Our financial institutions, modeled as risk neutral agents operating in a perfect competition environment, maximize their expected profits and, consequently, set their optimal interest rate. The optimization mechanism is designed such that bigger banks (i.e the more liquid ones) offer higher interest rates, while the smaller ones (i.e the less liquid ones) seek to attract customers by setting cheaper interest rates. From the point of view of the borrowing banks, knocking on the door of a big financial institution guarantees the loan satisfaction but at a high financing cost. Otherwise, knocking on the door of a small institution increases the chance of credit rationing but reduces financing costs. The fitness parameter, therefore, not only identifies different banks' strategies, but also behaviors that endogenously evolve on the base of the agents' size. Moreover, this method, based on a compound fitness parameter given by two different banks' strategies, is able to reproduce different network topologies ranging from the random graph to the scale-free one.

In each time period, we perturb the system with random liquidity shocks, arising ultimately from the deposit and withdrawal patterns of customers. Since liquidity fluctuations are unpredictable, a bank may find itself unable to meet payment obligations due to the illiquidity of its available assets. 
If no interbank market is present, the mere inability to meet customer demands triggers off failure. If interbank lending is possible, an illiquid bank might seek funds not just to make payments but also to repay past creditors. If despite such efforts, a bank ends up with insufficient funds, we assume for the sake of simplicity that it closes down too.

An important difference distinguishes our "failure mechanism" from those commonly used in physical and economic literature (see, for instance, Battiston et al. 2012a; Albert et al. 2000). All these models generate an exogenous random (or targeted) attack and study the consequences of removing a hit vertex on nodes connected to it and on the network structure. In line with these studies, we generate a random attack via a liquidity shock but, differently from them, not necessarily the hit node is removed. The failure depends endogenously from node's capacity to rise liquidity in the interbank market and, lastly, from the network topology.

Our work is closely related to Lenzu and Tedeschi 2012 (LT hereinafter). In their paper, the authors consider an interbank network where credit linkages evolve via a fitness parameter given by banks' expected profit. By changing the signal credibility that agents attribute to the counter-party performance (i.e the expected profit) the interbank network evolves through different architectures. Specifically, low values of the signal credibility characterize random graphs with a Binomial (or Poisson) in-degree distribution, exponential and scale-free topologies emerge for intermediate values of the parameter, while the market self-organizes into a pseudo-star for higher values of the signal. By perturbing the system with liquidity shocks, the authors test the network capacity to flow liquidity and its resilience. The authors find that even though random networks are characterized by a low credibility signal, they are more efficient in re-allocating liquidity from banks that have a surplus to the banks that have a shortage. Instead, as the network becomes scale-free with the increase in the credibility signal, banks become more prone to failure due to illiquidity. In particular, there would be just a small number of highly trusted agents, leaving all others with very few credit lines and hence being more exposed in case of negative liquidity shocks.

As in LT, we amplify our fitness measure with a multiplicative parameter which represent the signal on banks' attractiveness and shapes the interbank network topology. On the one hand, when the signal is high, the agents' behavior is characterized by "herding", a phenomenon which occurs in situations with high information externalities, when agents' private information is swamped by the information derived from directly observing others actions. In this circumstance, few lenders gain the lion's share of borrowers, attracting a high percentage of in-coming links at the expense of many feebly connected ones. On the other hand, when the signal is low, agents "shop around", the network does not condensed and the credit is more uniformly distributed in the system. 
A significant difference characterizes the evolution of our interbank network with respect to that of LT. We implement different banks' strategies which compete with each other. These strategies that parametrize the fitness measure not only generate competition among banks, but also modify endogenously the interbank network topology. In this circumstance, when we modify the "signal credibility", we are not only able to investigate how different banks' strategies perform in different network architectures, but also to estimate the impact that these strategies have in generating different network topologies.

Another relevant difference between this model and that of LT is the banks' balance-sheet structure. The LT interbank market is a zero-liquidity system, meaning that at the beginning and at the end of each period, banks hold no liquidity. The liquidity, thus, is exogenously generated as positive shocks affecting financial institutions. Specifically, each time period only two random banks receive a liquidity shock of equal magnitude but opposite sign. The bank receiving the negative shock becomes potential borrower, while the bank hits by the positive shock become potential lender. All other intermediate nodes act as liquidity conduits, receiving and forwarding funds. This assumption allows authors to define a flow network and solve the maximumflow problem by using the simple Ford-Fulkerson method. The use of an interbank flow network allow the authors to analytically determine the liquidity flow between any pair of banks in the market (see Ford-Fulkerson 1956 ; 1962). However assuming a zero-liquidity system means not to consider the repayment mechanism between borrower and lender. In this work we relax this hypothesis. Specifically, we apply multiple liquidity shocks on the bank deposit motion (not bilateral as in LT) and model a repayment mechanism between lenders and borrowers. The repayment mechanism, which requires banks to repay installment and interest, has two important consequences. First, it allows us to define a micro-founded interest rate, whereas this is constant in LT. Second, it generates a more interesting dynamic in the agents' failure. In fact, in the LT model bankruptcies depend exogenously on the random attack and endogenously on borrower's capacity to rise liquidity in several interbank network topologies. In this model we extend the two bankruptcy mechanisms presented in LT by adding a third one based on the repayment scheme. Specifically, the repayment mechanism can trigger an additional channel of failures. Starting from the failure of a borrowing financial institution, this mechanism has a negative feedback on the lender balance-sheet via bad debt. If the shock is big enough to completely erode the bank net-worth, then the lender itself will fail. Otherwise, if the shock does not fully corrode the lender equity, then the bank survives. However, in this circumstance, the "weakened" financial institution will attempt to recover losses or by raising interest rates or decreasing the supply of liquidity. In both cases, this attitude will further weaken the borrowing banks with the result, therefore, of causing additional bankruptcies. 
The rest of the paper is organized as follows. In Section 2 we describe the model by analyzing the dynamic of the interbank network as well as the functioning of the trading mechanism on the interbank system. In Section 3 we present the results of the simulations. Specifically, we proceed in two steps: firstly, we provide a general overview of the credit network dynamics by varying the credibility signal and banks' strategies; secondly, we study the impact of the different network topologies on contagion phases. Finally, Section 4 concludes.

\section{The model}

The model considers an interbank market in which financial institutions establish lending relationships. Each time period, banks receive stochastic shocks to their liquid reserves which arise from the deposit and withdrawal patterns of customers. Since liquidity fluctuations are unpredictable, banks may find themselves unable to meet payment obligations due to the illiquidity of their available assets. Credit relationships, therefore, allow the liquidity exchange among market participants. Specifically, banks facing a deposit increment become lenders in order not to accumulate excessive unproductive liquidity, while financial institutions running into a deposit reduction beyond their liquid reserves become borrowers so as to repay their creditors. The set of all bilateral lending agreements between lenders and borrowers describes the interbank network where banks try to fulfill their liquidity needs. The key element of the model is the mechanism describing the dynamic evolution of credit relationships (links) among financial institutions. Each bank signals its capacity to grant credit via a fitness measure which defines the bank ability in attracting clients. To this end, agents adopt two strategies: on the one hand, they grab clients' attention via their liquidity supply, on the other hand via their interest rate. Each time period, the financial institutions with liquidity requirements seek to establish, with a certain probability, a credit relationship with the more attractive agent in their neighborhood. This mechanism generates an endogenous evolution in the credit agreements (links) which, therefore, re-design the credit network architecture.

The essential details of the model time schedule are summarized in Fig.1.

From the methodological point of view, we adopt a pluralistic approach which combines two techniques. On the one hand, the heterogeneous agents approach reproduces the market microstructure and bank behaviour. On the other hand, the network theory describes the interaction among banks and "synthesizes" the resulting aggregate dynamics. The result of this pluralistic approach firstly provides insights into the consequences that banks' 


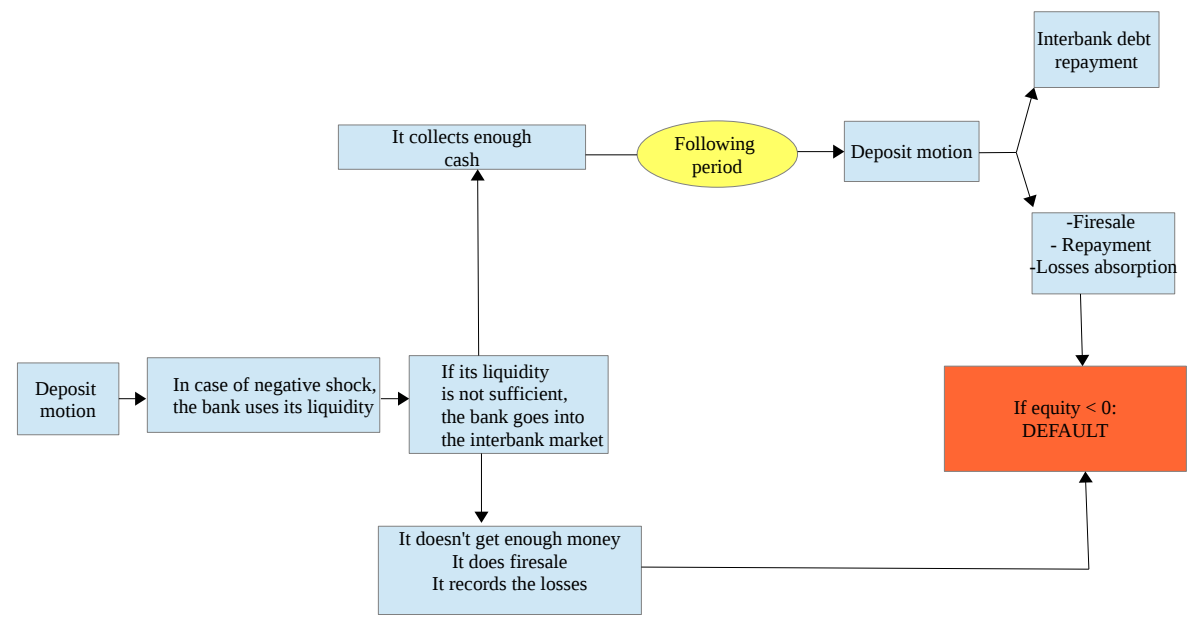

Figure 1: Model time schedule.

strategies have on micro and macro performances and, then, highlights the effect that different network topologies have on the resiliency and robustness of the interbank system (see Bargigli et al. 2014, for an extensive survey).

\subsection{The interbank credit relationships: a dynamic network approach}

We start the description of the model by explaining formation and evolution of the interbank network. In our network, nodes represent banks and edges are the connective links between them. Links are directional, they are created and deleted by banks who look for credit and point to the financial institution that grants loan.

In general local interaction models agents interact directly with a finite number of others in the population, the so-called "neighbors". In our model the number of out-going links is constrained to be $\bar{d}$, thus borrowing banks can only get loan from few lenders. There are two important reasons behind it. On the one hand, in a highly connected random network, synchronization could be achieved via indirect links. The impact of direct credit links on the systemic risk is easier to be tested in a diluted network where indirect synchronization is less likely to arise. On the other hand, by keeping a fixed connectivity, we can easily compare the performance of different market topologies to spread liquidity through the network. 
At any time $t$, the banking system is populated by $N$ banks belonging to the finite set $\Omega_{t}=i, j, k, \ldots$. Financial institutions are interconnected by credit relationships represented by the set $\mathcal{N}_{t}$, whose elements are ordered pairs of distinct banks. Banks (nodes or vertices) and their financial relationships (edges or links) form the financial network $\mathcal{G}_{t}\left(\Omega_{t}, \mathcal{N}_{t}\right)$.

We implement an endogenous mechanism of preferential attachment based on a compound fitness parameter. Specifically, we implement a fitness function which is a linear combination between the bank liquidity and its interest rate. Banks start with identical initial conditions, so that all agents have the same initial liquidity and interest rate. As time goes by, some financial institutions may become more liquid than others or offer rates lower than their competitors. As a measure of the agent attractiveness we define the fitness at time $t$ as a combination between the bank liquidity relative to the liquidity $C_{t}^{\max }$ of the most liquid agent $i^{\max }$ and its interest rate relative to that $r_{t}^{\min }$ of the cheapest financial institution:

$$
\phi_{t}^{i}=\epsilon\left(\frac{C_{t}^{i}}{C_{t}^{\max }}\right)+(1-\epsilon)\left(\frac{r_{t}^{\min }}{r_{t}^{i}}\right)
$$

$\epsilon$ measures the weight that the bank gives to the liquidity or to the interest rate. When $\epsilon$ is equal to zero, the bank strategy is in offering low rates while, when $\epsilon$ is equal to one, the strategy consists in providing high liquidity supply.

The bank's liquidity, $C_{t}^{i}$, in Eq. (1) comes from the inter-day bank balancesheet:

$$
C_{t}^{i}+R_{t}^{i}+L_{t}^{i}=D_{t}^{i}+E_{t}^{i}
$$

with assets (i.e liquidity $C_{t}^{i}$, reserves $R_{t}^{i}$ and long term assets $L_{t}^{i}$ ) on the left hand side of the identity and liabilities (i.e deposits $D_{t}^{i}$ and equity $E_{t}^{i}$ ) on the right hand side. Reserves $R_{t}^{i}$ are a percentage of deposits, $R_{t}^{i}=\hat{r} D_{t}^{i}$, and the required reserve rate $\hat{r}$ is in line with legal requirements and equal to 0.02 . In our simple framework, the liquidity $C_{t}^{i}$ corresponds to whole supply of liquidity on the interbank market.

The interest rate $r_{t}^{i}$ in Eq.(1) comes from the expected profit of a loan from the lender ${ }^{1} i$ to the borrower $j$ :

$$
E\left[\Pi_{t}^{i, j}\right]=\left(1-p_{t}^{j}\right) r_{t}^{i, j} c_{t}^{i, j}+p_{t}^{j}\left(\alpha A_{t}^{j}-c_{t}^{i, j}\right)+\delta A_{t}^{j}-\sigma A_{t}^{i} .
$$

The parameters in the Eq. (3) should be interpreted as follows: $p_{t}^{j}$ is the borrower's default probability, $c_{t}^{i, j}$ is the maximum amount bank $i$ is willing

\footnotetext{
${ }^{1}$ We identify with the index $i$ a generic bank or a lending bank. The index $j$, otherwise, identifies a borrowing bank.
} 
to lend to $j, \alpha$ is the liquidation cost of assets pledged as collateral, $A_{t}^{j}$ the agent $j$ 's assets and, $\delta$ and $\sigma$, are lender's screening costs of establishing a link. Eq.(3) requires that screening costs decrease with the dimension of the borrower's assets and increase with the lender's dimension (see, for example, Berger et al. 2001; Dell'Ariccia \& Marquez 2004; Maudos et al. 2004). Since empirical evidence is ambiguous on this relation, Appendix B analyzes the model dynamics assuming the opposite scenario, that is screening costs increasing with the borrower's dimension and decreasing with the lender's one. The first term on the right hand side of Eq.(3) shows the expected revenue if the borrower repays its obligation, the second term the expected revenue in case of the borrower's default (in this case borrower's collateral is sold) and the last two terms are the opportunity costs of the agreement. By imposing Eq.(3) equal to zero and solving it for $r_{t}^{i, j}$, we obtain the interbank interest rate ensuring zero expected profits:

$$
r_{t}^{i, j}=\frac{\sigma A_{t}^{i}-\delta A_{t}^{j}-p_{t}^{j}\left(\alpha A_{t}^{j}-c_{t}^{i, j}\right)}{\left(1-p_{t}^{j}\right) c_{t}^{i, j}} .
$$

Eq.(4), therefore, assumes that banks are risk neutral agents operating in a perfect competition environment. The interest rate asked by the lender $i$ to the borrower $j$ increases with the lender's size (i.e its assets) and the borrower's financial fragility. In other words, we assume that the interest rate charged by lenders embodies an external finance premium increasing with the leverage, and, therefore, inversely related to the borrower's net worth. This assumption comes from the balance sheet identity (see Eq.2), where we observe that the interest rate asked by the lender is a positive function of the borrower's leverage, $\lambda$, and a negative function of the lender's leverage: in fact $A_{t}^{i}=\frac{L_{t}^{i}}{\lambda_{t}^{i}}+D_{t}^{i}$, with $\lambda_{t}^{i}=\frac{L_{t}^{i}}{E_{t}^{i}}$.

In our model, therefore, the bank behaves as a lender in a Bernanke and Gertler $(1989,1990)$ world characterized by asymmetric information and costly state verification (see Bernanke, Gertler, and Gilchrist (1999) for a comprehensive exposition of the approach).

Moreover, the interest rate in Eq.(4) is not linearly related to the bank's probability of default $p_{t}^{j}$, and its capacity $c_{t}^{i, j}$. We implement a simple rule of thumb for determining a proxy of the default probability of the borrower $j$ given by:

$$
p_{t}^{j}=\left(1-\frac{E_{t}^{j}}{E_{t}^{\text {max }}}\right) .
$$

As we assume that our financial institutions go bankrupt when their equity at time $t$ becomes negative, $E_{t}^{j} \leq 0$, we implement a simple proxy of probability of bankruptcy in line with this idea: the higher the distance between the equity of bank $j$ with respect to that of bank with the highest equity, 
the higher its default probability ${ }^{2}$.

The lending capacity, $c_{t}^{i, j}$, in Eq.4, representing the maximum amount lender $i$ is willing to lend to $j$, is given by:

- $c_{t}^{i, j}=\left(1-h_{t}^{j}\right) A_{t}^{j}>0$ if $(i, j) \in \mathcal{N}_{t}$

- $c_{t}^{i, j}=0$ otherwise

where $A^{j}$ are the assets pledged by borrower $j$ to lender $i$ as collateral and $h^{j} \in\left(0, h^{\max }\right]$ is the borrower haircut. We define the haircut as $h_{t}^{j}=\left(\frac{\lambda_{t}^{j}}{\lambda_{t}^{\text {max }}}\right)$, with $\lambda_{t}^{j}=\frac{L_{t}^{j}}{E_{t}^{j}}$ to be the agent's leverage.

Each borrowing bank $j$ starts with some outgoing link with some random agents (i.e borrowing position), and possibly with some incoming links from other agents (i.e lending position). Links are rewired at the beginning of each period, in the following way: each financial institution $j$ cuts its outgoing link, with agent $i$, and forms a new link, with a randomly chosen agent $k$, with a probability

$$
\operatorname{Pr}_{t}^{j}=\frac{1}{1+e^{-\beta\left(\phi_{t}^{k}-\phi_{t}^{i}\right)}}
$$

or keep its existing link with probability $1-P r_{t}^{j}$. Thus, the probability that a link exists between a pair of banks is equal to the fitted probability from the logit regression (Vandenbossche et al. 2013; Tedeschi et al. 2012 and Tedeschi et al. 2014). The parameter $\beta \in[0, \infty]$ in Eq. 6 is the key element generating different network structures. It represents the "intensity of choice" and answers the question on how much financial institutions trust the information about other agents' performance. For $0<\beta<1$ differences in fitness are smoothed, unchanged for $\beta=1$ and amplified for $\beta>1$ (Domencich et al. 1975; Lenzu and Tedeschi 2012). The algorithm is designed so that successful banks gain a higher number of incoming links. Nonetheless, the algorithm introduces a certain amount of randomness, and links to more successful banks have a finite probability to be cut in favor of links to less successful banks. In this way, we model imperfect information and bounded rationality. At the same time, the randomness also helps unlock the system from the situation where all agents link to the same bank.

\subsection{A stylized interbank trading mechanism}

Each time period $t$, banks face deposit motions which modify their inter-day balance-sheet (see Eq.2). Deposits evolve as follows:

$$
D_{t}^{i}=D_{t-1}^{i}\left(1+\eta u_{t}^{i}\right)
$$

\footnotetext{
${ }^{2}$ The Eq. 5 can also be interpreted as a rule of thumb for determining the risk premium that lenders charge to a borrower.
} 
where $\eta$ is a constant and $u_{t}^{i} \sim \mathcal{N}(0,1)$ is a normal noise.

On the one hand, banks running into a deposit reduction and with insufficient liquidity to meet the withdrawal, enter the interbank market as borrowers. On the other hand, banks facing a deposit increment and, consequently, a liquidity increase, enter the interbank market as lenders. The bank $i$ debt or credit positions in the interbank market are given by:

- borrower if $\Delta D_{t}^{i}+C_{t}^{i} \leq 0$, with demand of liquidity $d_{t}^{i}=\left|\Delta D_{t}^{i}+C_{t}^{i}\right|$,

- lender if $\Delta D_{t}^{i}+C_{t}^{i}>0$, with supply of liquidity $s_{t}^{i}=\Delta D_{t}^{i}+C_{t}^{i}$,

with $\Delta D_{t}^{i}$ to be the deposit variation between before and after the shock. In our model, thus, liquidity shocks trigger the interbank market. Liquid financial institutions become potential lenders, while illiquid banks can try to borrow from financial institutions they have previously entered into agreements with. Banks hit by the negative shock, thus, can raise funds by exploiting their lending agreements and, when the gathered loan is not enough to fully fulfill their liquidity need, by selling their long term assets, $L_{t}^{i}$ (see Eq.2). Given the long maturity of bank assets, we assume that banks consider the asset sale as a second-best choice which occurs at extremely discounted prices. Specifically, we define the granted loan from lender $i$ to borrower $j$ as: $l_{t}^{i, j}=\min \left(s_{t}^{i}, d_{t}^{j}\right)$. The borrowing bank finding, via the interbank market, enough loan to cope with the shock can deal with withdrawals. On the contrary, the rationed bank $j$ (i.e $d_{t}^{j}>s_{t}^{i}$ ) has to sell an amount of its long term asset equal to $d_{t}^{j}-s_{t}^{i}=\rho \tilde{L}_{t}^{j}$, where $\rho$ is the 'fire-sale' price and $\tilde{L}_{t}^{j}$ the amount of loan, $L_{t}^{j}$, bank $j$ has to sell for covering its residual liquidity need.

At the beginning of the next day, the repayment round takes place. Banks run into a new deposit motion (see Eq. 7) increasing or decreasing their liquidity. On one hand, lending banks facing a positive variation of deposits (i.e $\Delta D_{t}^{i} \geq 0$ ), increase their cash and, consequently, remain potential lenders. Otherwise, if they face a negative variation of deposits (i.e $\Delta D_{t}^{i}<0$ ), they become borrowers. On the other hand, borrowing banks addressing a positive variation of deposits can fully repay their previous loan if $\left.\Delta D_{t}^{j} \geq l_{t-1}^{i, j}\left(1+r_{t-1}^{i, j}\right)\right)$. Otherwise, if $\Delta D_{t}^{j}<l_{t-1}^{i, j}\left(1+r_{t-1}^{i, j}\right)$, they have to sell their long term assets in order to repay creditors. The amount of long term assets sold by $j$ is: $\rho \tilde{L}_{t}^{j}=\tilde{l}_{t-1}^{i, j}\left(1+r_{t-1}^{i, j}\right)$, with $\tilde{l}_{t-1}^{i, j}$ to be the amount of interbank loan the borrower $j$ has still to meet with. Borrowing banks addressing a negative variation of deposits have to sell their long term assets in order to pay their previous interbank loan and address the new liquidity needs. In this circumstance, the amount of asset sold is: $\rho \tilde{L}_{t}^{j}=$ $\tilde{l}_{t-1}^{i, j}\left(1+r_{t-1}^{i, j}\right)+\Delta D_{t}^{j}$. For the sake of simplicity, we assume that banks can not renegotiate their debt position, but should extinguish it by the day. 
Banks unable to fully fulfill their liquidity need default. Bankrupt agents' assets are liquidated in the claimants' favor. In this case, involved lenders incur a credit loss (i.e bad debt) equal to $B_{t}^{i, j}=\left(1-\alpha-h_{t}^{j}\right) A_{t}^{j}$, net of the collateral liquidation value. Borrowing and lending financial institutions absorb, with their equity, the 'fire-sale' and bad debt losses. The generic bank $i$ net worth evolves according to:

$$
E_{t}^{i}=E_{t-1}^{i}+\sum_{j} r_{t-1}^{i, j} l_{t-1}^{i, j}-\sum_{j \in \Theta_{t}^{i}} B_{t}^{i, j}-(1-\rho) \tilde{L}_{t}^{i}
$$

where $\Theta_{t}^{i}$ is the subset of the bank $i$ clients unable to pay their debts back because they go bankrupt. Financial institutions go bankrupt when their equity at time $t$ becomes negative, $E_{t}^{i} \leq 0$. The failed banks leave the market. When banks fail, they are replaced by new entrants, which are on average smaller than incumbents. So, entrants' size is drawn from a uniform distribution centered around the mode of the size distribution of incumbent banks (see Bartelsman et al. 2005).

\section{Simulation results}

We consider an economy consisting of $N=100$ banks over a time span of $T=1000$ periods. Each bank is initially endowed with the same balancesheet: $C_{0}=30, L_{0}=120, D_{0}=135$ and $E_{0}=15$. Three are the parameters entering into the interest rate. Specifically, we fix: $\delta=0.05, \sigma=0.02$ and $\alpha=0.3$.

We fix the number of out-going links, $\bar{d}=1$, and the constant parameter in Eq. $7, \eta=0.035$. The robustness of our qualitative results has been checked by employing Monte Carlo techniques. We have run 100 independent simulations for different values of the initial seed generating the pseudo-random numbers. This exercise has been repeated by changing the parameter $\bar{d}=1$, which represents the number of bank's potential lenders starting from 1 to 6 with steps of 2 ; and $\eta=0.035$, which represents the variance of the deposit shock $^{3}$ starting from 0.01 to 0.06 with steps of 0.005 . We have then studied the moments of the distributions of the statistics of interest. Results in Appendix A confirm that our findings are quite robust.

In order to study the impact of the bank's strategies on the financial distress, we run simulations for different values of the parameters A) $\epsilon$ in Eq. 1 , capturing the bank's preference for a low interest rate (i.e $\epsilon=0$ ) versus a high liquidity (i.e $\epsilon=1$ ) and B) $\beta$ in Eq. 6, representing the intensity of choice. For each investigation, we have repeated the simulations 100 times with different random seeds.

\footnotetext{
${ }^{3}$ Furthermore, we have simulated the model using a different deposit low of motion given by $D_{t}^{i}=D_{t-1}^{i}\left(\mathcal{U}_{(\xi, \zeta)}\right)$, with $\xi=0.6$ and $\zeta=1.2$. Under a qualitative point of view, our results do not consistently change by varying deposit shocks.
} 


\subsection{The network topology}

In this first experiment we analyze the evolution of the network topology by varying $\beta$ and $\epsilon$. Specifically, we study the impact that the different banks' strategies - banks can use a fitness measure based on a high liquidity (i.e $\epsilon=1$ ), on a low interbank interest rate (i.e $\epsilon=0$ ) or a mixed strategies which combines the two possibilities (i.e $\epsilon=0.5$ ) - have on the network topology by varying the intensity of choice $\beta$. In Fig. 2 we show that, by
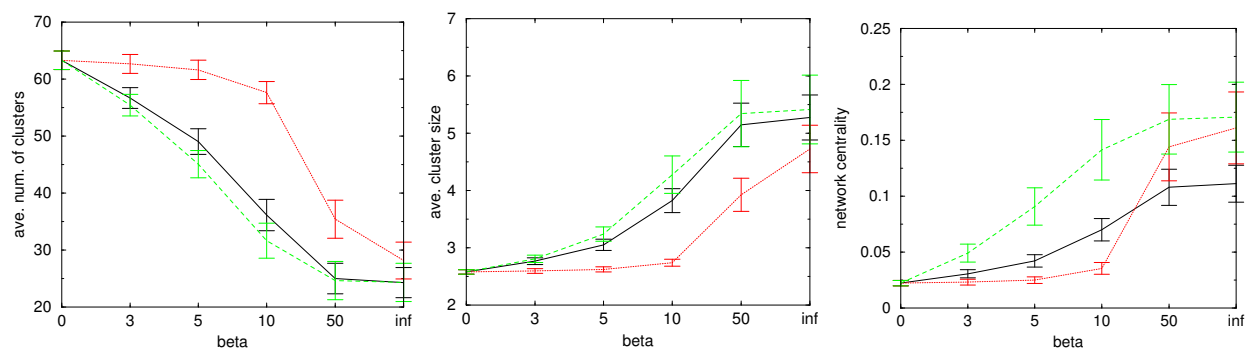

Figure 2: Average number of clusters (left), average size of clusters (middle), and network centrality (right), over all times and all simulations as a function of $\beta$. The lowest interest rate strategy (i.e $\epsilon=0$ ) is highlighted in black solid line, the mixed strategy (i.e $\epsilon=0.5$ ) in red dotted line, and the highest liquidity one (i.e $\epsilon=1$ ) in green dashed line. Colors are available on the web site version.

increasing $\beta$, regardless of strategies, the network tends to centralize. The existence of clusters of highly interconnected banks is an important empirical evidence of credit networks (see, for instance, Boss et al., 2004). In this work, a cluster is defined as a group of banks directly or indirectly connected by lending relationships and corresponds to a so-called "connected component" in network theory jargon ${ }^{4}$. Fig.2, left side, shows that, for small values of $\beta$, the network tends to be fragmented in many (63 on average) and small (2.5 on average) clusters of banks. However, for increasing $\beta$, such clusters decrease in number while they increase in size and the network becomes more clustered and centralized (see Fig.2, middle and right panels). As the figure shows, the tendency of the network to condense, by increasing $\beta$, is independent of the bank strategy $\epsilon$ : banks can use different fitness measures but the intensity of choice plays a leading role. However, Fig. 2 shows that, for the two pure strategies (i.e $\epsilon=0$ - black solid lineand $\epsilon=1$ - green dashed line - ), the relationship between centralization and intensity of choice is linear and increases at a very fast rate. The mixed strategy, instead, performs in a different way: the network condensation is low up to $\beta$ equal to 10 , then it reaches very high levels. Specifically, at $\beta$

\footnotetext{
${ }^{4}$ Connected communities have been performed using the appropriate $R$ package (see http : //igraph.org/r/doc/components.html).
} 
equal to 10 , when $\epsilon$ is 0.5 , we observe a phase transition: the network jumps from a decentralized one to a very condensed one.

In order to better identify the structure of the interbank network, we divide the population in two subsets: the core and the periphery. Specifically, we identify "core" banks (also said hubs) via the K-core decomposition of graph $^{5}$ (see Alvarez-Hamelin et al. 2005). This mechanism identifies the $\mathrm{k}$-core of a graph as the maximal subgraph in which each vertex has at least degree $\mathrm{k}$. Therefore, the $\mathrm{k}$-core of the network is obtained by recursively removing all vertices of degree less than $k$, until all vertices in the remaining graph have degree at least $k$. Here, we fix $k=50 \%$, while in Appendix A we study the model performance for $k$ equal to $75 \%$ and $85 \%$, respectively. The separation between core and periphery is essential to identify the effect of each bank's strategy. For any $\beta$, in fact, if the core represents agents with higher fitness, the periphery shows the behavior of banks with the lower fitness. In term of strategies, thus, if we use the liquidity fitness (i.e $\epsilon=1$ ), the core represents banks with the higher liquidity and, consequently, via Eq.4, the higher interest rate. The periphery, instead, shows agents with the lower interest rate and, consequently, lower liquidity ${ }^{6}$. In this simple way, in the same scenario, we can analyze a strategy and its opposite. The left panels in Fig.3 show that the average number of agents belonging to the core (the periphery is just the reciprocal) and its average in-degree follow the same pattern (in term of dynamics) of the cluster's number and size as displayed in Fig.2. Interestingly, our simulated results on the percentage of banks belonging to the core and the periphery are quite in line with some empirical studies. Specifically, Craig and von Peter 2014, by analyzing the German interbank market, find that the periphery is larger and comprises about the $90 \%$ of banks. Whereas, Fricke and Lux 2015, by analyzing the e-MID trading platform, find a periphery consisting of roughly $72 \%$ of all banks before the global financial crisis and $77 \%$ afterwards.

The figure, moreover, gives us an important information in term of agents' strategies and, thus, fitness. The two pure strategies have a greater attractivity in terms of fitness, with the liquidity overlooking the interest rate. In fact, for values of $\beta$ between 0 and 10, we note that the attractivity of hubs with the highest liquidity (green dashed lines) dominates that of hubs with the lowest rate (black solid lines). The reason is that, in the model, up from low values of the intensity of choice, the liquidity becomes very heterogeneous and, therefore, differences in terms of fitness amplified. Interest rates, instead, are more homogeneous and, consequently, need of higher levels of $\beta$

\footnotetext{
${ }^{5}$ Another interesting approach to define the core-periphery networks is in Fricke and Lux 2015.

${ }^{6}$ The opposite is true for $\epsilon=0$. In this circumstance the core shows financial institutions with the lower interest rate and, consequently, the lower liquidity; the periphery, otherwise, represents the more liquid banks with the higher rates.
} 

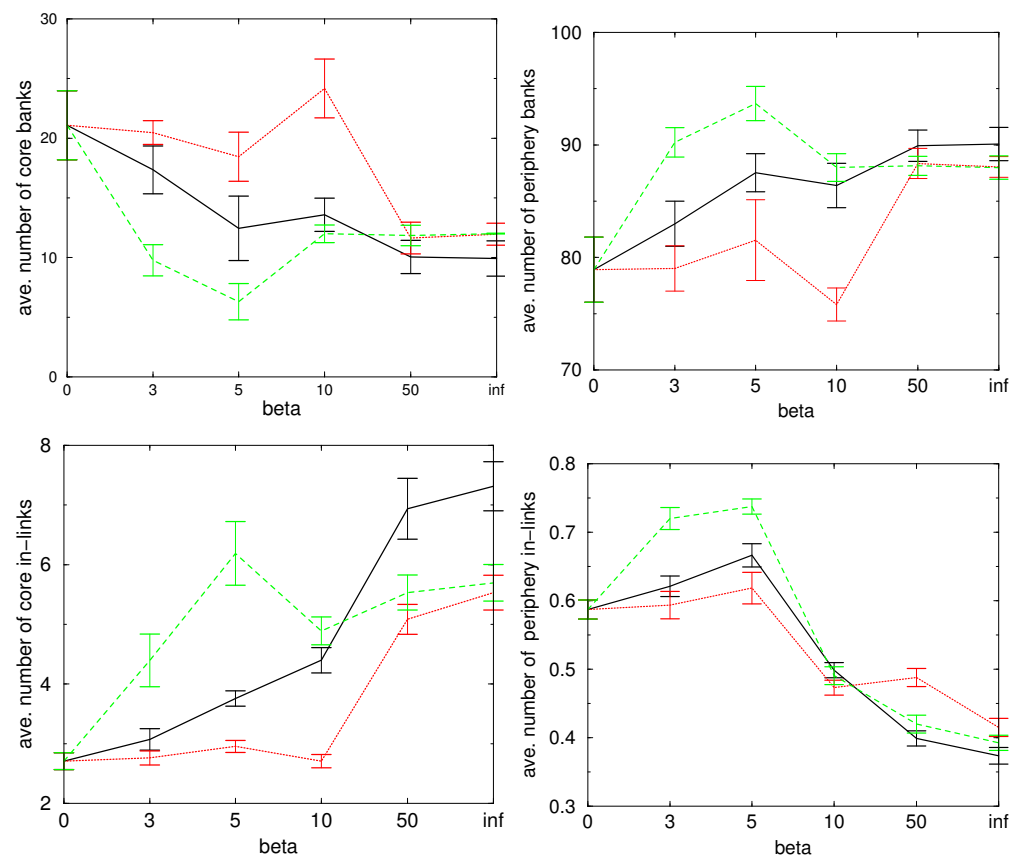

Figure 3: Average number of banks belonging to the core (top left panel) and to the periphery (top right panel) and their average number of in-coming links(bottom left and right for core and periphery respectively), over all times and all simulations as a function of $\beta$. The lowest interest rate strategy (i.e $\epsilon=0$ ) is highlighted in black solid line, the mixed strategy (i.e $\epsilon=0.5$ ) in red dotted line, and the highest liquidity one (i.e $\epsilon=1$ ) in green dashed line. Colors are available on the web site version.

to condense the network. However, for values of $\beta$ higher than 10, this effect reverts: in this case a fitness measure based on a low interest rate prevails on the one based on a high liquidity. With regard to the mixed strategy (red dotted line), it needs high value of $\beta$ to centralize the network but, however, the hubs never reach an attractivity as high as in pure strategies. This result is in line with other studies which find evidence on the endogenous formation of core-periphery interbank network just in presence of banks' heterogenous size. Specifically, int' Veld et al 2014, by developing a gametheoretical network model calibrated on the Dutch interbank market, show that a core-periphery network structure can form endogenously if one allows for heterogeneity among banks in size. To prove that the different strategies generate different levels of heterogeneity in the fitness distribution by varying $\beta$, we estimate, on the upper tail of the distribution (from the 70th percentile onward), the average exponent $\alpha$ of the power-law function and its standard error by means of the Maximum Likelihood Method (MLM), as in Clauset et al. (2009), over 100 simulations. Table 1 shows that, by 


\begin{tabular}{cccc}
\hline \multicolumn{4}{c}{ MLM fitness, $\alpha$ and (st.dev) } \\
\hline \hline & $\epsilon=0.0$ & $\epsilon=0.5$ & $\epsilon=1.0$ \\
\hline$\beta=0$ & $2.30(0.021)$ & $2.30(0.021)$ & $2.30(0.021)$ \\
$\beta=3$ & $1.77(0.035)$ & $2.20(0.038)$ & $1.73(0.041)$ \\
$\beta=5$ & $1.51(0.039)$ & $2.00(0.039)$ & $1.40(0.045)$ \\
$\beta=10$ & $1.20(0.034)$ & $1.98(0.044)$ & $1.10(0.051)$ \\
$\beta=50$ & $0.98(0.051)$ & $1.20(0.053)$ & $1.02(0.053)$ \\
$\beta=\infty$ & $0.98(0.026)$ & $1.08(0.021)$ & $1.01(0.015)$ \\
\hline
\end{tabular}

Table 1: Maximum Likelihood Method (MLM) estimation of the power law exponents $\alpha$ of the fitness distribution tails over the 100 simulations for different values of $\epsilon$ and $\beta$ and their standard error.

increasing $\beta$, we generate a smooth transition to fatter tails. This result is more evident for the two pure strategies, with a more evident heterogeneity in the liquidity (i.e $\epsilon=1.0$ ) with respect to the interest rate (i.e $\epsilon=0.0$ ) up to $\beta$ equals 10. Then the effect reverses as shown by the sharp drop in the power law exponents $\alpha$ in the case of $\epsilon=0.0$ when $\beta$ is greater than 10 .

We now investigate the evolution of core banks along a dynamic path ${ }^{7}$. The charts in Fig.4 show how the three different strategies impact on the evolution of the network topology at different values of $\beta$ : for $\beta=0$ (first column), $\beta=10$ (second column) and $\beta=\infty$ (third column). Specifically, the first and second row show the interest rate and the liquidity time series of banks adopting the interest rate strategy (black solid line), the mixed strategy (red dotted line) and the liquidity strategy (green dashed line). Increasing $\beta$, the model is able to generate a stronger volatility of the two variables for each strategy. Then, the bottom row of Fig. 4 shows the agents' incoming link time series. We observe that the volatility of the degree increases with the intensity of choice as well. Last but not least, we have to prove that the degree dynamics is driven by the fitness (i.e. by the interest rate and the liquidity dynamics). In particular, the higher the fitness in a single group, the higher the number of incoming links of banks belonging to that group. A natural way to assess the co-movement between the increase (decrease) in fitness and the increase (decrease) in the in-links is to study their correlation. We find that the average Pearson correlation coefficient over 100 simulations for each strategy is an increasing function of $\beta$ and reaches a value of 0.71 (st.dev 0.04) when the fitness signal strength is significant. These results on the evolution of the network are in line with other works (Brock et al. 1998; LeBaron et al. 2009; Tedeschi et al. 2014; Grilli et al. 2014b).

\footnotetext{
${ }^{7}$ Results for peripheral banks are omitted, but similar in spirit.
} 

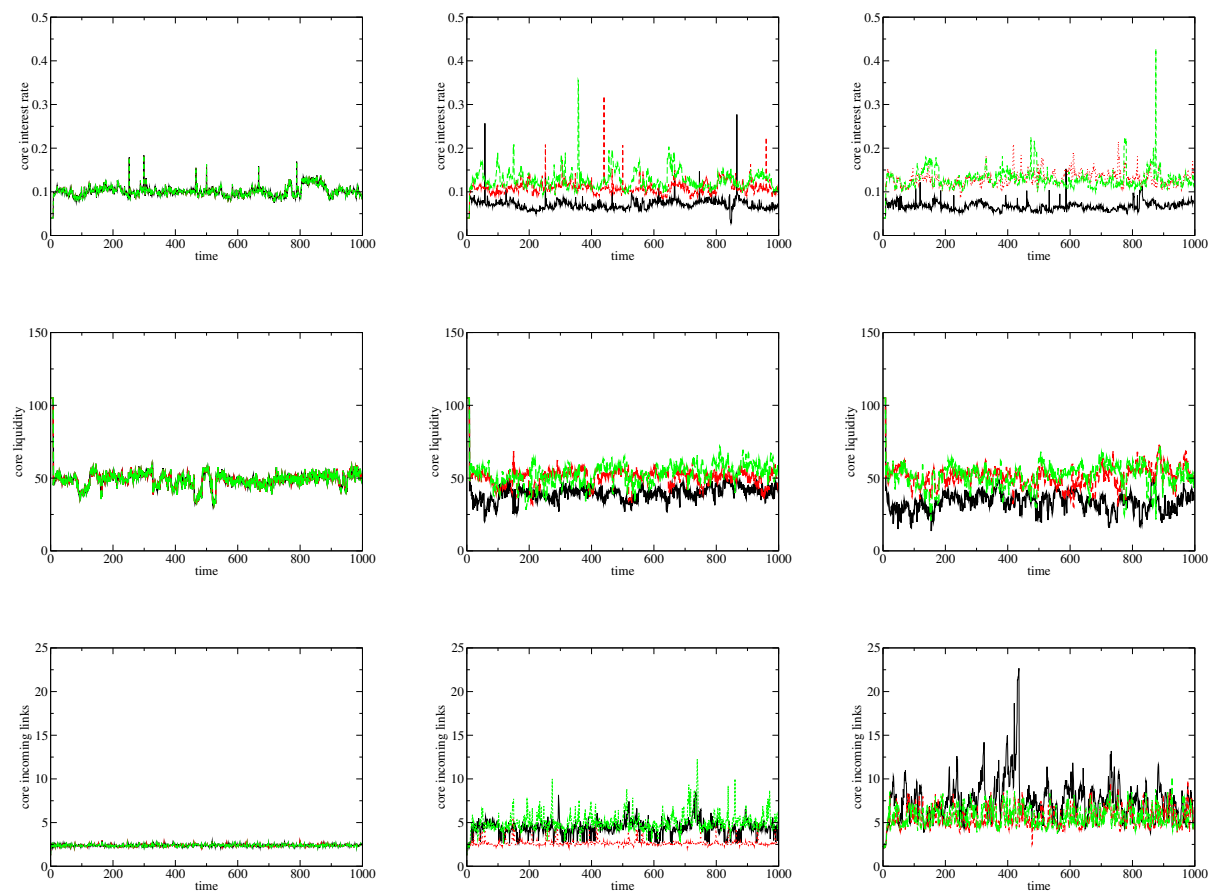

Figure 4: Time series of core interest rate (top row), liquidity (middle row) and number of incoming links (bottom row) for $\beta=0$ (first column), $\beta=$ 10 (second column) and $\beta=\infty$ (third column). The lowest interest rate strategy (i.e $\epsilon=0$ ) is highlighted in black solid line, the mixed strategy (i.e $\epsilon=0.5)$ in red dotted line, and the highest liquidity one (i.e $\epsilon=1$ ) in green dashed line. Colors are available on the web site version.

\subsection{From banks strategies to financial distress}

In this section we investigate the consequences that banks' strategies have on agents' financial distress and on the network resiliency. Given the fitness measure in Eq.1, we identify, as already stressed in previous sections, two pure strategies, one based on the interest rate and the other one on the liquidity, and a mixed one, based on a linear combination of the pure ones.

Top panels of Fig.5 show the average core and periphery banks' leverage for the different strategies by varying the intensity of choice. Given our naive banks' balance-sheet, we define the leverage as assets on equity. In this simple framework, thus, leverage is a good proxy of bank financial fragility. Our results show that the financial fragility of the core is much higher than that of the periphery. Although, on average, the core net-worth is higher than the periphery one, it is not sufficient to compensate for the high level of loans granted by core banks. Specifically, the average core equity (average periphery equity) over all $\beta$ and $\epsilon$ and all time steps and all 

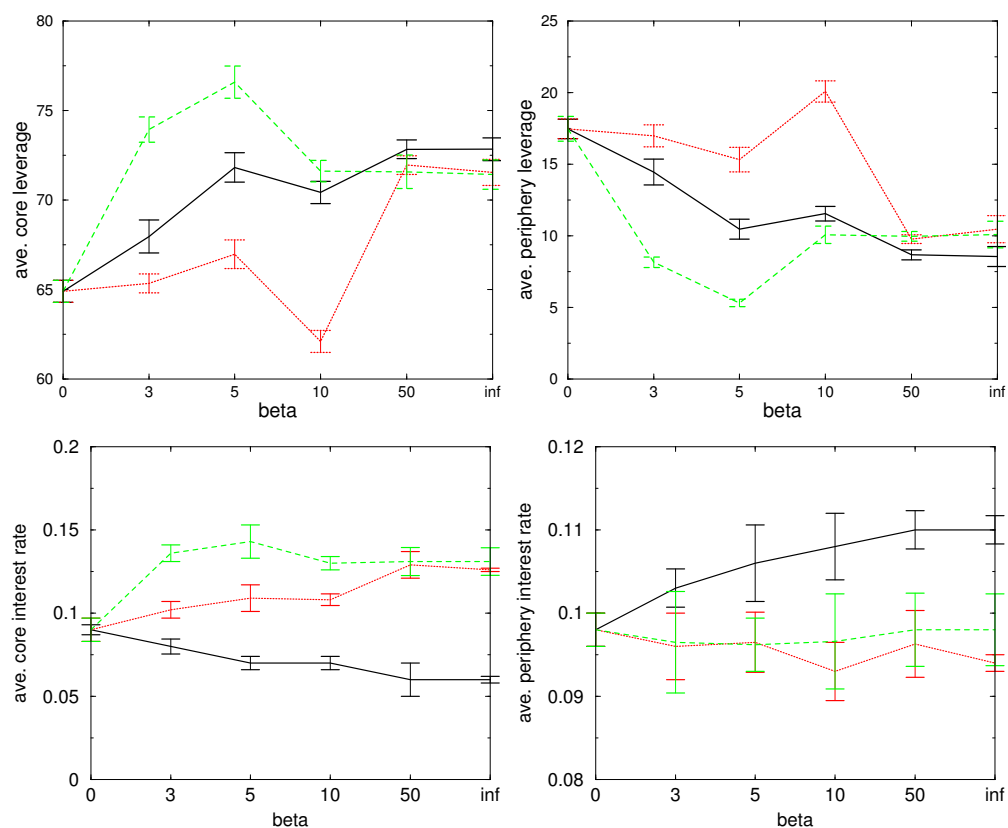

Figure 5: Average core and periphery leverage (top left and right panel, respectively), average core and periphery interest rate (bottom left and right panel, respectively), over all times and all simulations as a function of $\beta$. The lowest interest rate strategy (i.e $\epsilon=0$ ) is highlighted in black solid line, the mixed strategy (i.e $\epsilon=0.5$ ) in red dotted line, and the highest liquidity one (i.e $\epsilon=1$ ) in green dashed line. Colors are available on the web site version.

simulations is 17.47 (14.73) with standard deviation 0.23 (0.14). The average loan granted by core banks (periphery banks) is 22.81 (11.43) with standard deviation 1.13 (0.98). This result is in line with other empirical and theoretical studies showing that an increase in interbank market volume/loans until a tipping point can be dangerous and generate contagion effects (see Georg 2013; Fricke and Lux and 2015). Moreover, the leverage of core banks increases with the intensity of choice $\beta$. This is because, by increasing $\beta$, the number of core borrowers ${ }^{8}$-and so the core loan- increases as shown in the bottom panels of Fig.3, while the average core-equity decreases from 20.62 to 14.94 . Last but not least, the two pure strategies are able to attract more incoming links (i.e borrowers) than the mixed one, thus, generating a greater fragility. On the other hand, the behavior of periphery banks is very different in term of leverage. In this population, the growth of activities better balance the growth of liabilities. Peripheral banks, in fact, manage

\footnotetext{
${ }^{8}$ Clearly, the average number of the core in-coming links is a proxy of the average number of the core borrowers.
} 
to attract a number of clients - not too high- sufficient to increase their net-worth more than their loans. In this scenario, an increasing number of borrowers (i.e when $\beta$ increases) is able to decrease the lenders' financial instability. The periphery has advantages in never exceeding a critical threshold in the number of customers.

The bottom panels of Figure 5 display the "behavior" of the interbank interest rate for $\epsilon$ equal to $0,0.5$ and 1 , as a function of the intensity of choice $\beta$. This behavior is strictly linked with the fitness measure and the interest rate formula. We observe that, for the core banks, the interest rate decreases with $\epsilon$. Specifically, $\epsilon$ equal to zero describes a strategy where lenders try to attract clients applying a very low interest rate. However, these lenders have a low supply of liquidity. Their customers, therefore, are themselves advantaged by the low cost of credit, but may face severe credit rationing. On the other hand, $\epsilon$ one describes a world where lenders are 'rich', that is very liquid, and apply very high interest rates in return to a low probability of rationing. Specifically, the average percentage of rationing for the core-bank clients over all $\beta$ and all time steps and all simulations is $1.3 \%$ for $\epsilon=0,0.14 \%$ for $\epsilon=0.5$ and $0.065 \%$ for $\epsilon=1$.

The figure gives us, also, some interesting results in term of intensity of choice. We can observe that, when $\epsilon$ is equal to 1 , by increasing $\beta$, the interest rate increases, but at a decreasing rate. For high values of intensity of choice, in fact, core banks become more poor. When the network is very centralized, the core has too many clients and, consequently, faces an excessive risk of insolvency, which reduces the core asset. It, in turn, tends to reduce, a tiny bit, via Eq.4 the core interest rate. Table 2 confirms this

\begin{tabular}{|c|c|c|c|}
\hline \multicolumn{4}{|c|}{ Bad-debt of core-banks } \\
\hline & $\epsilon=0.0$ & $\epsilon=0.5$ & $\epsilon=1.0$ \\
\hline$\beta=0$ & $7.87(1.95)$ & $7.87(1.95)$ & $7.87(1.95)$ \\
\hline$\beta=3$ & $5.70(1.53)$ & $7.22(1.76)$ & $6.04(1.86)$ \\
\hline$\beta=5$ & $4.10(1.23)$ & $6.51(1.6)$ & $6.11(1.85)$ \\
\hline$\beta=10$ & $4.76(1.23)$ & $6.57(1.19)$ & $11.68(2.54)$ \\
\hline$\beta=50$ & $4.40(1.23)$ & $9.18(1.31)$ & $12.84(1.21)$ \\
\hline$\beta=\infty$ & $4.87(1.95)$ & $9.38(1.32)$ & $12.79(1.95)$ \\
\hline
\end{tabular}

Table 2: Average bad-debt of core-banks and its standard error over time and 100 simulations for different values of $\epsilon$ and $\beta$.

result. Specifically, banks adopting the liquidity strategy (i.e $\epsilon=1$ ) face a growing insolvency in their customers' repayments by increasing $\beta$. The effect becomes very pronounced for $\beta$ greater than 5 , which corresponds to the slow decline in the core interest rate. 
On the other hand, when $\epsilon$ is equal to zero, by increasing $\beta$, the network concentration increases and consequently the borrowers hunt lenders offering interest rate increasingly lower. In other words, in this scenario, when the network concentration increases, lenders obtain a higher number of clients. However, when banks have many borrowers, their assets increase and, consequently, via Eq.4 the interest rate tends to increase too. Since the fitness measure, in this case, is designed in order to look at banks with the lowest interest rate (which corresponds to a low supply of liquidity), by increasing $\beta$ we observe a strong switching able to re-direct the system to banks with the lowest rate. Specifically, when $\epsilon=0$, the average switching ${ }^{9}$ between borrowers and lenders takes values of 0.84 (st.dev. 0.01), 0.74 (st.dev. 0.03), 0.61 (st.dev. 0.02), 0.65 (st.dev. 0.01), 1.18 (st.dev. 0.10), 1.17 (st.dev. 0.11), for $\beta=0,3,5,10,50, \infty$, respectively. Otherwise, when $\epsilon=1$, the average switching linearly decreases from 0.84 (st.dev. 0.01), when $\beta=0$, to 0.17 (st.dev. 0.05), when $\beta=\infty$. Interestingly, the theoretical and empirical literature puts great emphasis on the relationship between preferential lending -corresponding to low switching- and interest rate. These studies show that preferential interest rates for borrowers with strong attachment to a lender may guarantee the banks' survival (see Iori et al. 2015; Lux 2015, Temizsoy et al. 2015).

We now analyze the efficiency of banks' strategies and interbank structure in absorbing liquidity shocks which, in our framework, are driven by the deposits' motion. As Figure 6 shows, from a strategical point of view, the
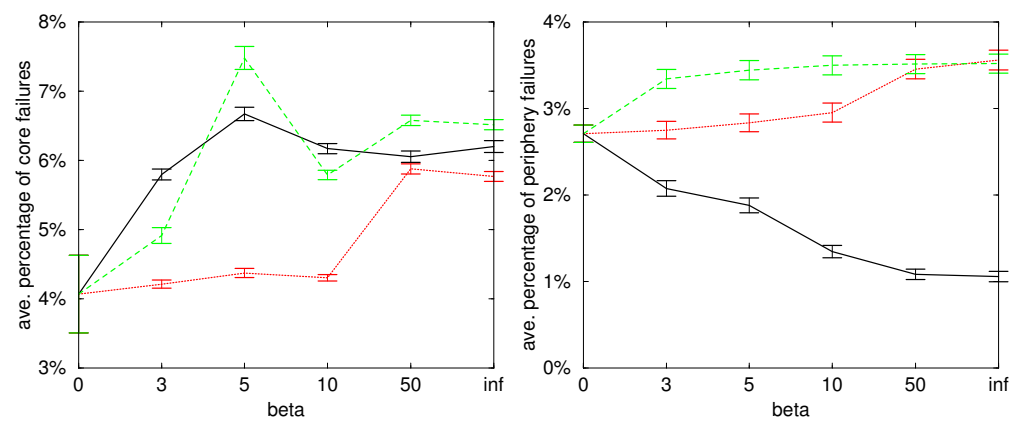

Figure 6: Average percentage of core and periphery banks failures (left and right panel, respectively), over all times and all simulations as a function of $\beta$. The lowest interest rate strategy (i.e $\epsilon=0$ ) is highlighted in black solid line, the mixed strategy (i.e $\epsilon=0.5$ ) in red dotted line, and the highest liquidity one (i.e $\epsilon=1$ ) in green dashed line. Colors are available on the web site version.

\footnotetext{
${ }^{9}$ The average switching between borrowers and lenders is defined as the average number of times, over time-steps and simulations, each borrower changes its lender from period $t$ to period $t+1$.
} 
core banks have the highest benefit in applying the mixed strategies for any different interbank network topology. This strategy, in fact, by maintaining the number of bank client relatively lower respect to the two pure strategies (and consequently a lower leverage), is able to contain the number of banks' failures. However, as shown for the number of incoming links and the leverage (see Fig. 3-5) when the intensity of choice becomes very high (i.e $\beta>10$ ), the mixed strategy reaches the phase transition and, consequently, we observe a sharp increase in bankruptcies (see Caccioli et al. 2014, for similar results). This result clearly appears also in the analysis of the baddebt of banks adopting the mixed strategy. By observing the middle column of table 2 , in fact, we can notice the abrupt jump in the banks' bad-debt for $\beta>10$. The efficiency of the two pure strategies is, instead, strongly related with the interest rate and the leverage motion. On the one hand, when $\epsilon$ is equal to one, by increasing the intensity of choice (and so the network centralization) the higher number of core clients generates a too high core financial fragility and interest rate. Higher leverage coupled with higher interest rate increases the core fragility via two effects. First, too much clients are detrimental for the core because an increasing in the granted loan is not counterbalanced by an increasing in net-worth. Second, the too high interest rate paid by borrowers tends to dramatically increase the core bad debt, as shown in the right hand side of table 2 .

On the other hand, when $\epsilon$ is equal to zero, core banks, by increasing $\beta$, tend to offer too low interest rates. In this circumstance, the increasing number of the core clients is not enough to compensate the very low profits given by too low interest rates ${ }^{10}$.

When we analyze the effect of the three strategies on the periphery banks by varying the intensity of choice (see right panel of Fig.6), we observe a very different behavior. It is important to notice that, in this circumstance, strategies are reversed. Specifically, when $\epsilon$ is equal to one, the periphery banks apply a strategy which offers low rates in the face of a small liquidity supply, on the other hand, when $\epsilon$ equals zero, they apply higher rates in return for a high liquidity. This is simply due to the fact that the periphery has a fitness measure opposite to the core. By analyzing this population we learn an important lesson. In this scenario, the lenders requiring higher

\footnotetext{
${ }^{10}$ It is worthy of note that, when banks choose the strategy $\epsilon=0$, a negative relation between the interest rate and the banks' failure emerges (see black solid lines in the bottom left panel of Fig. 5 and in the left panel of Fig. 6). This phenomenon reflects the fact that the failing banks are small lenders who (i) offer lower interest rates, all else equal, (ii) are more fragile because of their low margins and (iii) are increasingly prevalent in the core as the competition for offering low interest rates intensifies in a scenario where fitness depends only on interest rates. In this case, a parallel with real banking crisis is not apt as in those crises the idea is that interbank interest rates are driven by increasing risk premia charged to borrowers. Anyway, this contingency is interesting, as it shows the negative impact that low interest rates may have on the financial robustness of lending banks via too low profit margins.
} 
interest rates (i.e $\epsilon=0$ ) are more resistant in facing shocks. By increasing $\beta$, all three strategies face a contraction in the number of customers, which is particularly evident at $\beta$ greater than 5 (see bottom right panel in Fig.3). The dynamics in the periphery in-degree is, however, quite similar for all the three strategies. What changes, instead, is the behavior of the interest rate (see bottom right panel in Fig.5). Periphery banks using the strategy $\epsilon=0$ are able to apply higher rates (with a maximum around 11\%) but, otherwise, they never reach a level of the rate as high as to be detrimental to them as, however, is the case of core banks under the strategy $\epsilon=1$. The model, then, identifies a minimum and a maximum interest rate, above or below which banks fail either for low profits or for insolvent customers.
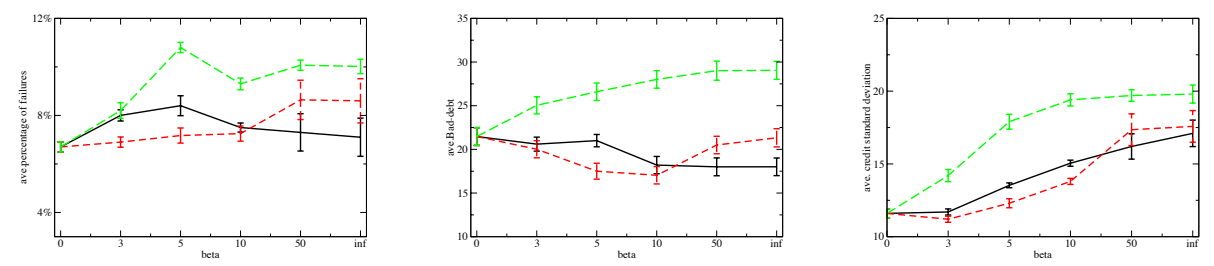

Figure 7: Average percentage of banks failures (left), average bad-debt (middle) and average credit standard deviation (right), over all times and all simulations as a function of $\beta$. The lowest interest rate strategy (i.e $\epsilon=0$ ) is highlighted in black solid line, the mixed strategy (i.e $\epsilon=0.5$ ) in red dotted line, and the highest liquidity one (i.e $\epsilon=1$ ) in green dashed line. Colors are available on the web site version.

The last part of this session is dedicated to the analysis of the fragility of the interbank system as a whole. In this regard, we investigate the aggregate dynamics in term of whole failures and bad debt (see Fig. 7 left and middle panels, respectively). As the figure shows, aggregate failures follow a trend very similar to that of the core bankruptcies. At the aggregate level, however, some features are more pronounced. Firstly, the strategy based on a high supply of liquidity is the one that worse performs in terms of failures and bad-debt. In fact, the too high interest rate and the too strong lenders' fitness are deleterious for banks using this strategy. Secondly, the mixed strategy overperforms the other two tactics in terms of lower risk and lower bad debt up to a value of $\beta \leq 10$. When the intensity of choice reaches the phase transition, instead, we observe a competition in term of riskiness (i.e percentage of failures) between the mixed strategy and the interest rate one. In this circumstance, a clear supremacy of one strategy over the other does not emerge anymore, as shown by the high standard deviation in case of high levels of $\beta$ (see left panel of Fig. 7). To better quantify this observation we compare the average percentage of failure for $\epsilon=0$ with those obtained 
for $\epsilon=0.5$, over 100 simulations, by applying the two-sample KolmogorovSmirnov (KS) goodness-of- fit hypothesis test. The test confirms that the historical series of failures for the two samples (for any level of $\beta>10$ ), are drawn from the same population at a significance level of 0.05 . The analysis of the bad debt, instead, would seem to suggest best performances of the interest rate strategy with respect to the mixed one, for $\beta>10$ (see middle panel of Fig.7). However, it is worthy of note that the tactic based on the interest rate produces the highest probability of rationing, which clearly corresponds to the lowest bad debt. Specifically, the average percentage of rationing is $10.25 \%$ for $\epsilon=0,4.01 \%$ for $\epsilon=0.5$ and $1.23 \%$ for $\epsilon=1$. The higher probability of rationing for $\epsilon=0$ is motivated by two factors: i) lenders adopting this tactic are less liquid and smaller in size and, therefore, easily cut the granted loans ii) the network emerging when financial institutions apply the interest rate strategy is very sparse, then some borrowers, which are isolated nodes, are fully rationed and, consequently, do not have any bad-debt.

Last but not least, the right panel of Fig.7 displays the credit volatility, which can be considered as a synthetic measure of interbank fragility. As the empirical literature well documents, the standard deviation of credit is a good proxy of financial and macroeconomic uncertainty (see Baum et al., 2004; Ghosal and Loungani, 2000). The figure shows that the credit volatility increases with the intensity of choice for any strategy. This confirms a key finding of the model: an overly centralized network, where few lenders manage several borrowers, is unstable and very fragile, as proved by the strong weakness emerging when banks adopt the strategy based on the high supply of liquidity.

\section{Concluding remarks}

In this paper we have studied, in a very simple framework, the impact of different network topologies on banks' financial fragility. By implementing an endogenous attachment mechanism which evolves via a fitness measure based on three different banks' strategies, we have investigated how systemic risk emerges from the interaction and which network topology and bank strategy are more resilient against a random attack to vertices. In all the investigated scenarios, our findings have shown that the system vulnerability is strongly related with the network concentration. When in the interbank system we have a narrow core, corresponding to very few hubs acting as lenders, we observe high leverage often associated with high financial fragility. Network concentration leads core banks to grant too much credit compared to their equity and, consequently, in the unlike event of shock, to be overwhelmed by their debtors' insolvency. We have shown that this result holds even if core banks charge high interest rates in return for their 
high liquidity supply (i.e. when $\epsilon=1$ ). The application of this strategy, in fact, produces strong negative feedbacks. On the one hand, core banks grant too much loan with respect to their liquidity and, thus, become very illiquid in case of shock. On the other hand, by applying too high interest rates to their borrowers, they are likely to have many insolvent customers and, consequently, through the bad debt which erodes their equity, to fail themselves. When core banks, otherwise, apply very low interest rates to their clients, (i.e. when $\epsilon=0$ ), they suffer from an excessive erosion of their profits that turns out to be very harmful. The model identify, then, a mixed strategy which, by combining not too high (or too low) interest rates with a network concentration below the transition phase, appears to be the most efficient in case of liquidity shocks.

Given its stylized framework, the model can be easily extended and modified to allow for different analyses. For instance, efficient responses to cascading disaster spreading could be identified. This important point could be addressed by adding a Central Bank and analyzing the best policies for reducing the interbank market vulnerability. Furthermore, in a future article we will introduce a proper utility function from which to derive bank's supply of liquidity and we will perform a more careful study of how the results depend on the agents' microfounded strategies.

\section{Acknowledgements}

The research leading to these results has received funding from the European Union, Seventh Framework Programme FP7, under grant agreement MATHEMACS, $n^{0}: 318723$ and FinMaP $n^{0}: 612955$. The authors are grateful for funding this research from the Universitat Jaume I under the project $P 11 B 2012-27$.

\section{Appendix A. Robustness analysis on the model pa- rameters}

In this Appendix we analyze the robustness of the model by changing some key parameters. Specifically, we evaluate the sensitivity of some simulated time series with respect to the choice of the number of bank's potential lenders, $\bar{d}$, to the variation of the percentage of core banks, $k$, and, then, to the variance of the deposit shock, $\eta$.

Firstly, we investigate how the model dynamics change with $\bar{d}$. We focus the study on the two variables which are mainly affected by the variation of the parameter, namely the network centrality and the percentage of failures. Fig. 8 displays the average network centrality for the three different strategies as a function of $\beta$. Specifically, each panel represents a distinct 
level $\bar{d}$, equal to 1,3 and 5 , respectively. By increasing $\bar{d}$, ceteris paribus, the centralization slightly increases. Although this result is trivial - it is, in fact, obvious that the higher the number of lenders each borrower can look at the higher the network centralization - it clarifies an important finding: by increasing $\bar{d}$, the higher network centralization is associated with a faster centralization in terms of $\beta$ (i.e. by raising $\bar{d}$, the network centralizes for lower value of intensity of choice, $\beta$ ). Moreover, for any value of $\bar{d}>3$ (see right panel of Fig.8), each variation of $\beta, \forall \beta>3$, does not produce any change in the network topology. This result clarifies the importance of maintaining $\bar{d}$ low and constant in order to better analyze the effect of $\beta$.

Fig.9 shows the strong correlation between network centrality and banks' failures. As Fig.9 shows, to high levels of centralization, due both to high levels of $\bar{d}$ and/or to high levels of $\beta$, corresponds a high mortality of banks. Last but not least, we observe that, by increasing $\bar{d}$, the impact of the different strategies on the aggregate banks failures does not qualitatively change.
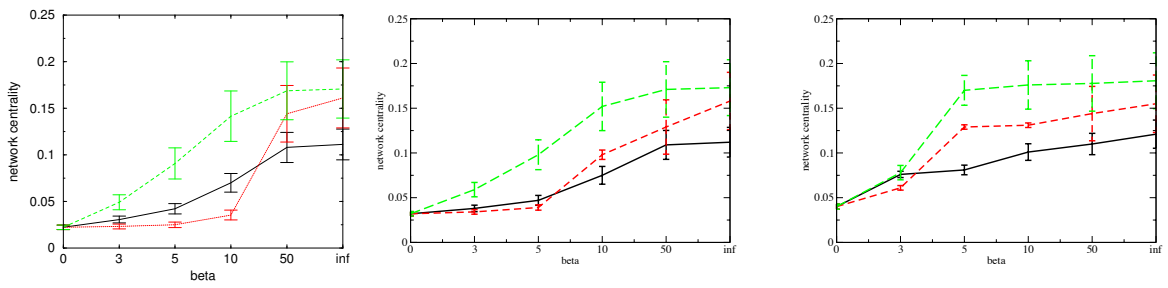

Figure 8: Average network centrality, over all times and all simulations as a function of $\beta$. Left panel $\bar{d}=1$; middle panel $\bar{d}=3$, right panel $\bar{d}=5$. The lowest interest rate strategy (i.e $\epsilon=0$ ) is highlighted in black solid line, the mixed strategy (i.e $\epsilon=0.5$ ) in red dotted line, and the highest liquidity one (i.e $\epsilon=1$ ) in green dashed line. Colors are available on the web site version.

Secondly, we analyze the robustness to the variation of the network k-core. Specifically, we investigate the model performance for $k=75 \%$ and $k=85 \%$. As shown in the top row of Fig.10, where the average number of core banks for $k=75 \%$ (left panel) and $k=85 \%$ (right panel) is displayed, the higher is $k$, the lower the number of core banks. Moreover, by increasing the intensity of choice, $\beta$, the number of core clients increases (see second row of Fig.10). This behaviour remains unchanged by modifying $k$.

It is worthy of note that, by varying $k$ from $50 \%$ to $85 \%$, the model reproduces similar dynamics in terms of strategies and intensity of choice. However, by comparing the left panels of Fig. 3 with the first and second row of Fig.10, we observe that, by increasing $k$, the model dynamics becomes "more linear" when $\beta$ rises. Specifically, the spikes present in left 

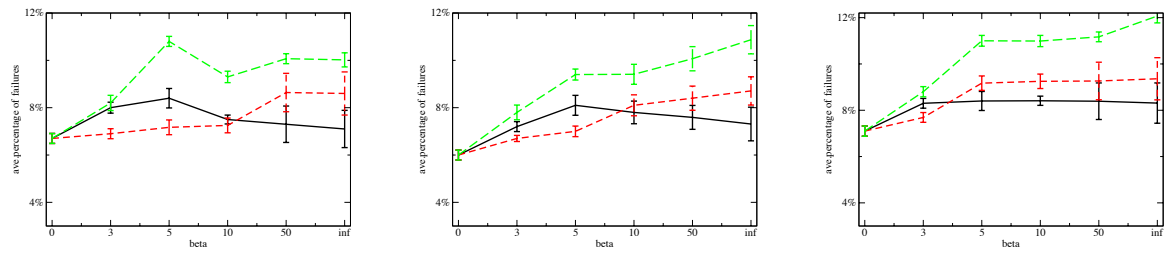

Figure 9: Average percentage of banks failures, over all times and all simulations as a function of $\beta$. Left panel $\bar{d}=1$; middle panel $\bar{d}=3$, right panel $\bar{d}=5$. The lowest interest rate strategy (i.e $\epsilon=0$ ) is highlighted in black solid line, the mixed strategy (i.e $\epsilon=0.5$ ) in red dotted line, and the highest liquidity one (i.e $\epsilon=1$ ) in green dashed line. Colors are available on the web site version.

panels of Fig.3 (see, in particular, the spike in the average number of core banks at $\beta=10$ for the mixed strategy and the abrupt change in the average number of core in-links at $\beta=5$ for $\epsilon=1$ ) disappear. The explanation is quite intuitive: by decreasing the core size, we are decreasing the chances of switching between core and periphery and, consequently, we are generating more stable dynamics for each $\beta$. In other words, the higher $k$, the smaller the number of core banks, but the longer their permanence in the core and, therefore, the higher the stability of the system itself. By increasing $k$ from $50 \%$ to $85 \%$, in fact, the average switching between core and periphery over time and simulations decreases by the $42 \%$ (st.dev $4.12 \%$ ). The other investigated variables show similar behaviors. Specifically, by varying $k$, the leverage and interest rate of core banks (see third and fourth row of Fig.10) maintain their characteristics for the different strategies and values of intensity of choice, but they smooth jumps.

Last but not least, the bottom row of Fig. 10 shows the average percentage of core banks failures, as a function of $\beta$ for $k=75 \%$ (left panel) and $k=85 \%$ (right panel). Also in this case, for any $k$, core banks have the highest benefit in applying the mixed strategy for any $\beta$. Furthermore, by increasing $k$, we observe the same "linearization" in the model performances. Results for peripheral banks are consistent with our analysis and available upon request.

Lastly, we analyze the robustness to the variation of the variance of the deposit shock, $\eta$. Specifically, we study, for each of the three different strategies the average percentage of banks failures and its standard deviation for each value of intensity of choice by varying $\eta$ from 0.01 to 0.06 with steps of $0.005^{11}$. Results confirm that the variation of $\eta$, by maintaining constant $\beta, \forall \epsilon$, does not change the average percentage of banks failures. This re-

\footnotetext{
${ }^{11}$ Numerical results are omitted by available upon request.
} 

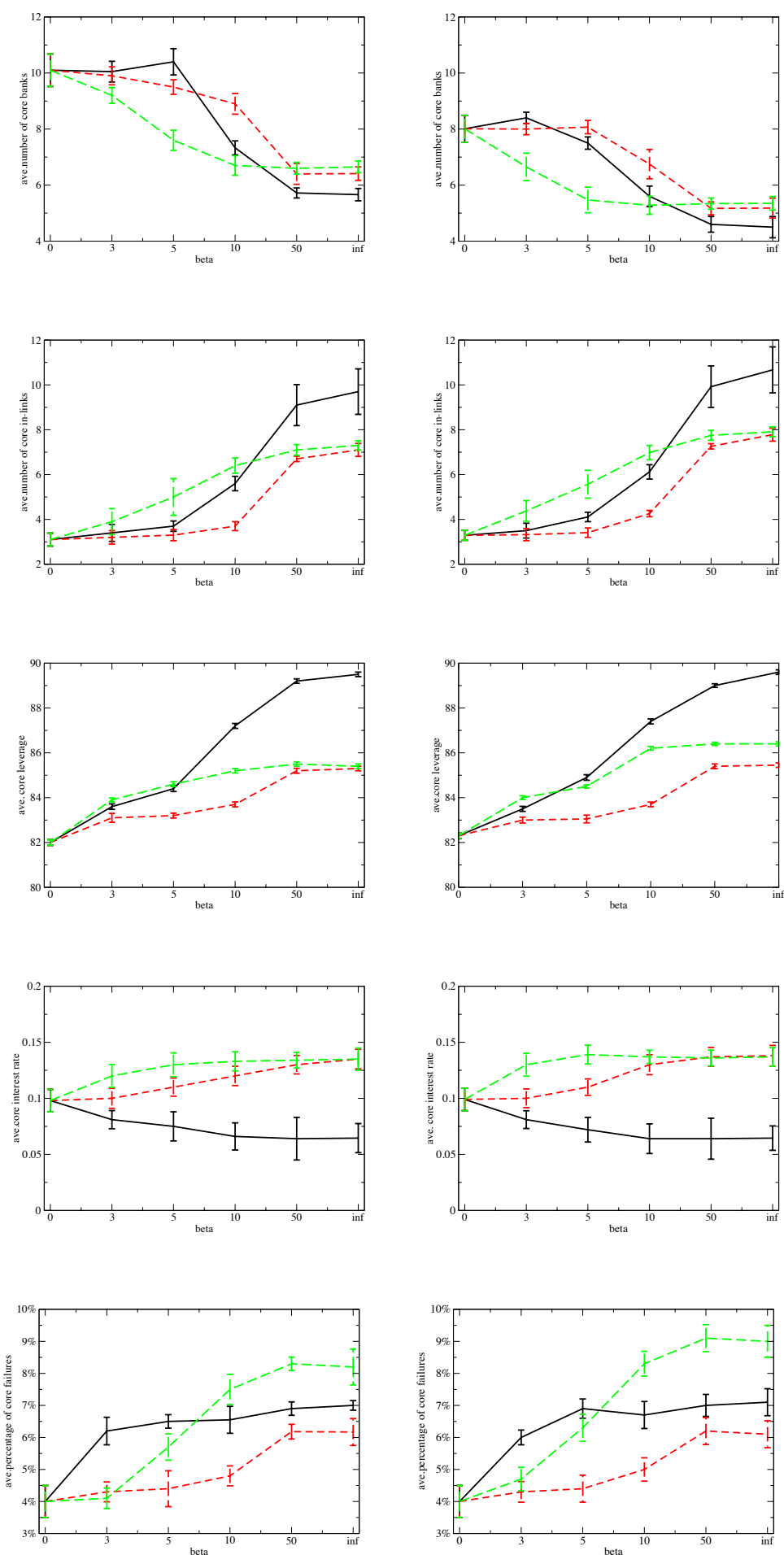

Figure 10: Average number of core banks (first row) and their incoming links (second row). Average core leverage (third row) and interest rate (fourth row). Average percentage of core failures (bottom row). In the left panels for $k=75 \%$; in the right panels and for $k=85 \%$. The strategy $\epsilon=0$ is highlighted in black solid line, the strategy $\epsilon=0.5$ in red dotted line and the strategy $\epsilon=1$ in green dashed line. 
sult is confirmed by the two-sample Kolmogorov-Smirnov (KS) test which supports that the historical series of failures by varying $\eta$, but keeping the strategy and $\beta$ fixed, are drawn from the same population at a significance level of 0.05 . Understanding this result is quite intuitive: the variance of the deposit shock affects positively and negatively the banks' liquidity, by making lenders (i.e. agents receiving the positive shock) more liquid and borrowers (i.e. agents negatively attacked) more in need. This generates an off-setting between the two positions which leaves the average unchanged. What varies, however, is the standard deviation in the percentage of banks failures which, obviously, increases with $\eta$.

\section{Appendix B. Different derivations of the interest rate equation}

The relationship between screening costs and interest rate has been widely explored in the economic literature and often associated with the imperfect information paradigm (see Aleem 1990; Bester 1985; Hoff and Stiglitz 1990 ). Following this interpretation the explanation for high interest rate lies in the problem of asymmetric information. Specifically, lenders having less information than borrowers about the latter's ability and willingness to repay a loan have to screen applicants and charge the cost of this operation on borrowers. However, it is very rare to find evidence about the costs associated with screening and, more generally, about the effect of imperfect information on the behavior of credit market participants.

In the previous analysis, we assumed the interest rate as an increasing function in the lender's dimension and decreasing in the borrower's size. This hypothesis allowed us to distinguish between the two pure strategies. Specifically, we modeled a strategy, $\epsilon=1$, where the high liquidity corresponded to the high interest rate and one, $\epsilon=0$, where the low interest rate corresponded to a low liquidity. Here, we modify Eq.4 in order to investigate two different scenarios. Firstly, we model an interest rate which increases with the borrower's size and decreases with the lender's one. Then, we include in the original Eq. 4 a reference interest rate fixed by the Central Bank.

Let us firstly consider the case where screening costs decrease with the dimension of the borrower's assets and increase with the lender's dimension. This implies a modification of Eq.3 in the following way:

$$
E\left[\Pi_{t}^{i, j}\right]=\left(1-p_{t}^{j}\right) r_{t}^{i, j} c_{t}^{i, j}+p_{t}^{j}\left(\alpha A_{t}^{j}-c_{t}^{i, j}\right)-\delta A_{t}^{j}+\sigma A_{t}^{i} .
$$

Consequently, the new setting rule for the interbank interest rate becomes:

$$
r_{t}^{i, j}=\frac{\delta A_{t}^{j}-\sigma A_{t}^{i}-p_{t}^{j}\left(\alpha A_{t}^{j}-c_{t}^{i, j}\right)}{\left(1-p_{t}^{j}\right) c_{t}^{i, j}} .
$$


This implies an inverse relation between the lender's size and the interest
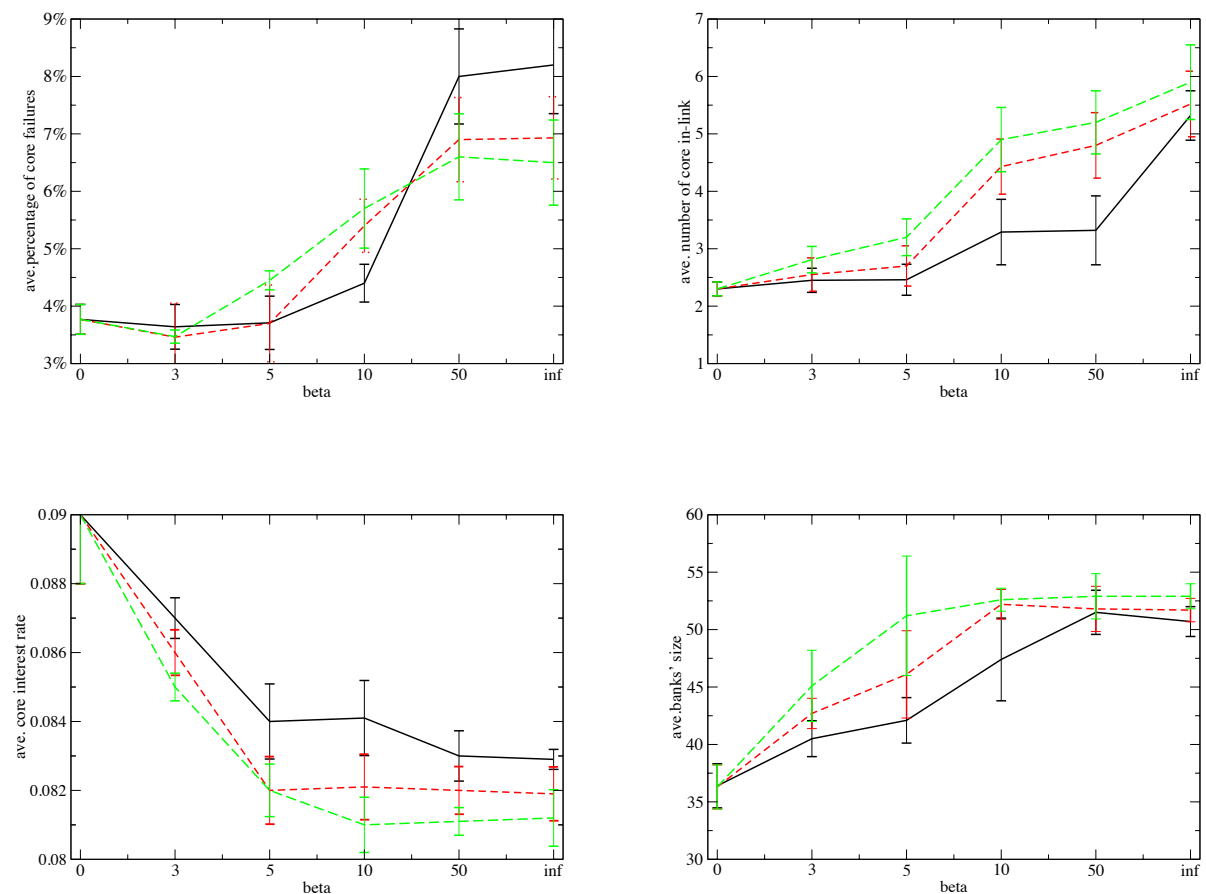

Figure 11: Average percentage of core failures (top left panel), average number of core in-coming links (top right panel), average core interest rate (bottom left panel) and average core size (bottom right panel), over all times and all simulations as a function of $\beta$. The strategy $\epsilon=0$ is highlighted in black solid line, the strategy $\epsilon=0.5$ in red dotted line and the strategy $\epsilon=1$ in green dashed line. Results are obtained using Eq. 10.

rate the financial institution offers on the interbank market: the most liquid lender offers the best conditions in terms of interest rate. In this circumstance, the two different banks' strategies, described in the fitness (see Eq. 1), collapse to the same one. Specifically, on the one hand, the strategy based on the higher liquidity (i.e $\epsilon=1$ ), via Eq.10, now describes a situation where the most liquid agent corresponds to the one offering the lowest interest rate. On the other hand, the strategy based on the lower interest rate (i.e $\epsilon=0$ ) now characterizes a world where the cheapest lender in term of interest rate is also the most liquid one. Since the banks' strategies go in the same direction, their impact on the simulated dynamics is similar. As Fig.11 shows there are no statistically significant results in terms of strategies in the investigated series. In fact, as highlighted by the high standard deviation among the three strategies, their impact on core failures, 
in-coming links, interest rate and banks' size is equivalent. However, what is relevant is the impact of $\beta$. In fact, by increasing the intensity of choice the percentage of core failures increases (see top left panel of Fig.11). The network becomes centralized and lenders have too many customers (see top right panel) paying too low interest rates $^{12}$ (see bottom left panel). The combined effect of many customers paying low rate produces the interbank market "collapse".

We now briefly describe a world where banks set their interest rate also according to a common reference rate. This analysis requires the modification of the expected profit by adding a reference interest rate, $\bar{r}$, fixed to $2 \%$. According to this modification the expected profit of a loan from the lender $i$ to the borrower $j$ becomes:

$$
E\left[\Pi_{t}^{i, j}\right]=\left(1-p_{t}^{j}\right) \bar{r} c_{t}^{i, j}+\left(1-p_{t}^{j}\right) r_{t}^{i, j} c_{t}^{i, j}+p_{t}^{j}\left(\alpha A_{t}^{j}-c_{t}^{i, j}\right)+\delta A_{t}^{j}-\sigma A_{t}^{i}
$$

All parameters in the Eq. (11) must be interpreted as in the Sec. 2.1, with the only exception for the the first term on the right hand side of Eq.(11). This, in fact, shows the expected revenue if the borrower repays its obligation at a fixed interest rate. By imposing Eq.(11) equal to zero and solving it for $r_{t}^{i, j}$, we obtain the new interbank interest rate ensuring zero expected profits:

$$
r_{t}^{i, j}=\frac{\sigma A_{t}^{i}-\delta A_{t}^{j}-p_{t}^{j}\left(\alpha A_{t}^{j}-c_{t}^{i, j}\right)}{\left(1-p_{t}^{j}\right) c_{t}^{i, j}}-\bar{r} .
$$

As the reader can notice, the introduction of this component just changes the level of the interest rate but does not affect the heterogeneity of the offered interest rate. Our simulated results show that the introduction of a fixed interest rate does not affect any of the investigated dynamics. Although the results shift up or down, the effects in term of strategies and intensity of choice remain unchanged. Figures are omitted but available upon request.

\section{References}

[1] Albert, R., Jeong, H., Barabasi, A. 2000. Attack and error tolerance of complex networks, Nature 406, 378-382.

[2] Aleem, I. (1990). Imperfect information, screening, and the costs of informal lending: a study of a rural credit market in Pakistan. The World Bank Economic Review, 4(3), 329-349.

[3] Allen, F., Gale D., 2000. Bubbles and Crises. Economic Journal 110: 236-55.

\footnotetext{
${ }^{12} \mathrm{By}$ construction, in this model the interest rate decreases with the bank size (see bottom right panel of Fig.11).
} 
[4] Alvarez-Hamelin, J. I., Dall'Asta, L., Barrat, A., Vespignani, A. 2005. k-core decomposition of Internet graphs: hierarchies, self-similarity and measurement biases. arXiv preprint cs/0511007.

[5] Arcand, J.L., Berkes, E., Panizza, U., 2011: Too Much Finance?, working paper.

[6] Aymanns, C., Georg, C.P., 2015. Contagious synchronization and endogenous network formation in financial networks. Journal of Banking $\mathscr{E}$ Finance, 50(C), pages 273-285.

[7] Barabasi, A.L, Albert, A., 1999. Emergence of scaling in random networks. Science 286, 509-512.

[8] Bargigli, L., Tedeschi, G. 2014. Interaction in agent-based economics: A survey on the network approach. Physica A: Statistical Mechanics and its Applications, 399, 1-15.

[9] Bartelsman, E., Scarpetta, S., Schivardi, F., 2005. Comparative analysis of firm demographics and survival: evidence from micro-level sources in OECD countries. Ind Corp Chang 14(3): 365-39.

[10] Battiston, S., Delli Gatti, D., Gallegati, M., Greenwald, B., Stiglitz, JE., 2007. Credit chains and bankruptcy propagation in production networks. Journal of Economic Dynamics and Control 31: 2061-2084.

[11] Battiston, S., DelliGatti, D., Gallegati, M., Greenwald, BC., Stiglitz, JE., 2012a. Liaisons dangereuses: Increasing connectivity, risk sharing, and systemic risk. J. of Economic Dynamics and Control.

[12] Battiston, S., DelliGatti, D., Gallegati, M., Greenwald, BC., Stiglitz, JE., 2012b. Default cascades: When does risk diversification increase stability? Journal of Financial Stability, 8 (3): 138-149.

[13] Baum, C.F., Caglayan, M., Stephan, A., Talavera, O. 2004. Uncertainty determinants of corporate liquidity. Economic Modelling, 25(5), 833-849.

[14] Berger, A.N., Klapper, L.F., Udell, G.F., 2001. The ability of banks to lend to informationally opaque small businesses. Journal of Banking $\mathscr{E}$ Finance, 25 (12),2127-2167.

[15] Bernanke, B., Gertler, M., 1989. Agency costs, networth, and business fluctuations. American Economic Review 79(1):14-31.

[16] Bernanke, B., Gertler, M., 1990. Financial fragility and economic performance. $Q J$ Economic 105(1):87-114 
[17] Bernanke, B., Gertler, M., Gilchrist, S., 1999. The Financial Accelerator in a Quantitative Business Cycle Framework, in J. B. Taylor, and M. Woodford, eds., Handbook of Macroeconomics, Amsterdam: North Holland.

[18] Bester, H. 1985. Screening vs. rationing in credit markets with imperfect information. The American Economic Review, 75(4), 850-855.

[19] Black, S.E., Strahan, P.E., 2002. Entrepreneurship and Bank Credit Availability. Journal of Finance, 57(6), pp. 2807-2833

[20] Boss, M., Elsinger, H., Summer, M., Thurner, S., 2004. Network topology of the interbank market. Quantitative Finance, 4 (6), 677-684.

[21] Brock WA., and Hommes, C., 1998. Heterogeneous beliefs and routes to chaos in a simple asset pricing model. J Econ Dyn Control 22: 1235-1274.

[22] Caccioli F., Catanach, TA., Farmer, JD., 2012. Heterogeneity, Correlations and Financial Contagion. Advance in complex system, Vol. 15, Issue supp02.

[23] Caccioli, F., Shrestha, M., Moore, C., Farmer, J. D. 2014. Stability analysis of financial contagion due to overlapping portfolios. Journal of Banking and Finance, 46, 233-245.

[24] Catullo, E., Gallegati, M., Palestrini, A., 2015. Towards a credit network based early warning indicator for crises. Journal of Economic Dynamics and Control, 50 (0), 78-97.

[25] Chinazzi, M., Fagiolo, G., Reyes, J.A., Schiavo, S., 2012. Post-Mortem Examination of the International Financial Network Working paper: http://dx.doi.org/10.2139/ssrn.1995499.

[26] Clauset, A., Shalizi, CR., Newman, MEJ., 2009. Power-law distributions in empirical data. SIAM Rev 51(4):661-703. arXiv:0706.1062v2.

[27] Cocco, J., Gomes, F., Martins, N., 2009. Lending relationships in the interbank market. Journal of Financial Intermediation, 181, 24-48.

[28] Craig, B., von Peter, G., 2014. Interbank tiering and money center banks. Journal of Financial Intermediation, vol. 23(3), pages 322-347.

[29] Dabla Norris, E., Kersting, E. Verdier, G., 2012. Firm productivity, innovation and financial development, Southern Economic Journal, forthcoming.

[30] Dell' Ariccia, G., Marquez, R., 2004. Information and bank credit allocation. Journal of Financial Economics, 72 (1), 185-214. 
[31] Domencich, T., McFadden, D., 1975. Urban travel demand. A behavioral analysis. North-Holland Amsterdam.

[32] Ford, L.R., Fulkerson, D.R. 1956. Maximal flow through a network, Canadian Journal of Mathematics 8, 399-404.

[33] Ford, L.R., Fulkerson, D.R., 1962. Flows in Networks. Princeton University Press, Princeton, NJ.

[34] Fricke, D., and Lux, T. 2015. Core-periphery structure in the overnight money market: evidence from the e-mid trading platform. Computational Economics, 45(3), 359-395.

[35] Georg, C.P., 2013. The effect of the interbank network structure on contagion and common shocks. Journal of Banking \& Finance, 37(7).

[36] Ghosal, V., Loungani, P. (2000). The differential impact of uncertainty on investment in small and large business. The Review of Economics and Statistics, 82, 338-349.

[37] Gonzalez, V. M., 2013. Leverage and corporate performance: International evidence. International Review of Economics 83 Finance, 25, 169184.

[38] Gonzalez, V. M., Gonzalez, F., 2014. Banking liberalization and firms' debt structure: International evidence. International Review of Economics \& Finance, 29, 466-482.

[39] Greenwald, BCN., Stiglitz, JE., 1993. Financial market imperfections and business cycles. Q J Economic 108(1): 77-114.

[40] Grilli, R., Tedeschi, G., Gallegati M., 2014. Bank interlinkages and macroeconomic stability. International Review of Economics $\& 3$ Finance, $34,72-88$.

[41] Grilli, R., Tedeschi, G., Gallegati M., 2014a. Markets connectivity and financial contagion. Journal of Economic Interaction and Coordination. doi:10.1007/s11403-014-0129-1.

[42] Grilli, R., Tedeschi, G., Gallegati M., 2014b. Network approach for detecting macroeconomic instability. Proceedings of the IEEE 05/2015; DOI:10.1109/SITIS.2014.96.

[43] Hale, G., 2011. Bank Relationships, Business Cycles, and Financial Crises. Working Paper 17356. National Bureau of Economic Research.

[44] Herrera, A.M., Minetti, R., 2007. Informed finance and technological change: evidence from credit relationships. Journal of Financial Economics, 83, pp. 223-269. 
[45] Hoff, K., Stiglitz, J. E. 1990. Introduction: Imperfect information and rural credit markets: Puzzles and policy perspectives. The world bank economic review, 4(3), 235-250.

[46] int' Veld, D., van der Leij, M., Hommes, C., 2014. The formation of a core periphery structure in heterogeneous financial networks. Tinbergen Institute Discussion papers 14-098/II Tinbergen Institute.

[47] Iori, G., Jafarey, S., Padilla, FG., 2006. Systemic risk on the interbank market. Journal of Economic Behavior \& Organization 61: 525-542. bibitemX Iori, G., Kapar, B., Olmo, J., 2015. Bank characteristics and the interbank money market: a distributional approach. Studies in Nonlinear Dynamics \& Econometrics, vol. 19(3), pages 249-283.

[48] Issing, O., 2009. Some Lessons from the Financial Market Crisis.International Finance, 12, 3, pp 431-444.

[49] Kaushik, R., Battiston, S., 2012. Credit Default Swaps Drawup Networks: Too Tied To Be Stable? Working paper, arXiv:1205.0976v1.

[50] LeBaron, B., Yamamoto R., 2009. The impact of imitation on long memory in an order-driven market. East Econ J 34(4):504-517.

[51] Lenzu, S., Tedeschi, G., 2012. Systemic risk on different interbank network topologies. Physica A 3914331-4341.

[52] Levine, R., 2005. Finance and Growth: Theory and Evidence. In: Aghion, P. Durlauf, S. 2005. Handbook of Economic Growth, Elsevier, pp. 865-934.

[53] Lorenz, J., Battiston, S., 2008. Systemic risk in a network fragility model analyzed with probability density evolution of persistent random walks. Networks and Heterogeneous Media 3.

[54] Lux, T., 2015. Emergence of a Core-Periphery Structure in a Simple Dynamic Model of the Interbank Market. Journal of Economic Dynamics and Control 52, A11-A23.

[55] Memmel, C., Sachs, A., 2013. Contagion in the interbank market and its determinants. Journal of Financial Stability 9 (1) 46-54.

[56] Maudos, J., De Guevara, J.F., 2004. Factors explaining the interest margin in the banking sectors of the European Union. Journal of Banking E Finance, 28 (9), 2259-2281.

[57] Minoiu, C., Reyes, J.A, 2011. A network analysis of global banking: 1978-2009. Working Paper 11/74. IMF. 
[58] Rajan, R.G., Zingales, L., 1998. Financial dependence and growth, American Economic Review, 88(3), pp. 559-586.

[59] Robinson, J., 1952. The Generalization of the General Theory, The Rate of Interest and Other Essays, Macmillan.

[60] Schiavo, S., Reyes, J., Fagiolo, G., 2010. International trade and financial integration: a weighted network analysis. Quantitative Finance. 104, 389-399.

[61] Schumpeter, J.,1911. A Theory of Economic Development, Harvard University Press.

[62] Sornette, D., Von der Becke, S., 2011. Complexity clouds financerisk models. Nature 471, 166.

[63] Tedeschi, G., Mazloumian, A., Gallegati, M., Helbing, D., 2012. Bankruptcy cascades in interbank markets. PLOS One, 7(12), e52749.

[64] Tedeschi, G., Vitali, S., Gallegati M., 2014. The dynamic of innovation networks: a switching model on technological change. Journal of Evolutionary Economics, 24, 4, pp 817-834.

[65] Temizsoy, A., Iori, G., Montes-Rojas, G., 2015. The role of bank relationships in the interbank market. Journal of Economic Dynamics and Control, vol. 59(C), pages 118-141.

[66] Thurner, S., Hanel, R., Pichler, S., 2003. Risk trading, network topology and banking regulation. Quantitative Finance 3: 306-319.

[67] Tonzar, L., 2015. Cross-border interbank networks, banking risk and contagion. Journal of Financial Stability (18), 19-32.

[68] Trichet, J.C., 2010. Reflections on the nature of monetary policy nonstandard measures and finance theory. Opening speech at the ECB Central Banking Conference. Frankfurt, 18 November 2010.

[69] Tridico, P., 2012. Financial Crisis and Global Imbalances: Its Labour Market Origins and Aftermath, Cambridge Journal of Economics, 36(1), pp. 17-42.

[70] Vandenbossche, J., Demuynck, T., 2013. Network formation with heterogeneous agents and absolutefriction. Comput Econ 42 :23-45.

[71] Wray, L.R., 2009. The rise and fall of money manager capitalism: a Minskian approach, Cambridge Journal of Economics, 33(4), pp. 807828. 


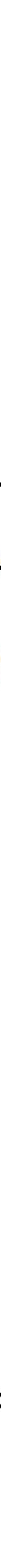

Figure1

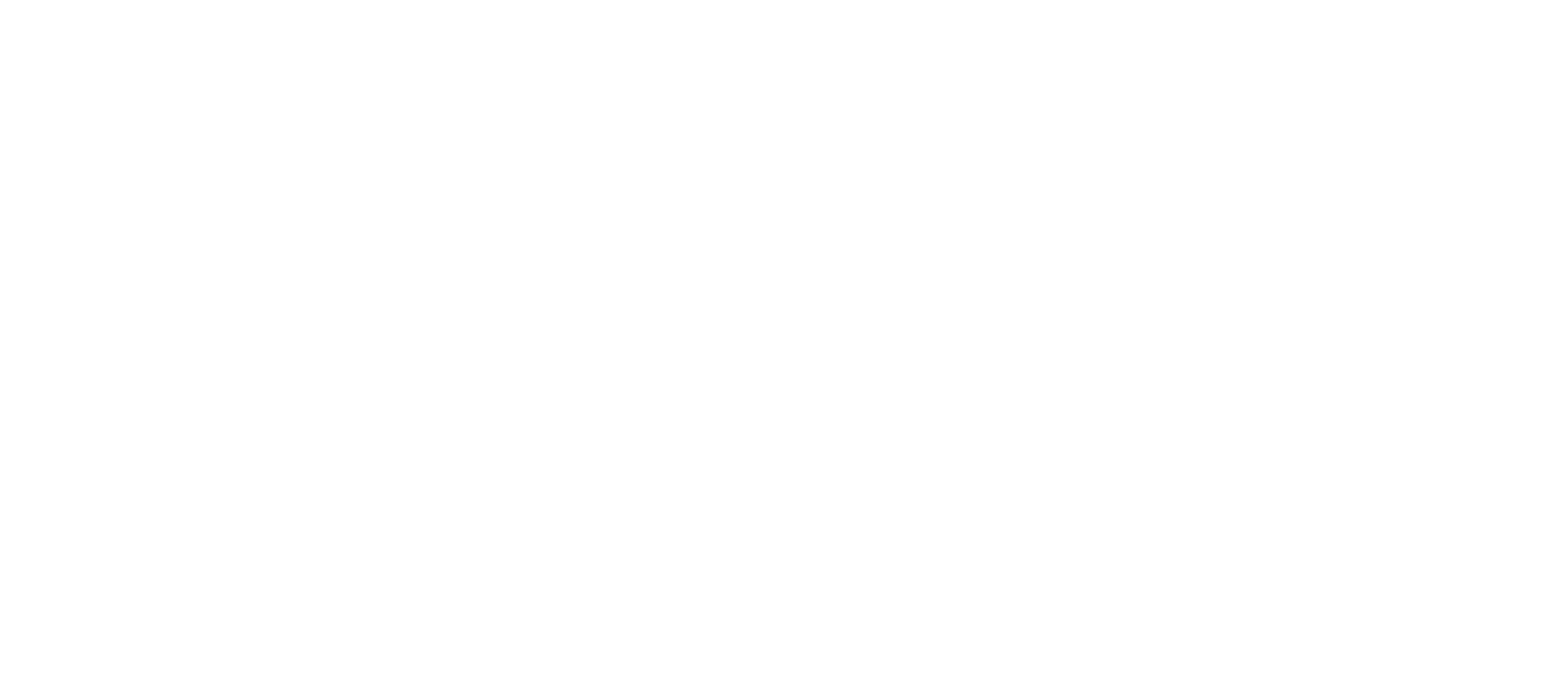




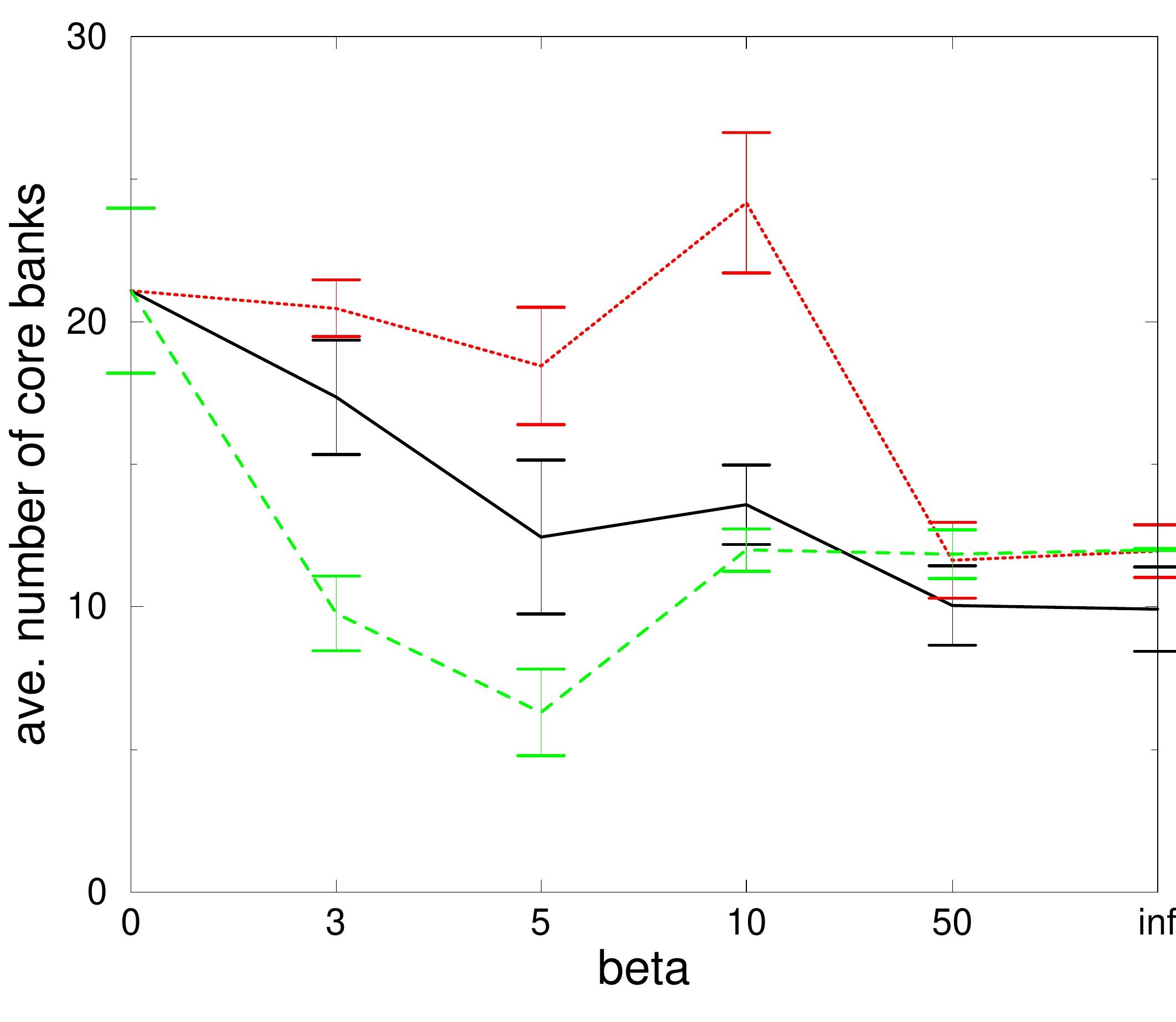

Figure3

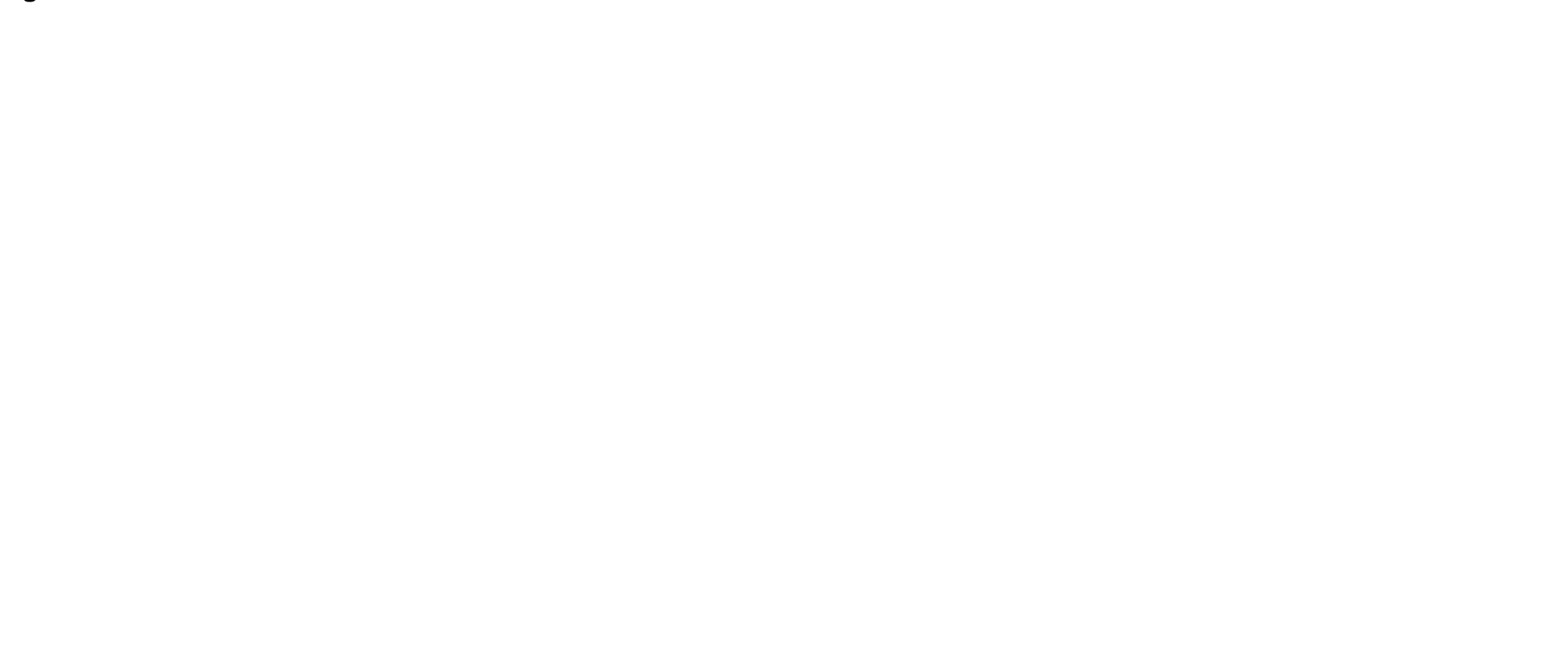




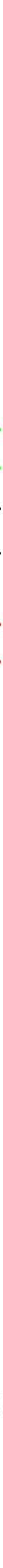

Figure4 


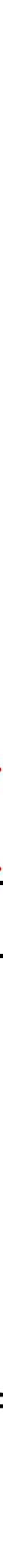

Figure6

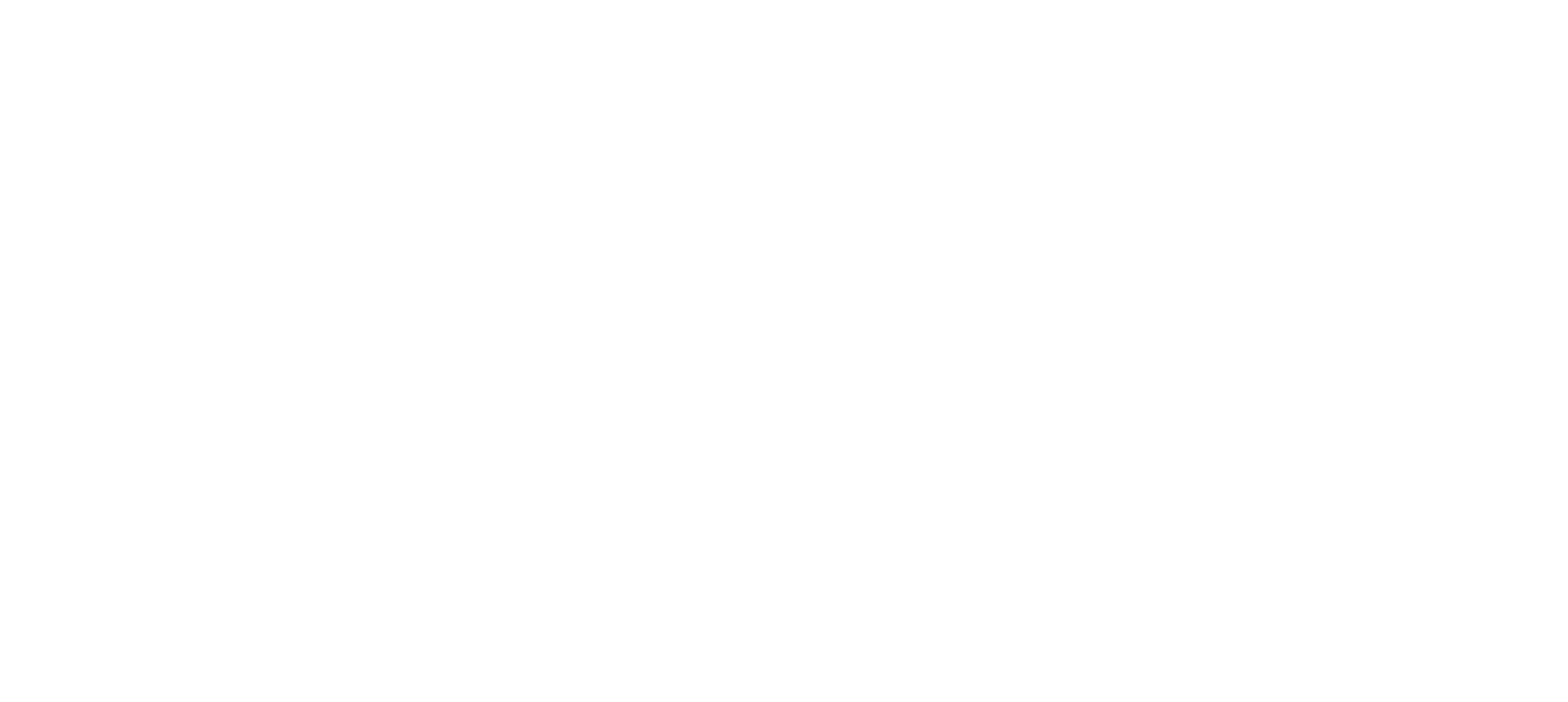




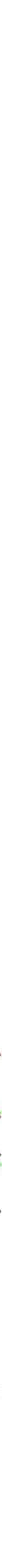

Figure7

\section{Figure7}

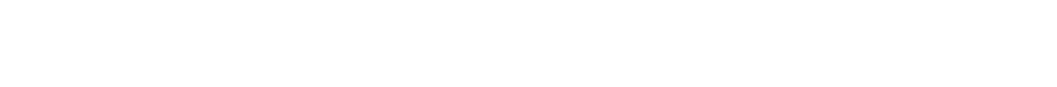

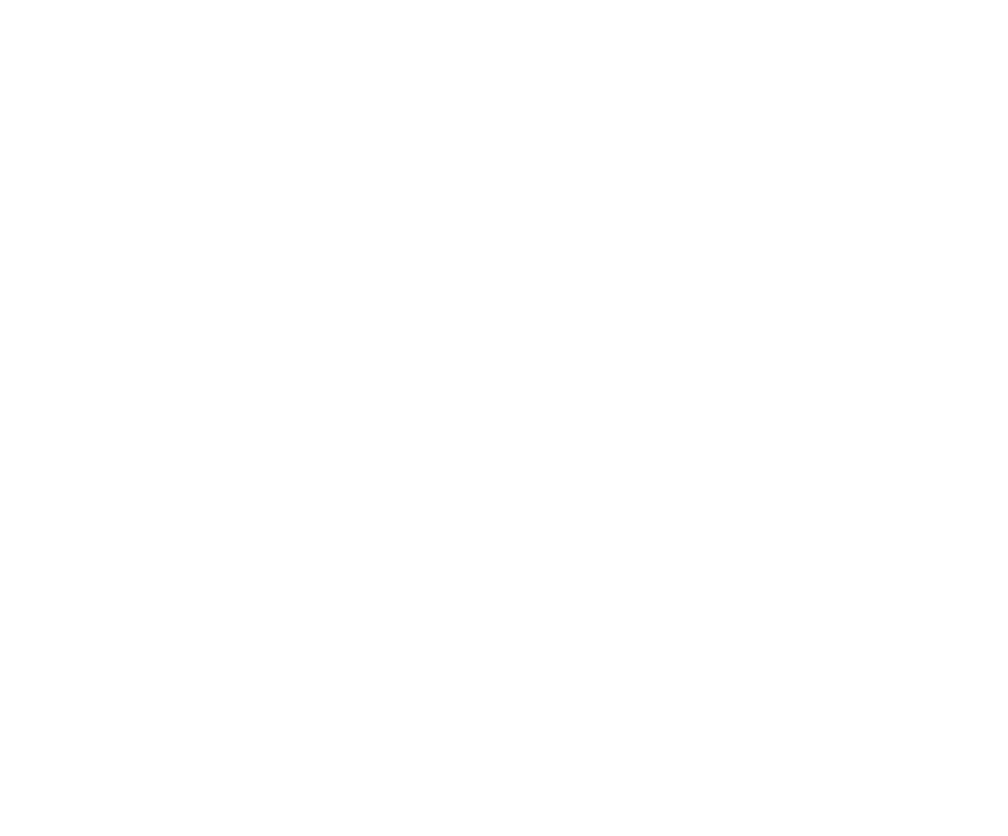

(1)

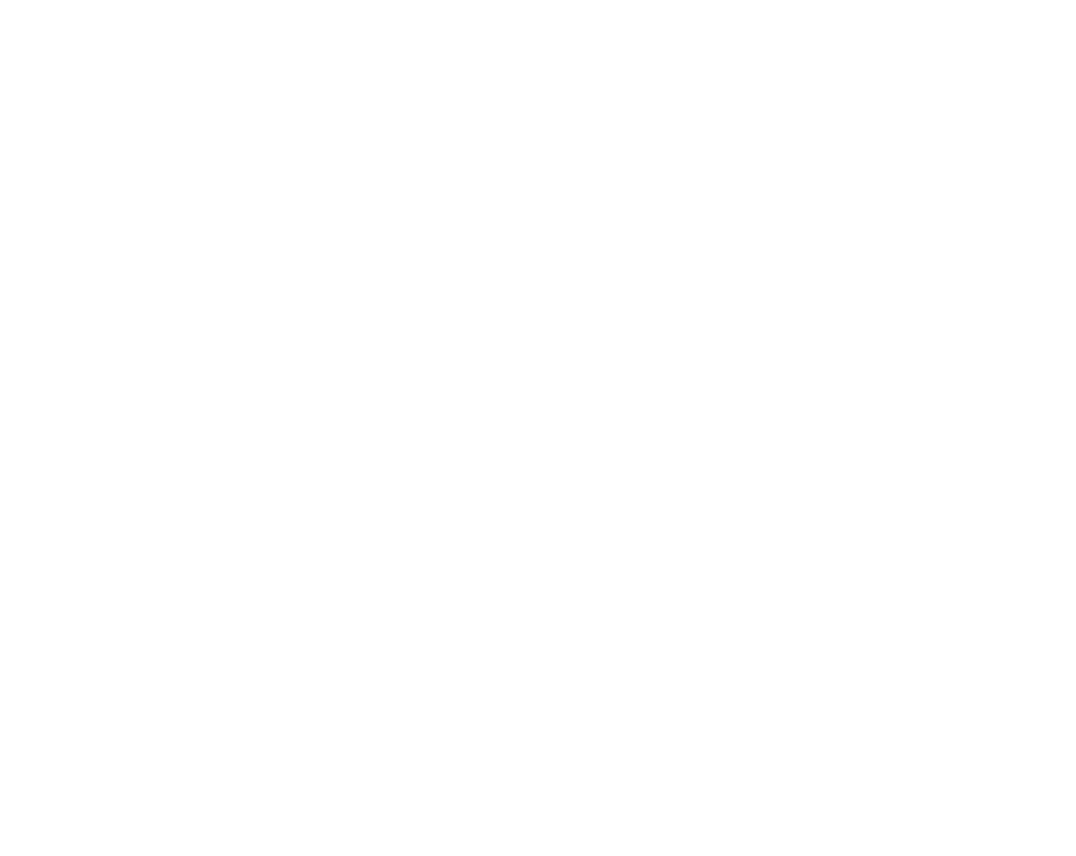




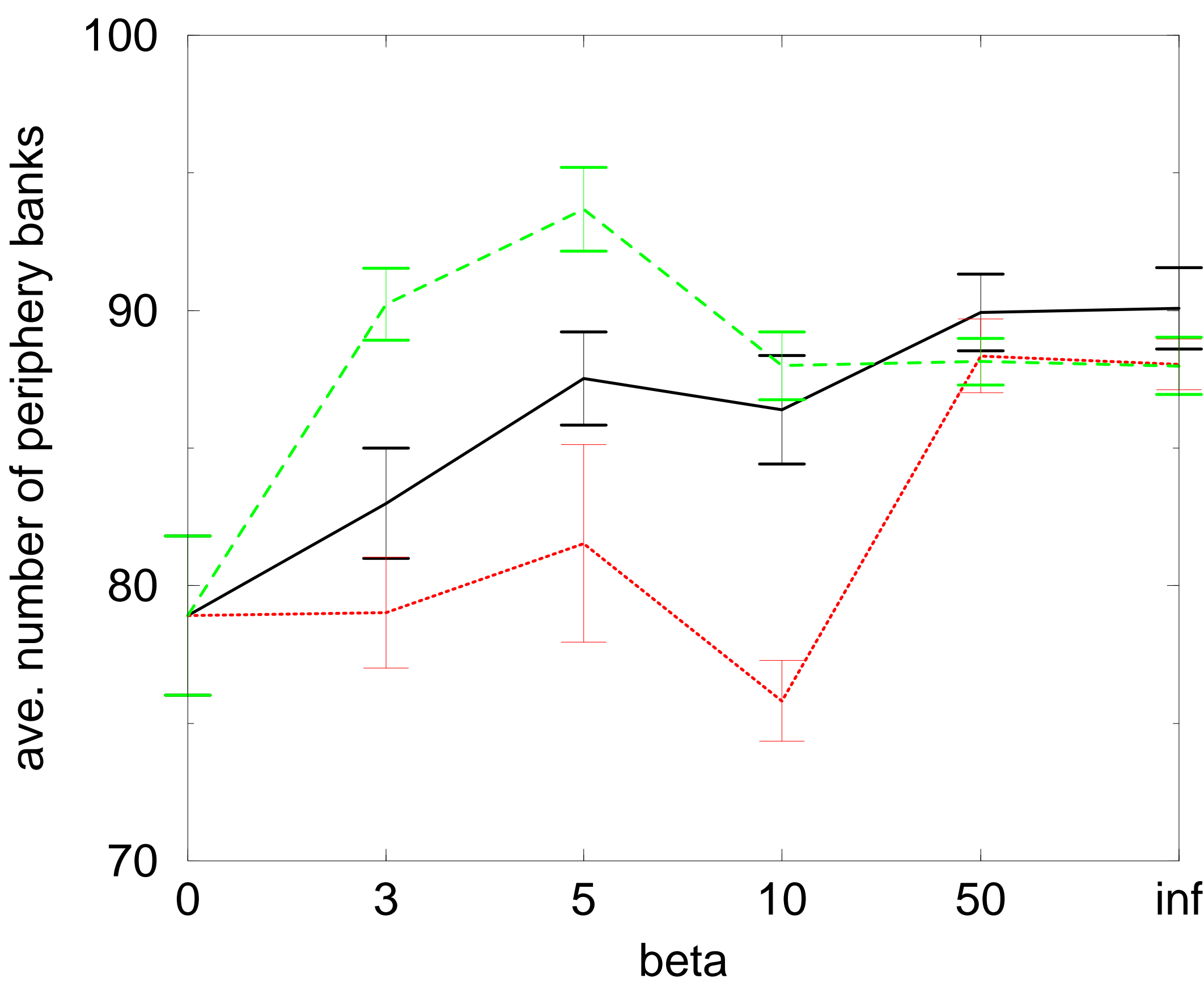

$\circlearrowleft$

$\frac{\tau}{\tau}$

을

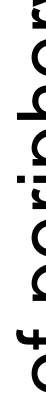

90

80

70

0

3

5

50 


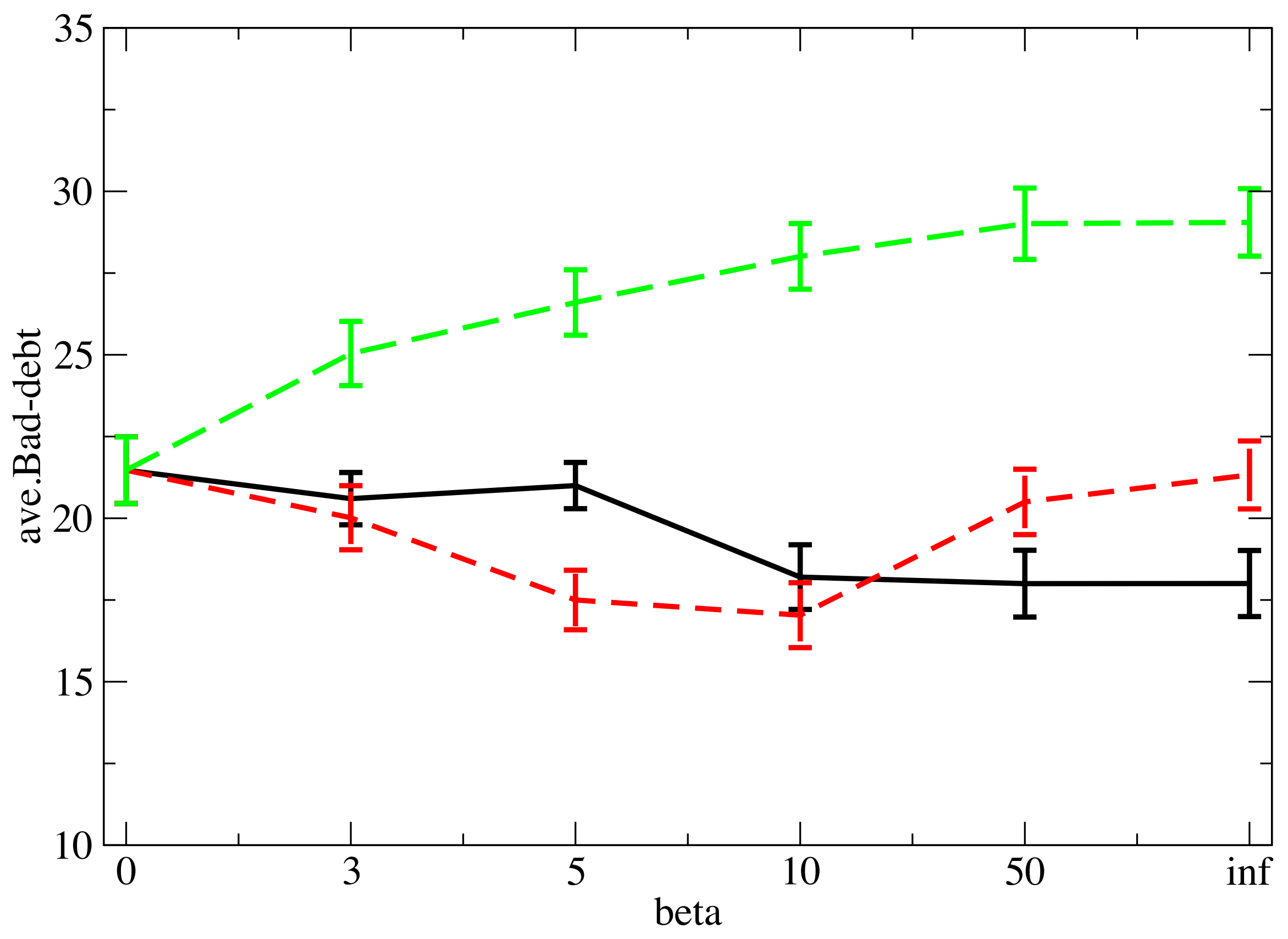




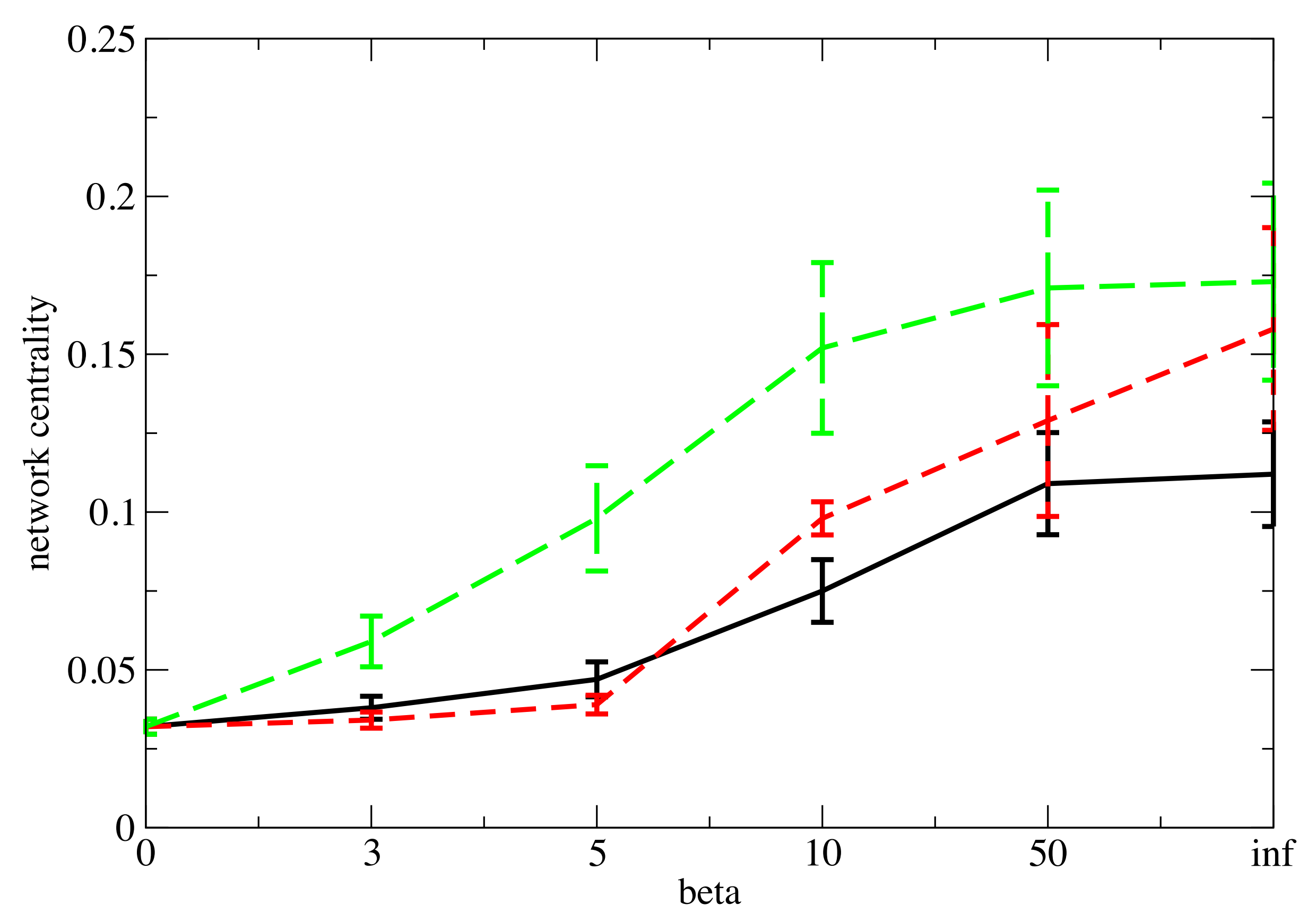




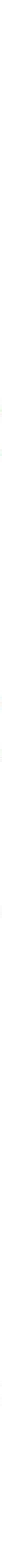

Figure13

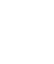

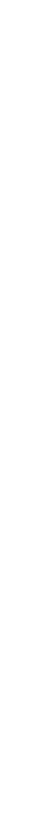




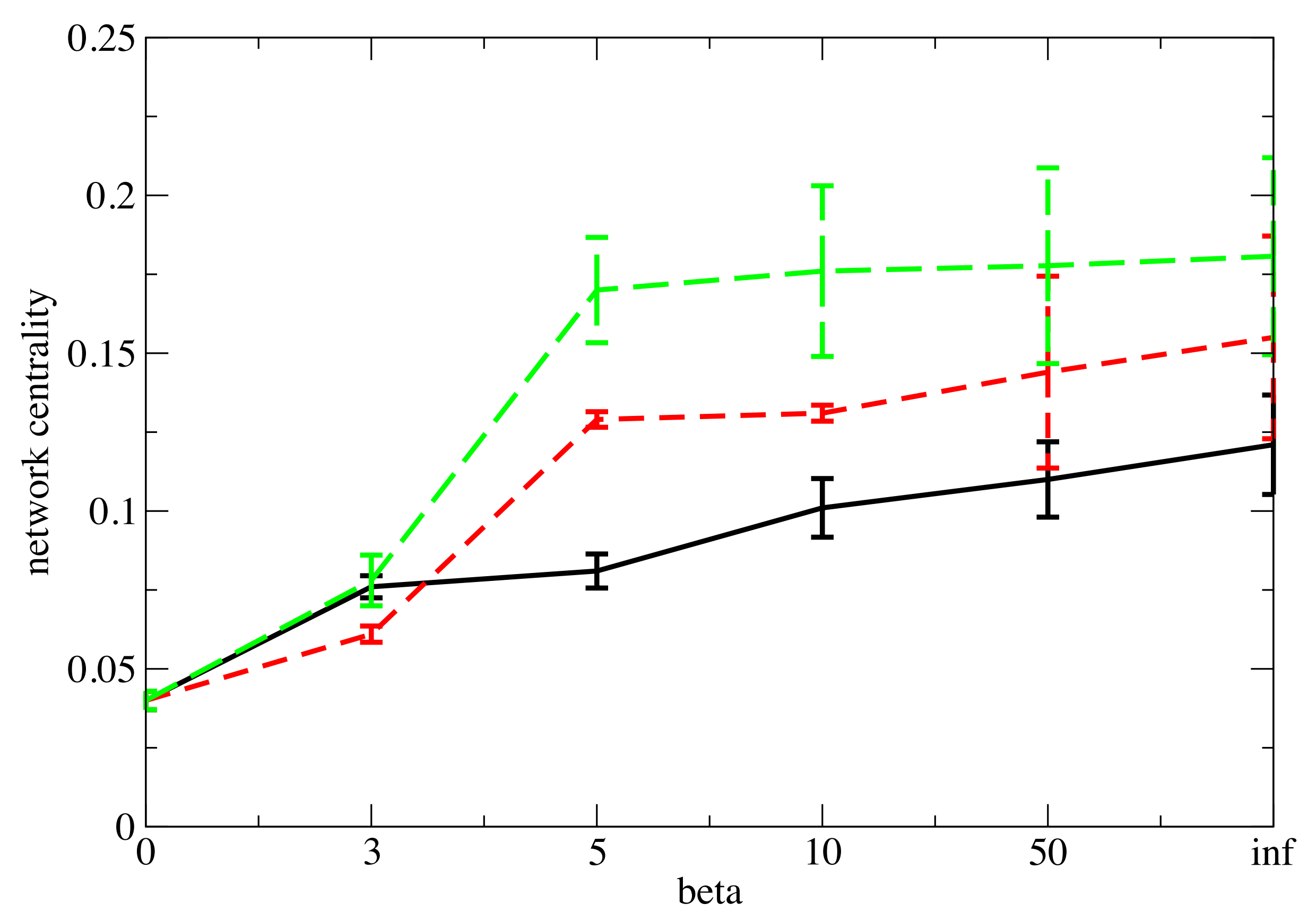




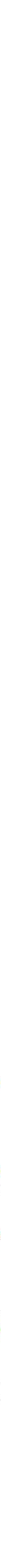

Figure15

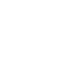

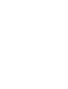

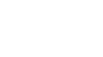

-

-

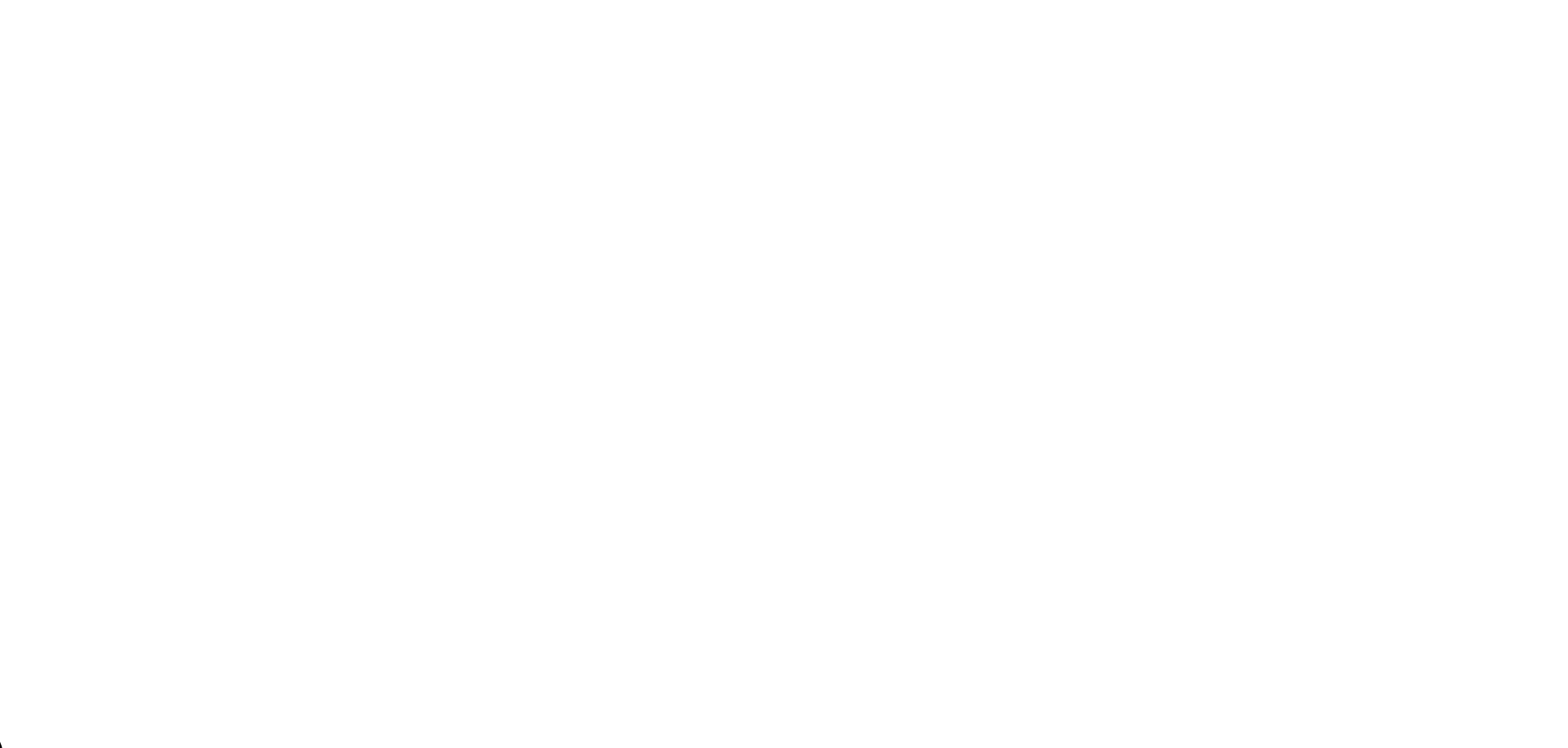




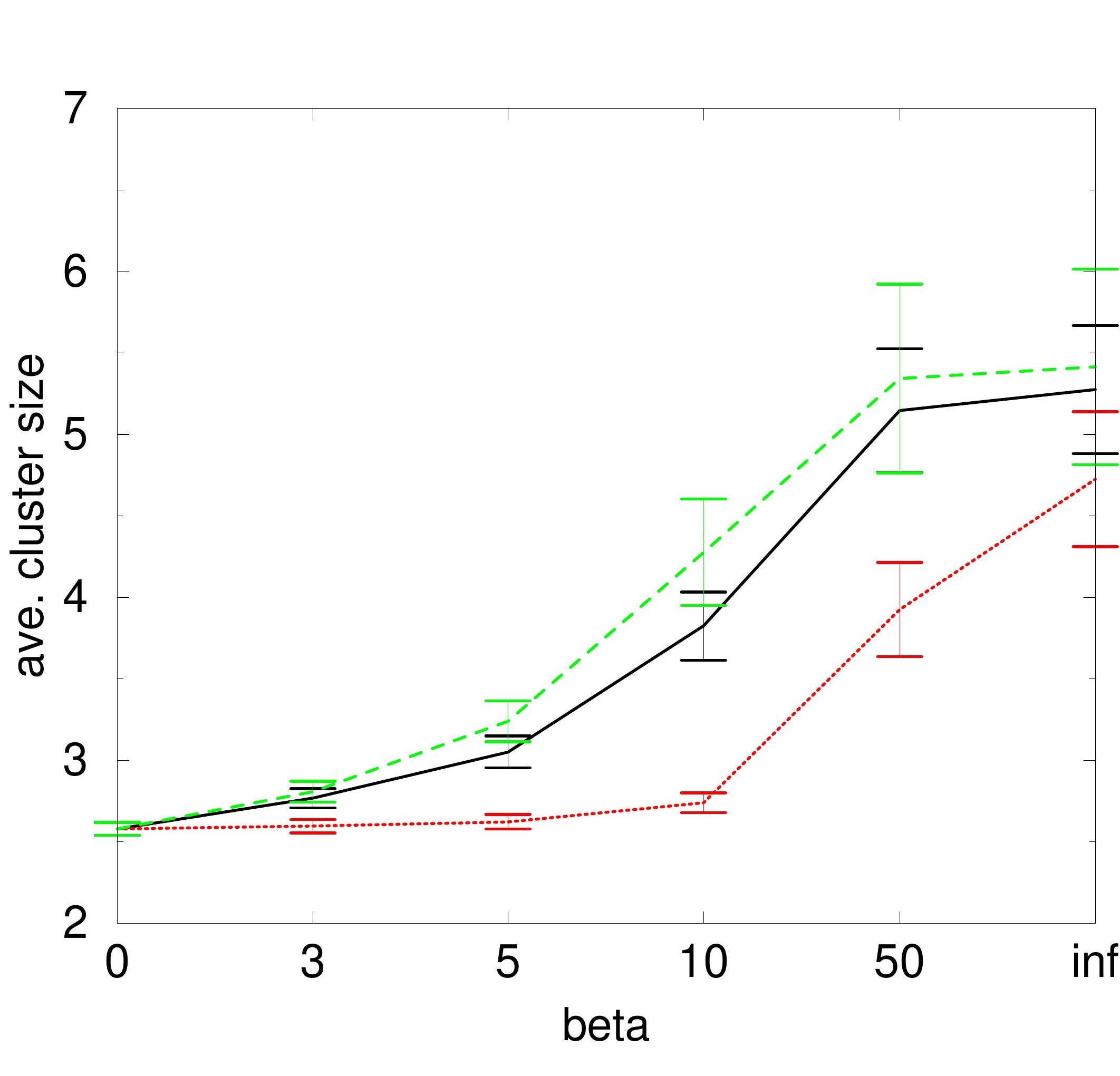

Figure16

Fure16

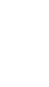

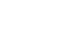
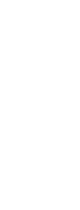


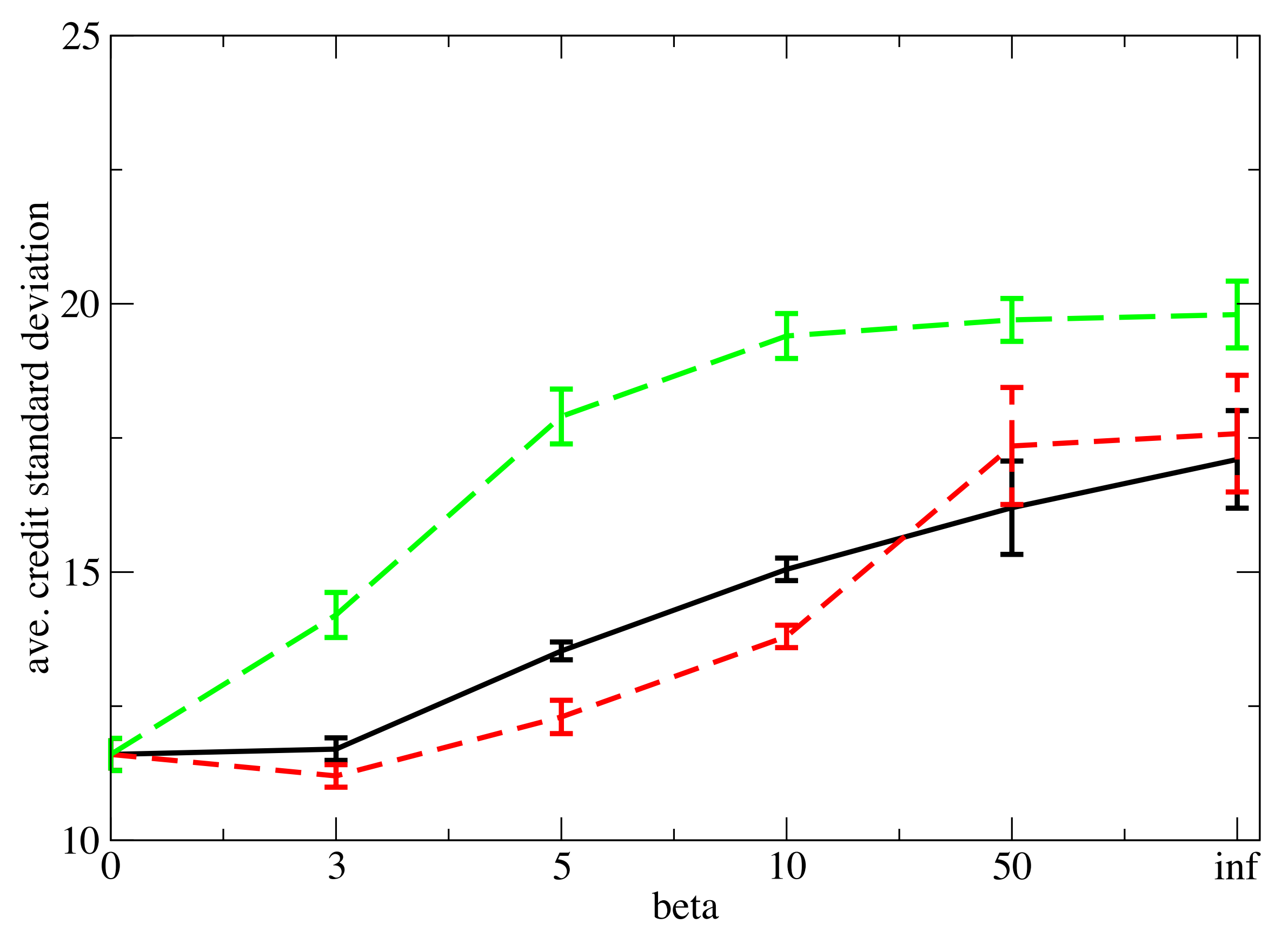




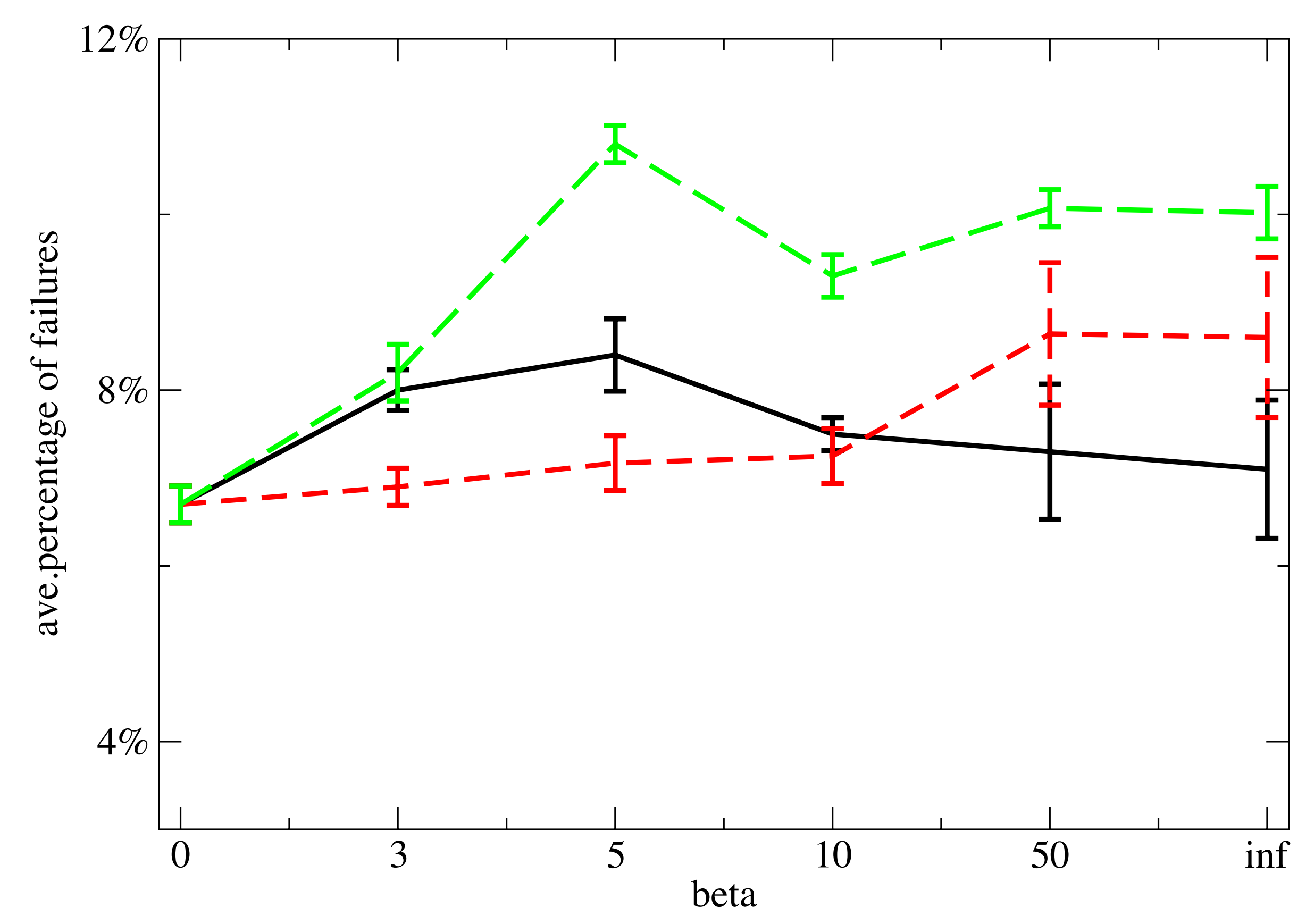




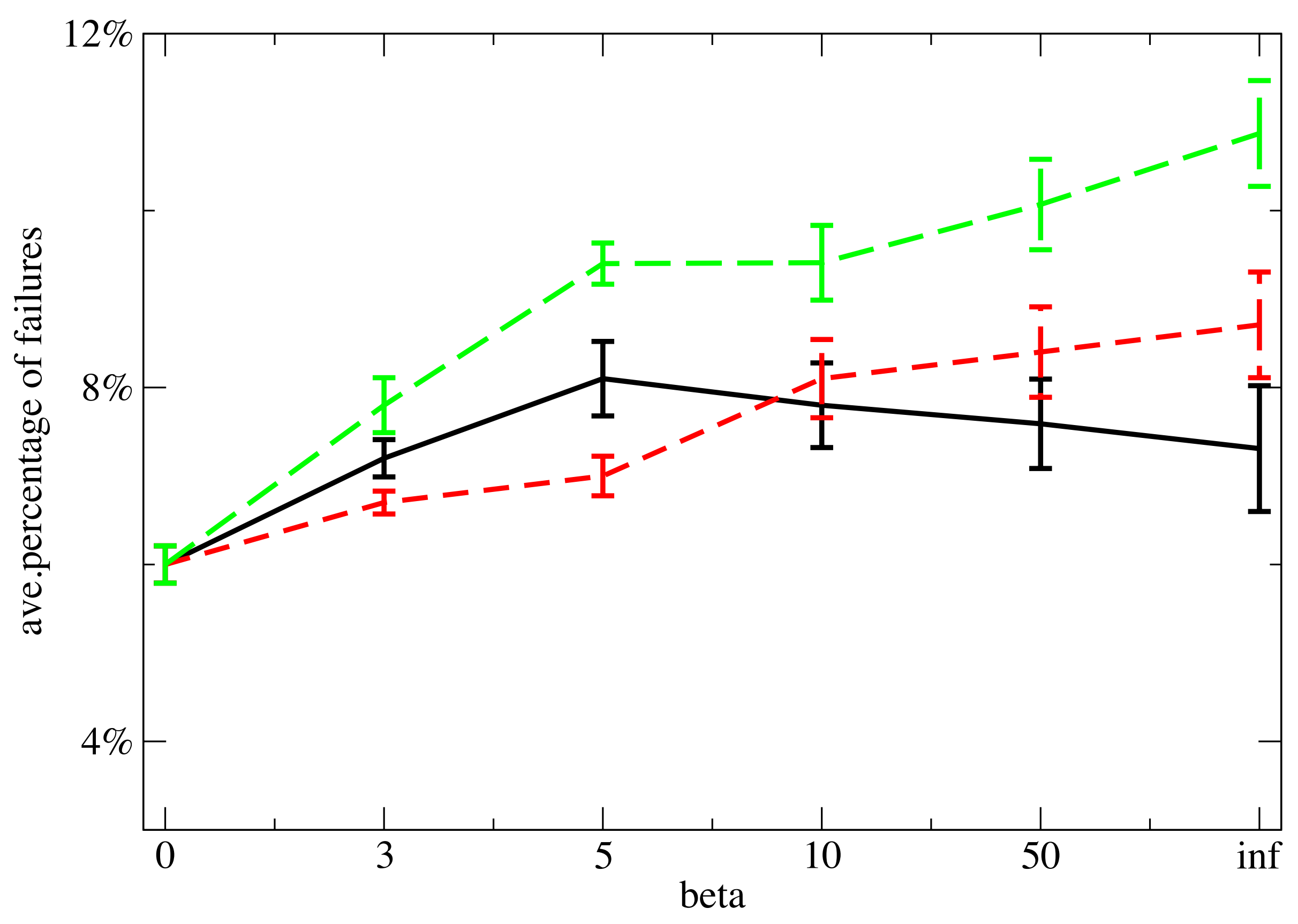




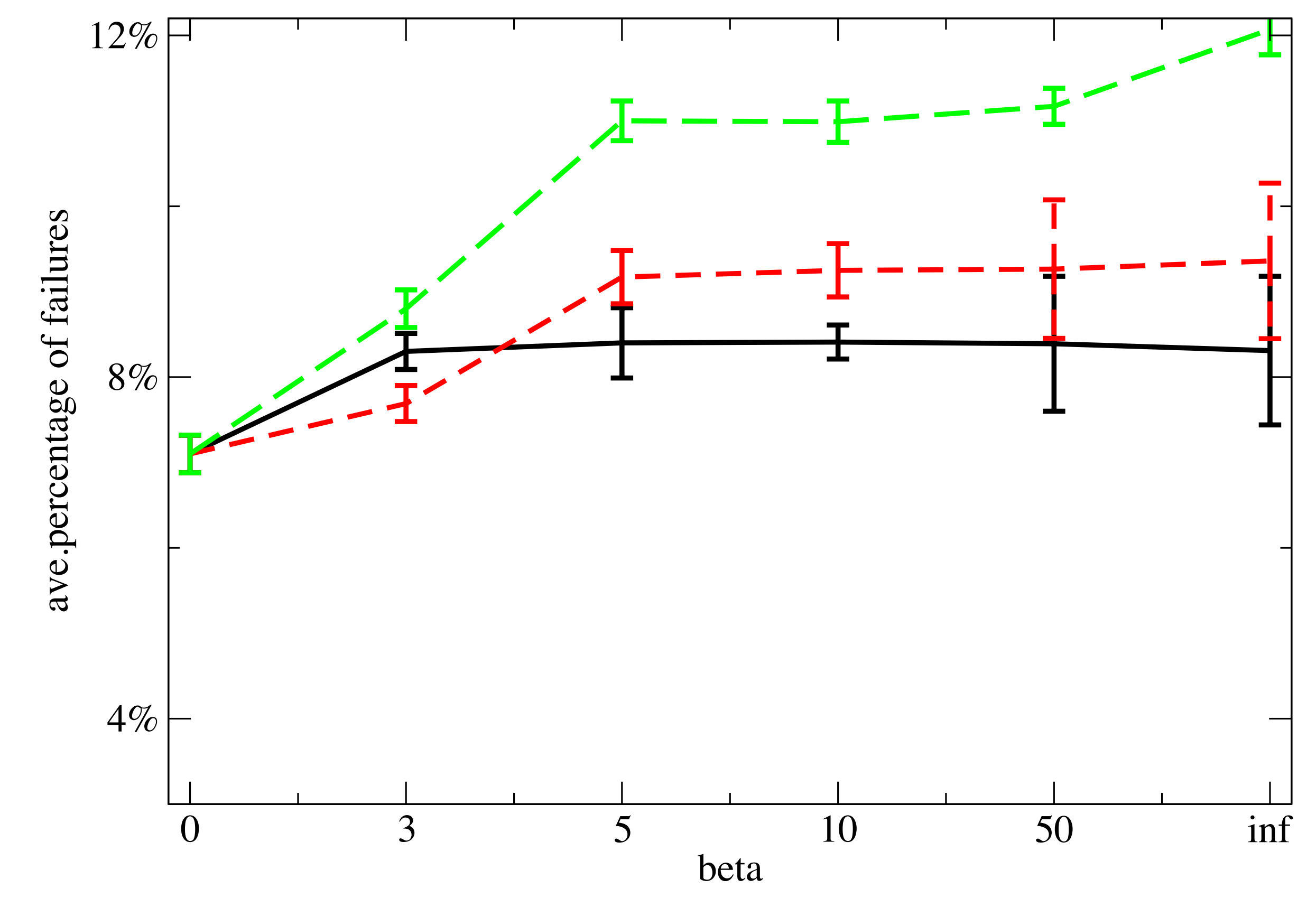




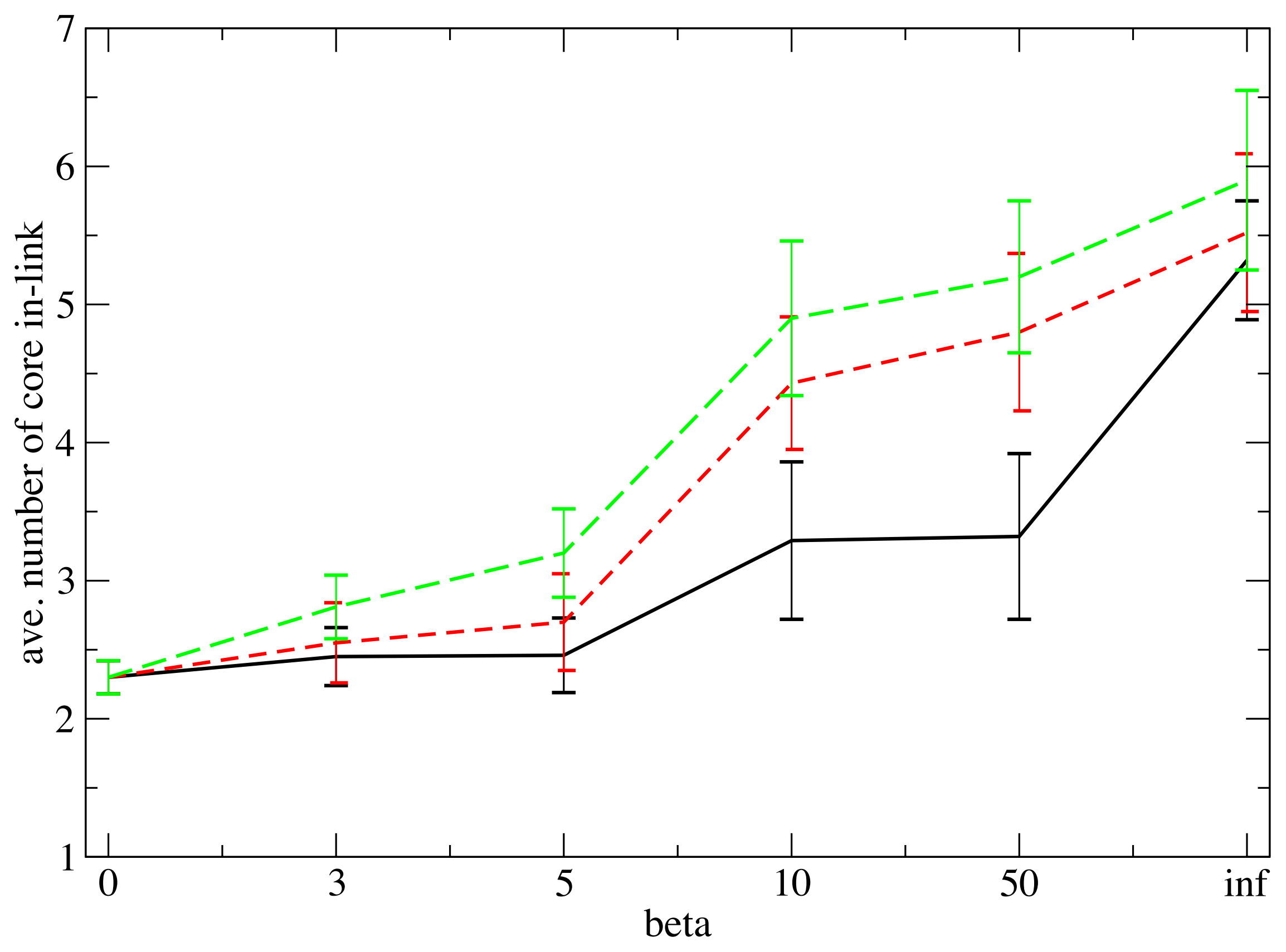




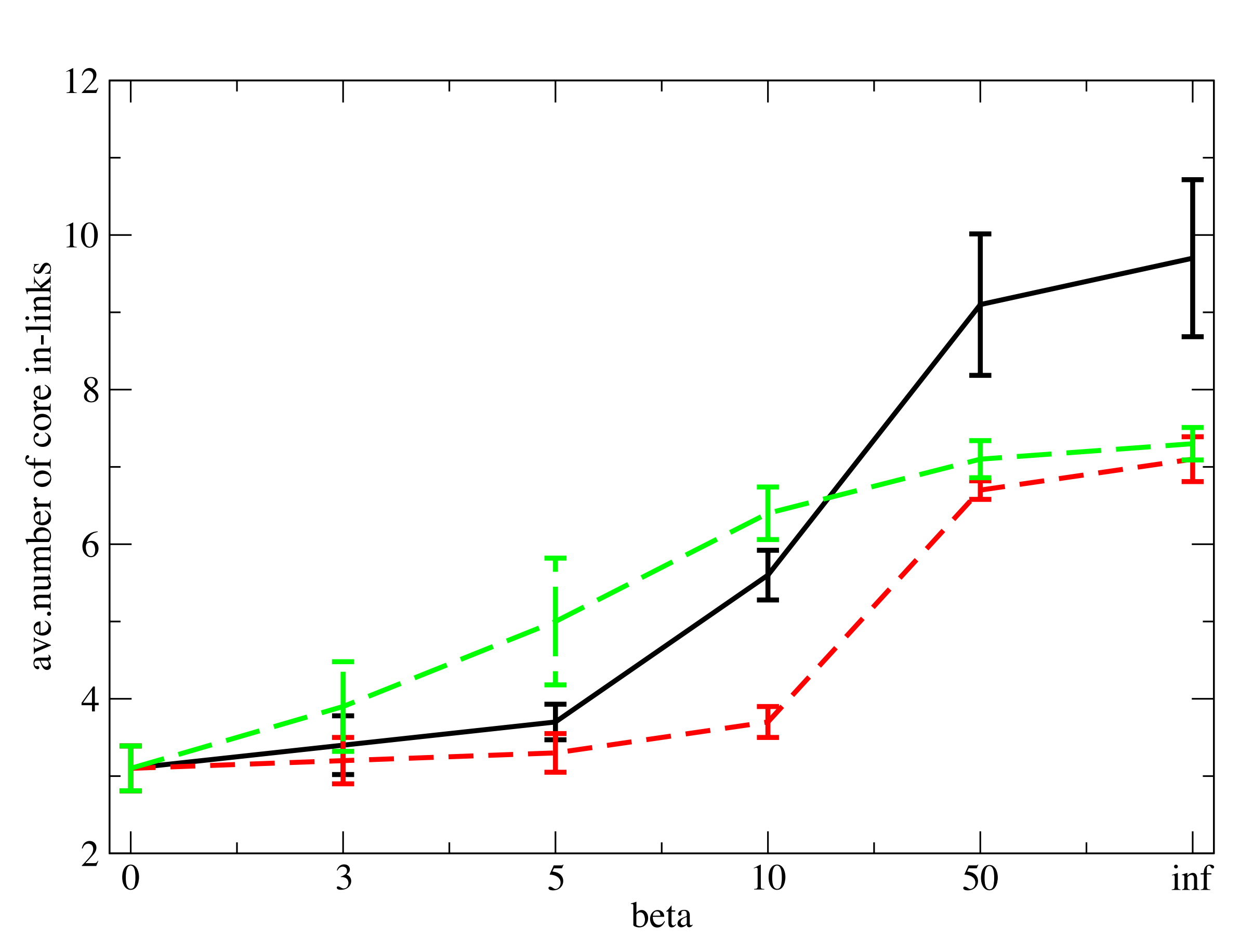




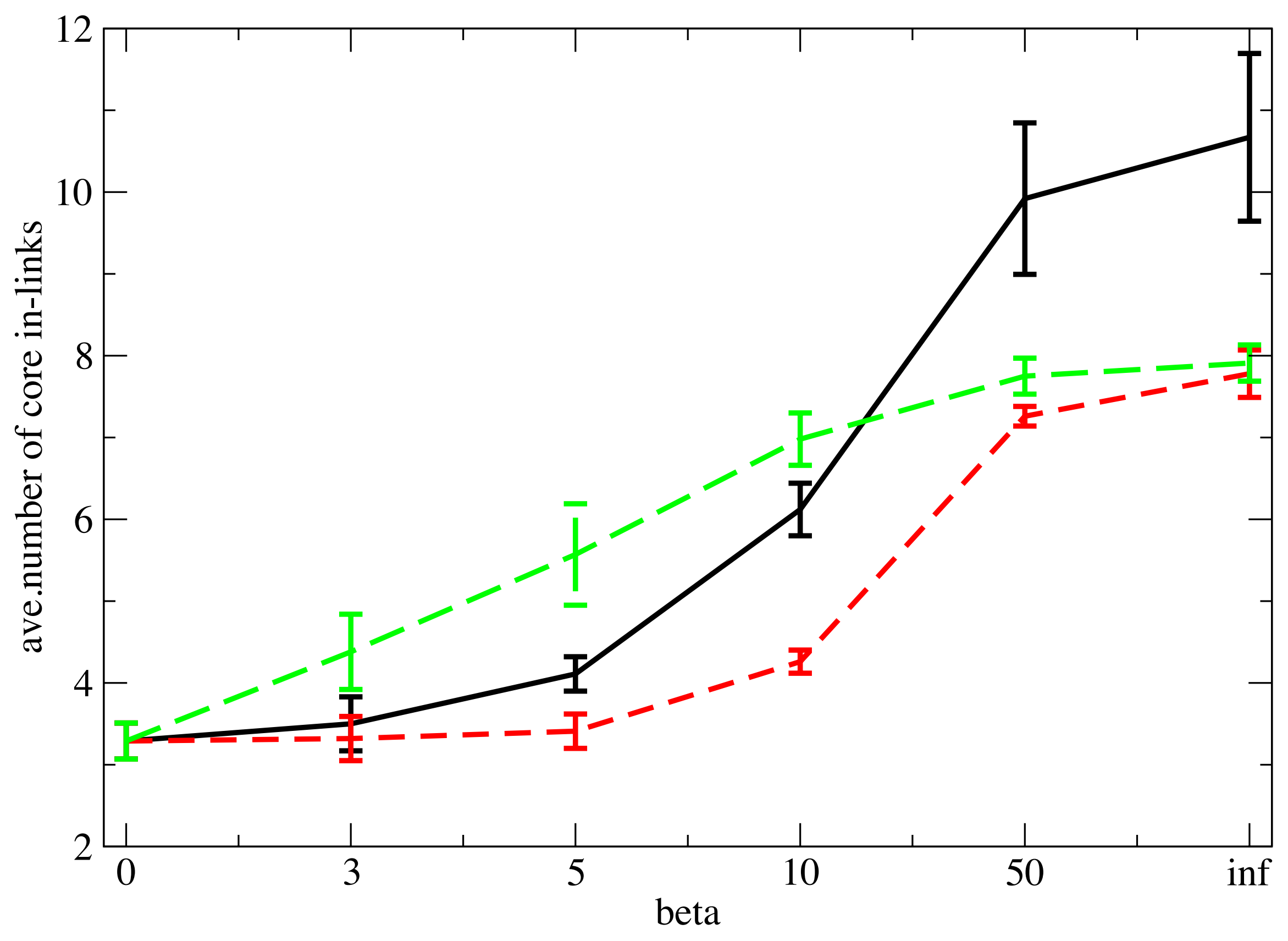




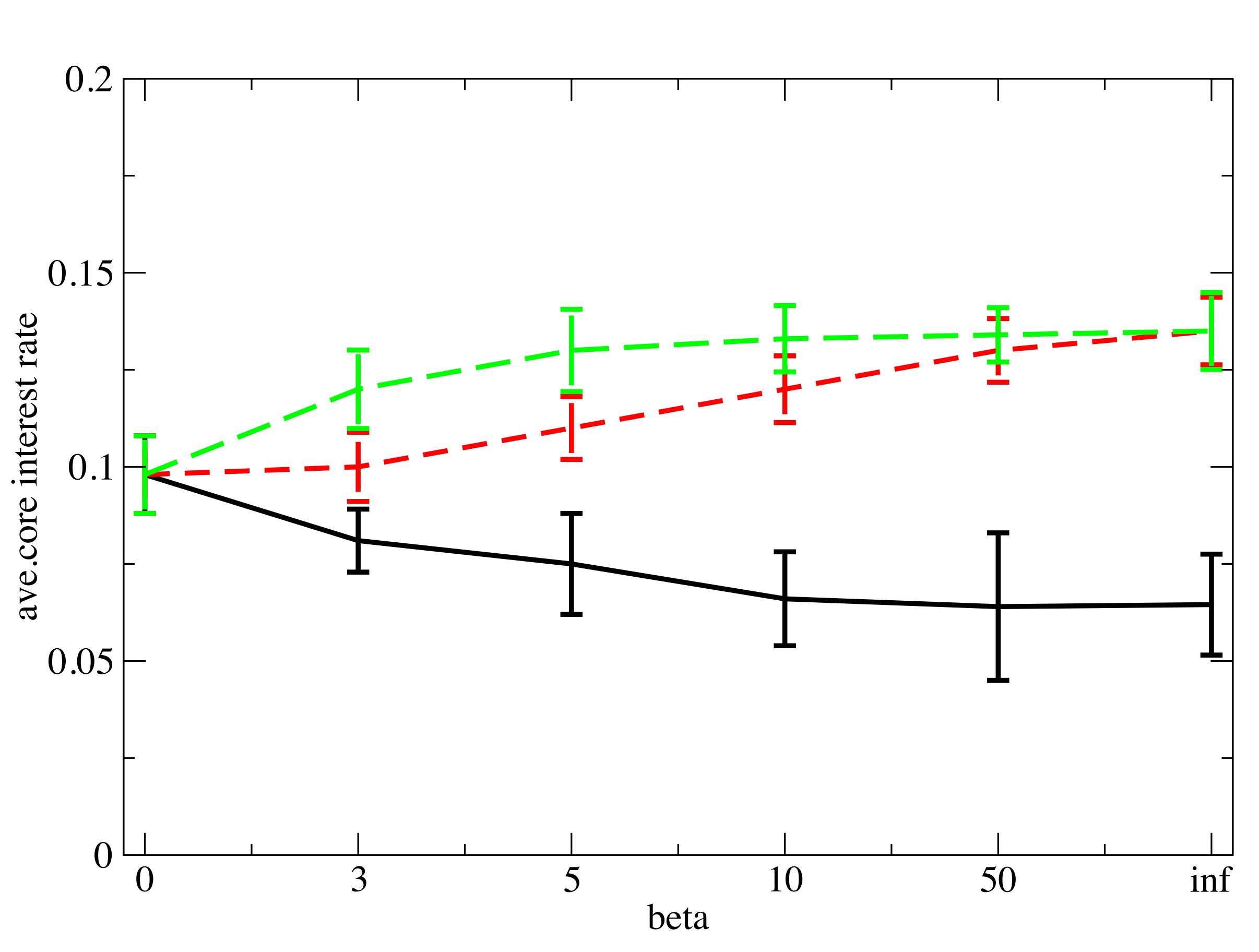




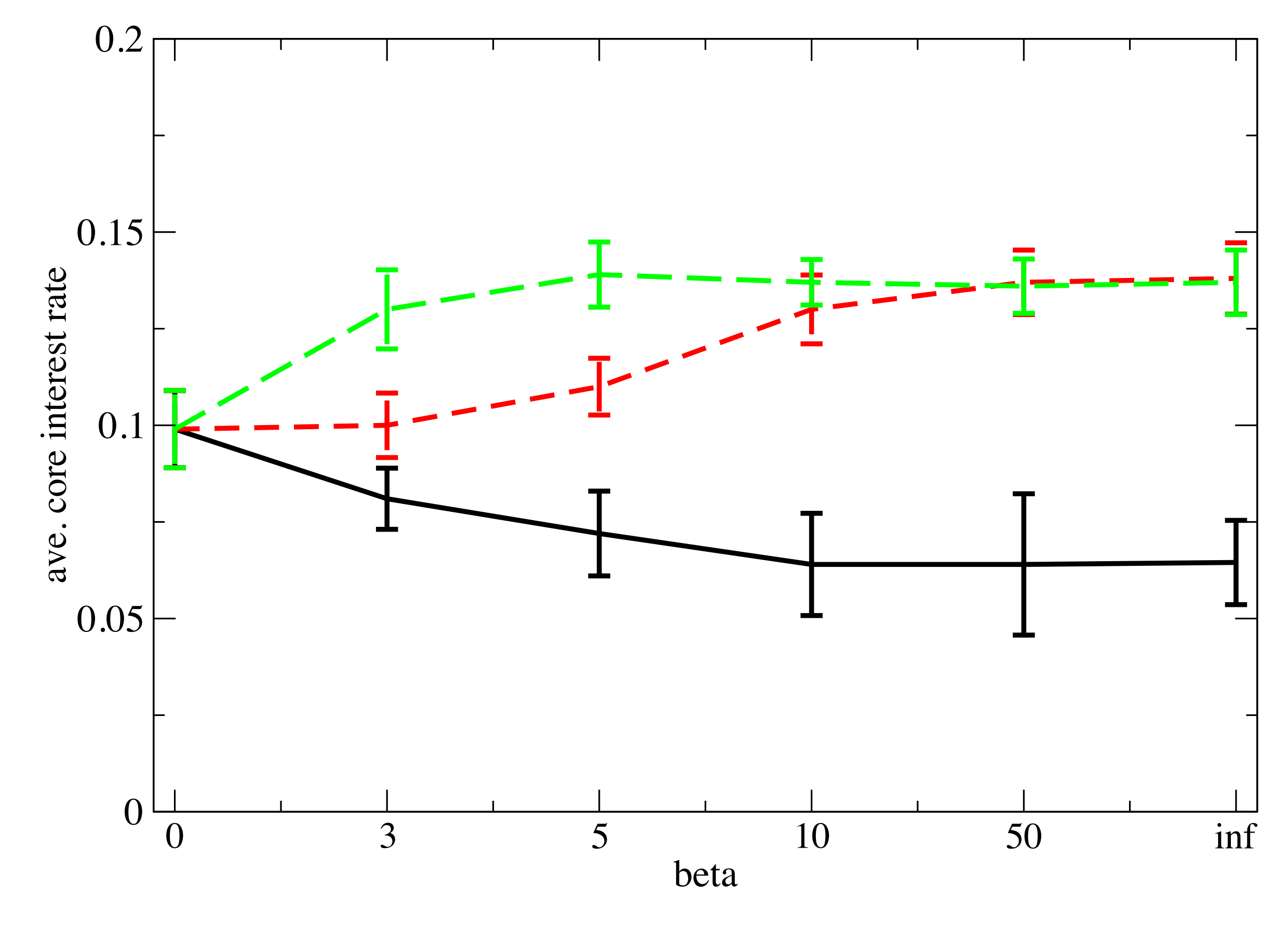

.

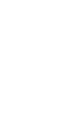




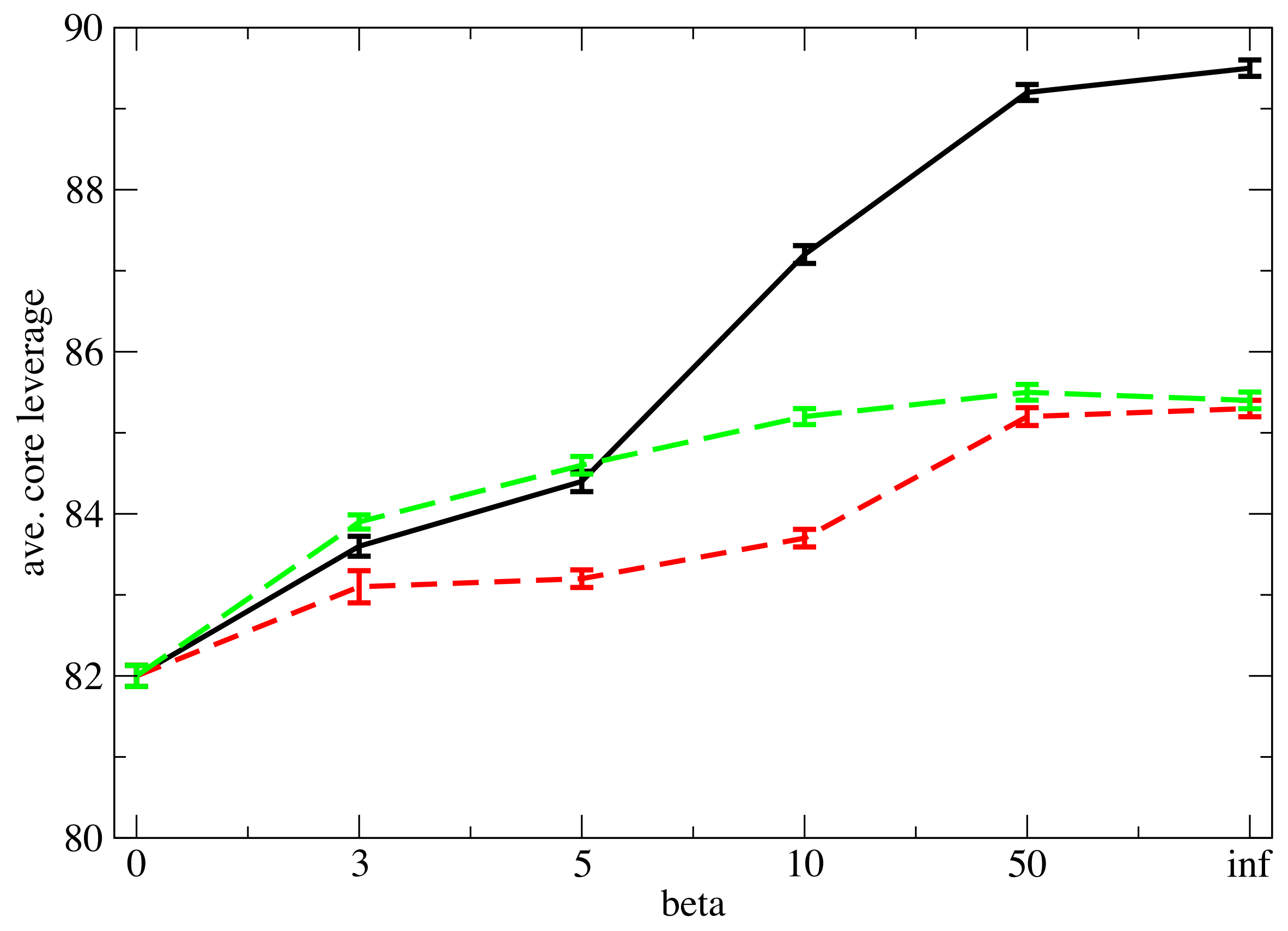




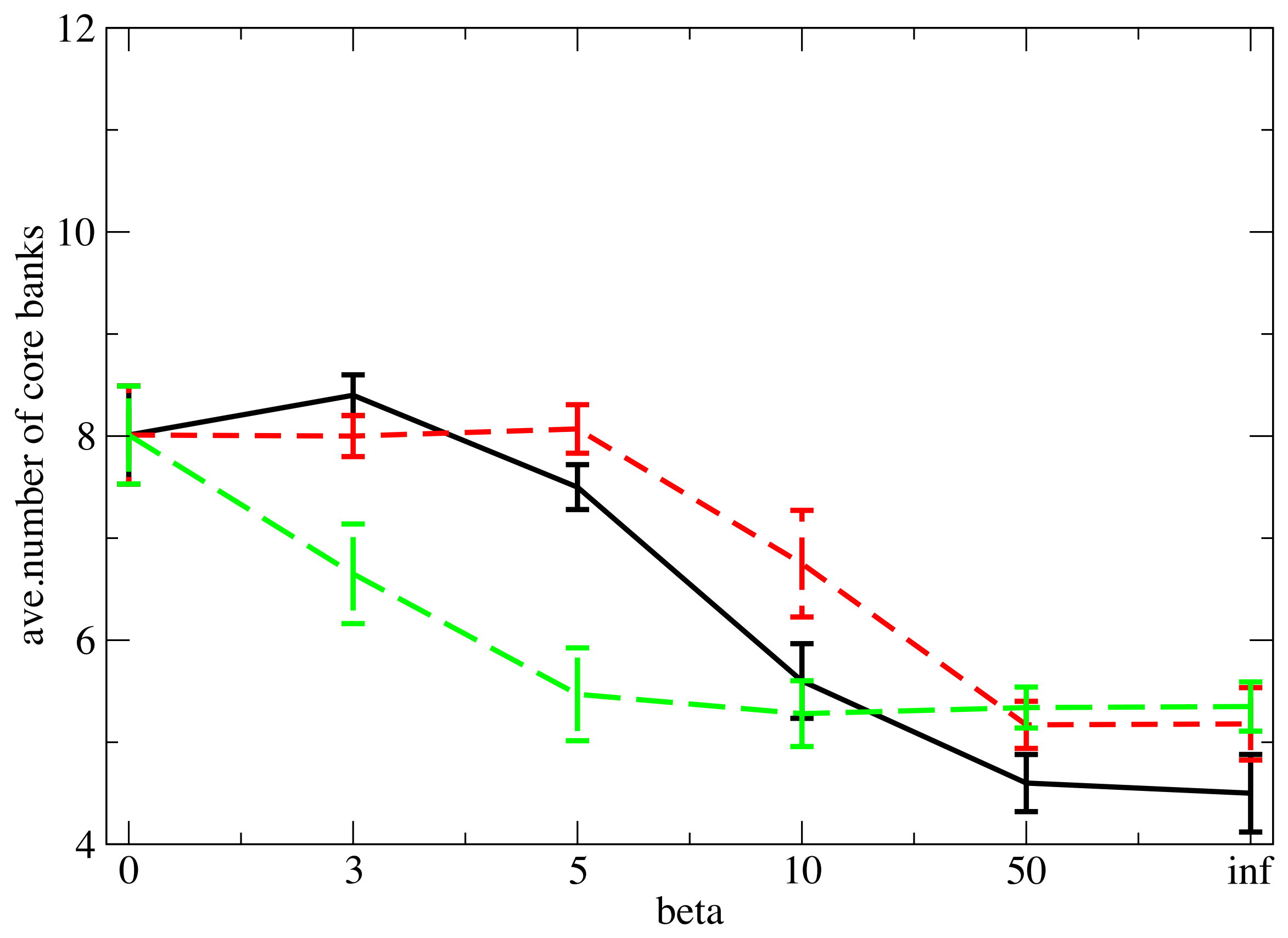




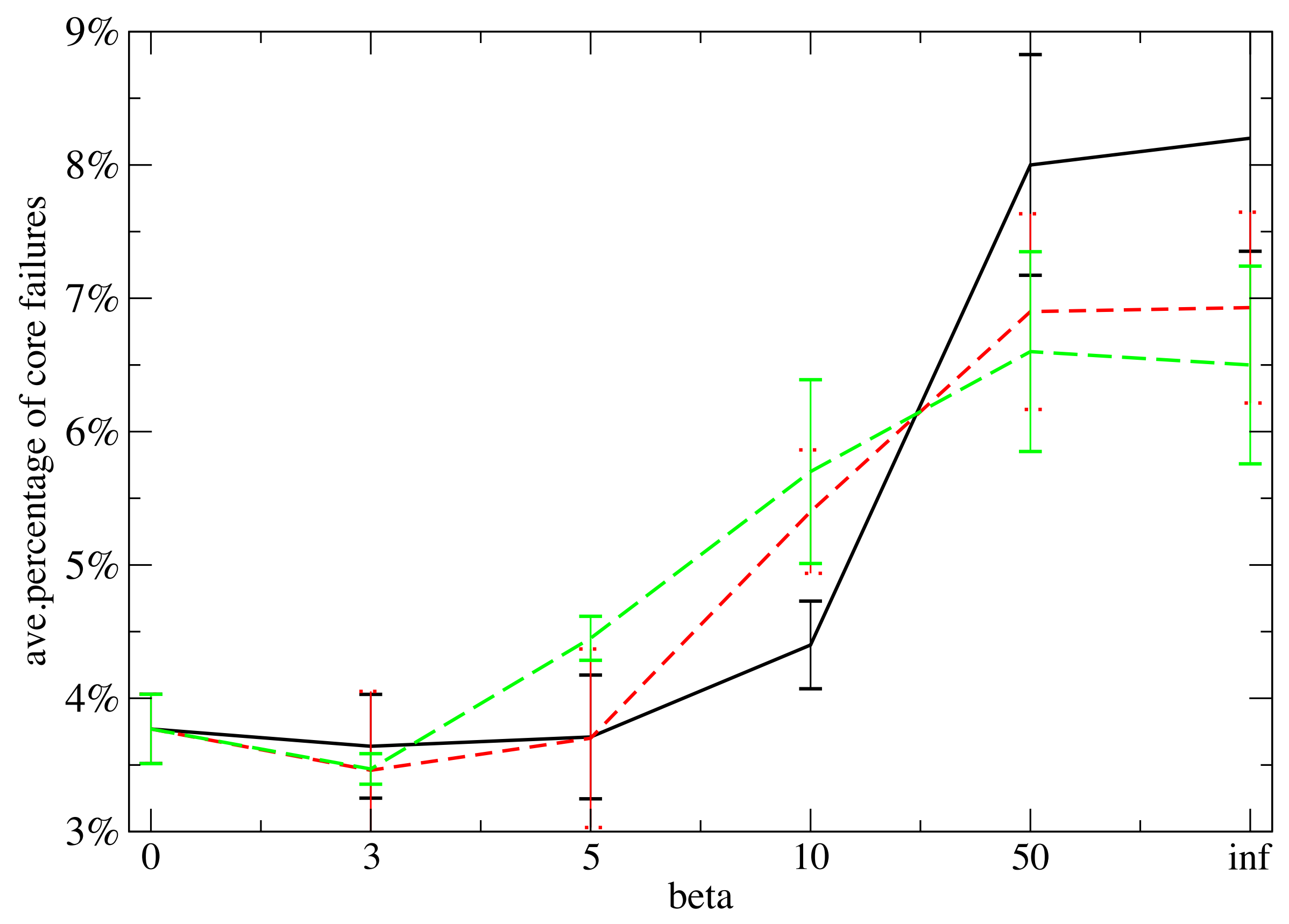




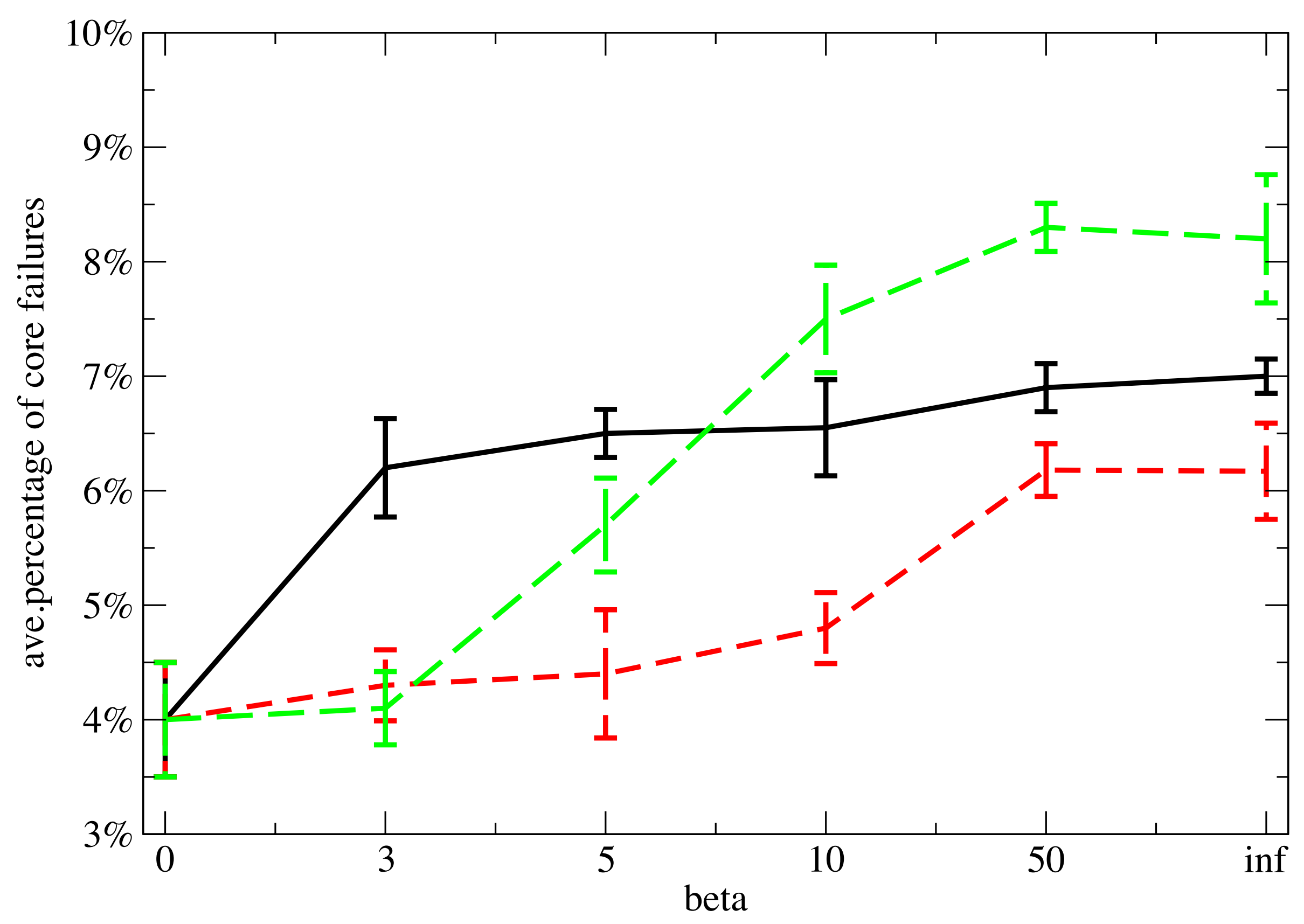




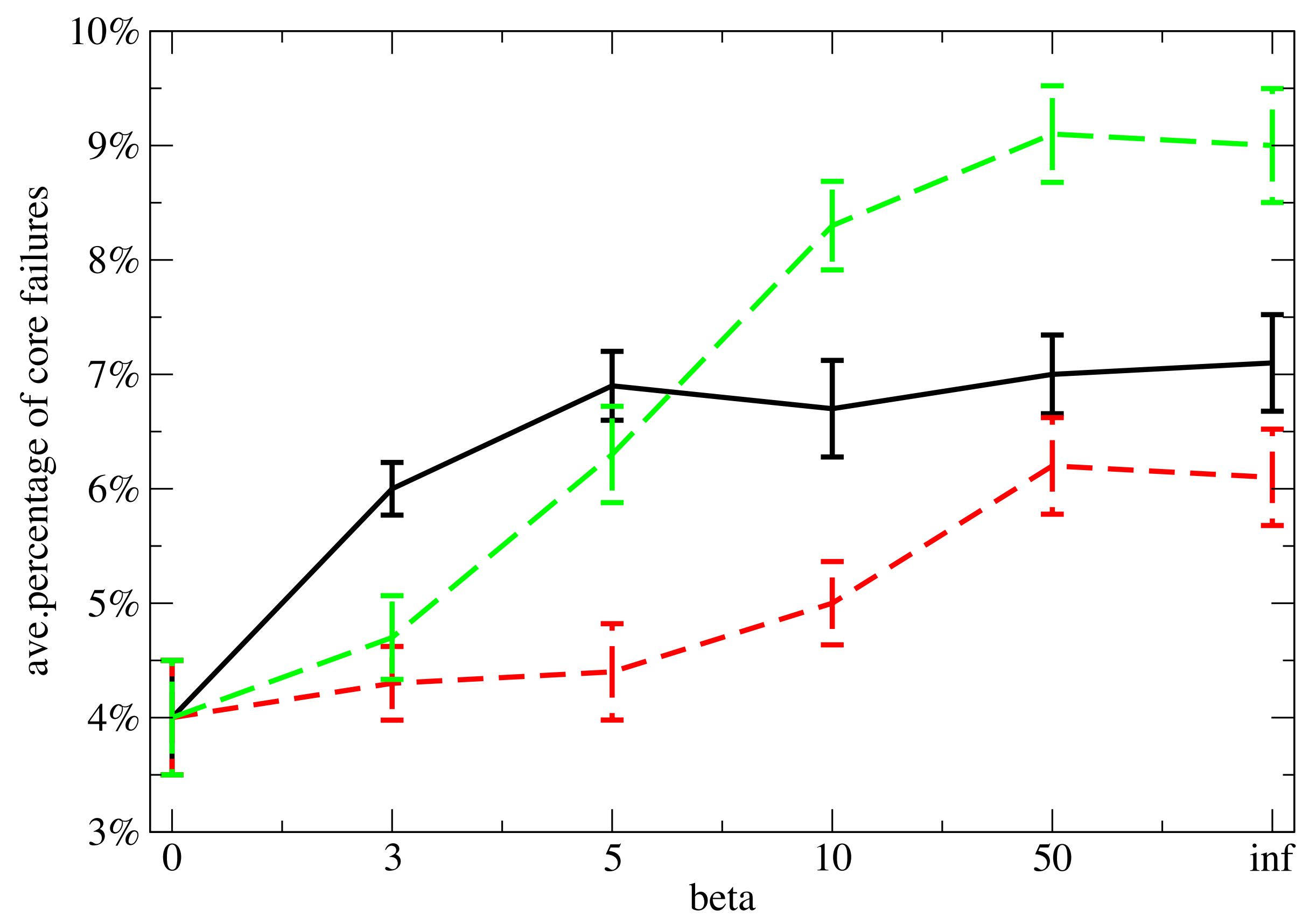


Interbank debt

repayment

4

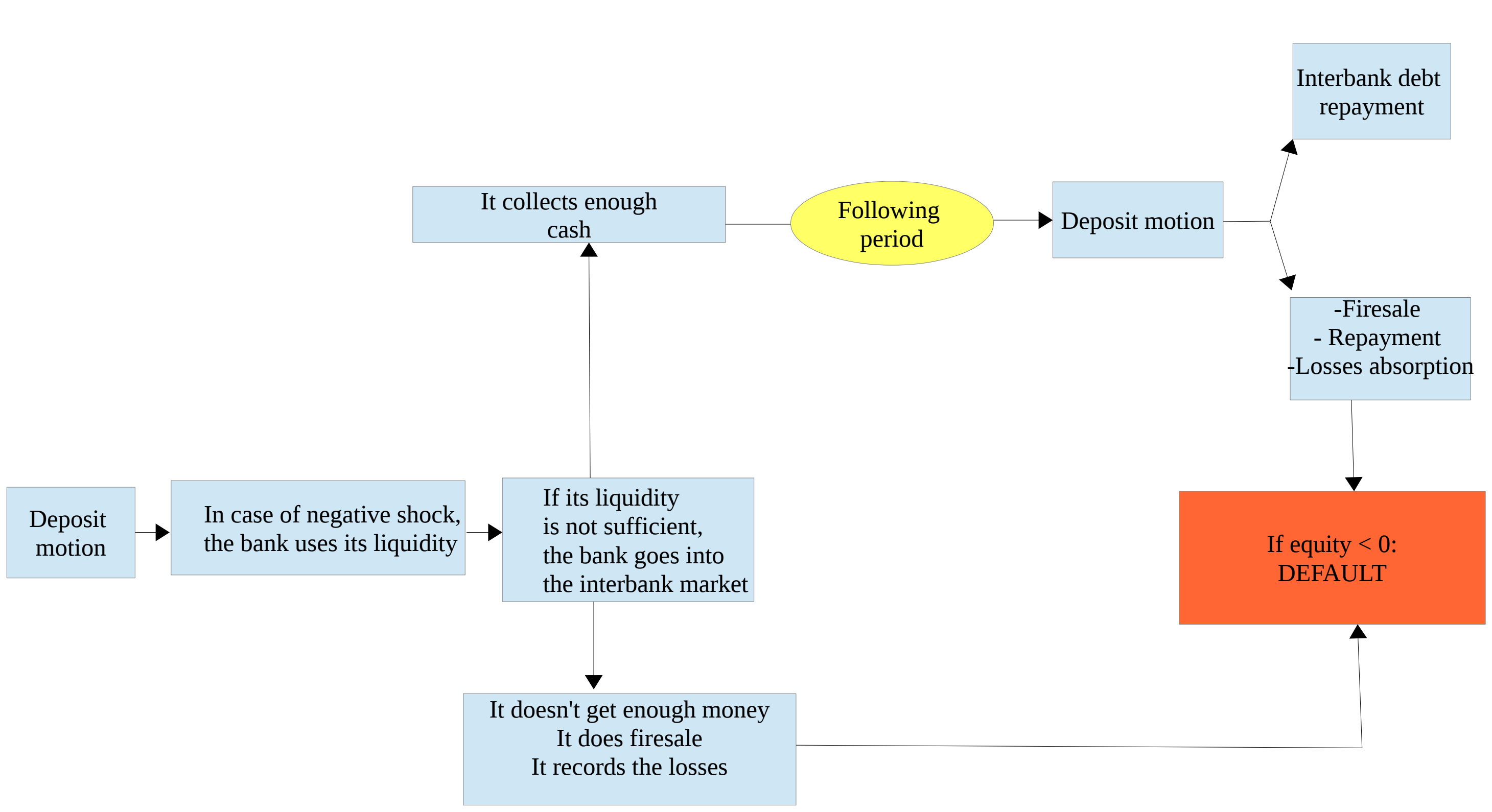

-Firesale

- Repayment

-Losses absorption

Deposit
motion

In case of negative shock, the bank uses its liquidity

If its liquidity

is not sufficient, the bank goes into the interbank market

It doesn't get enough money

It does firesale

It records the losses

\section{If equity $<0$ : DEFAULT}




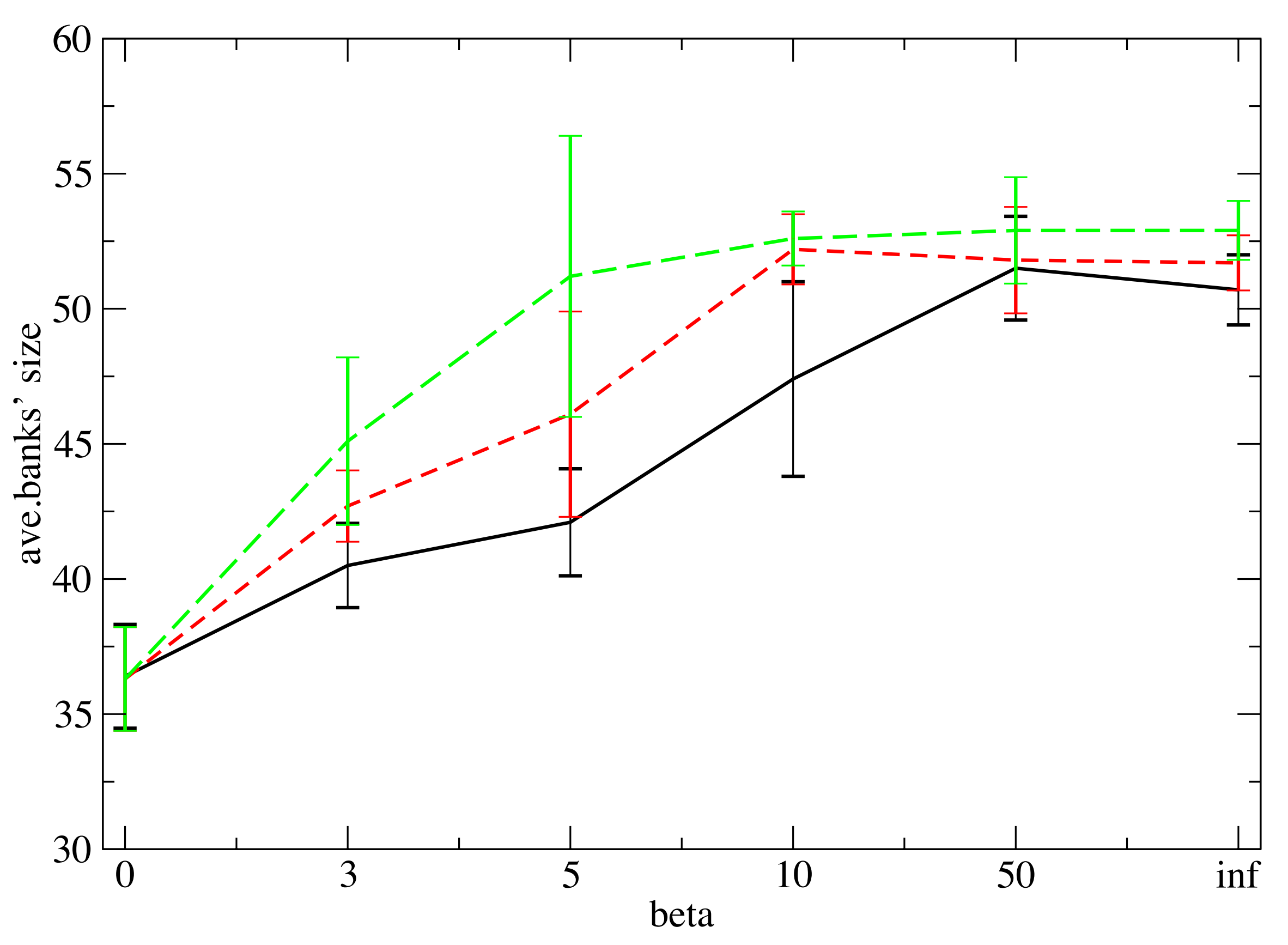


Figure

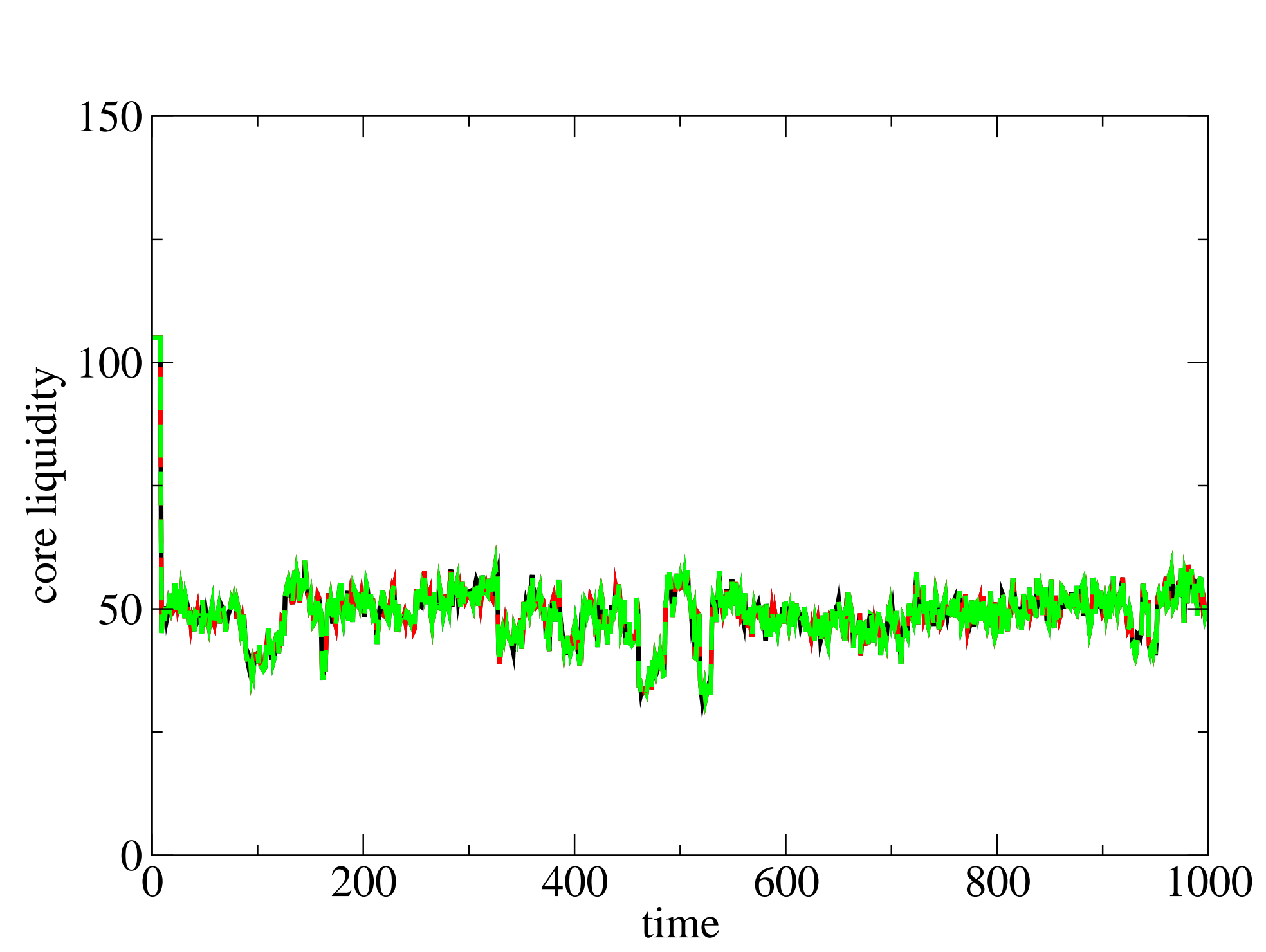

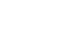


Figure

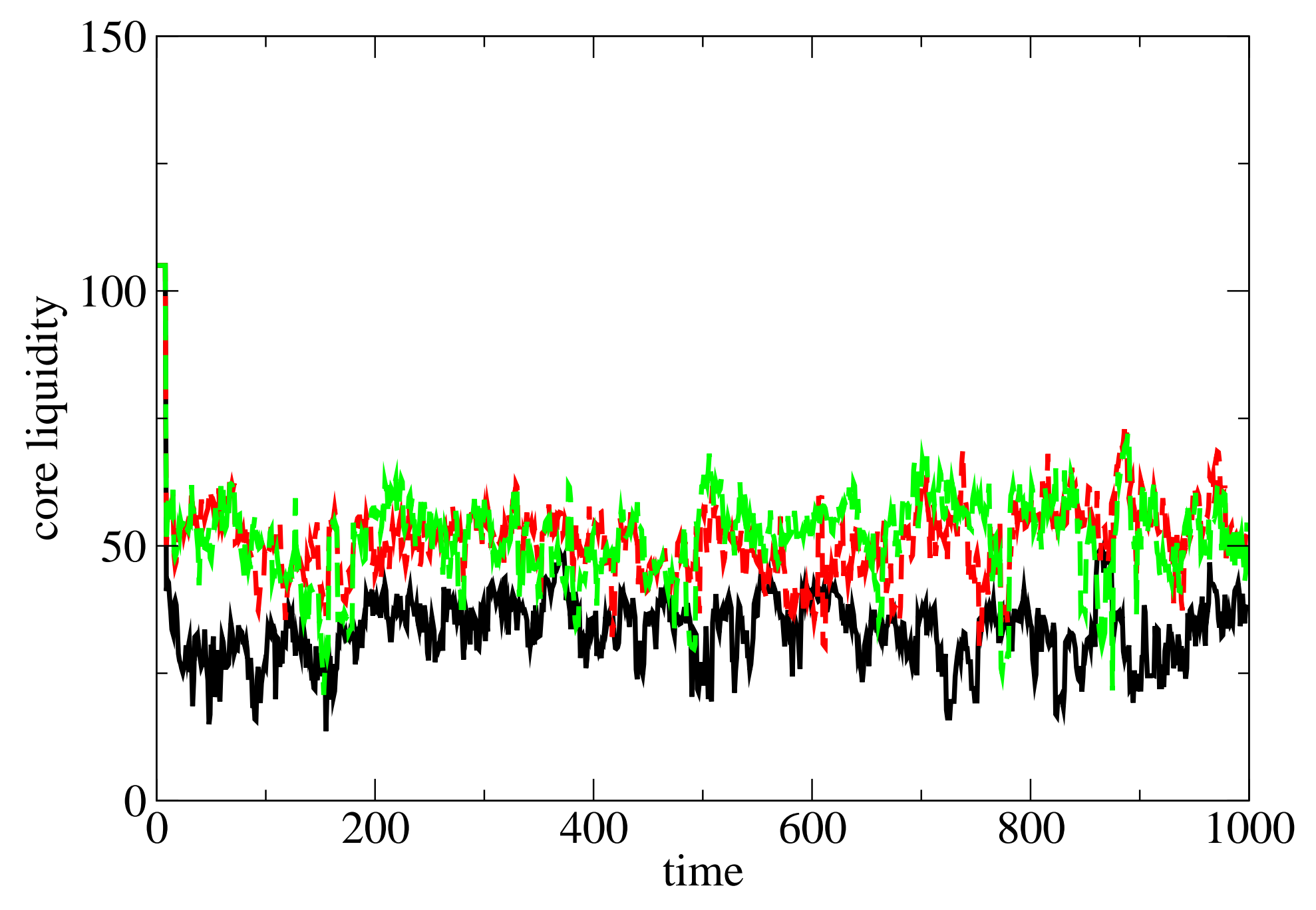
Figure

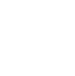

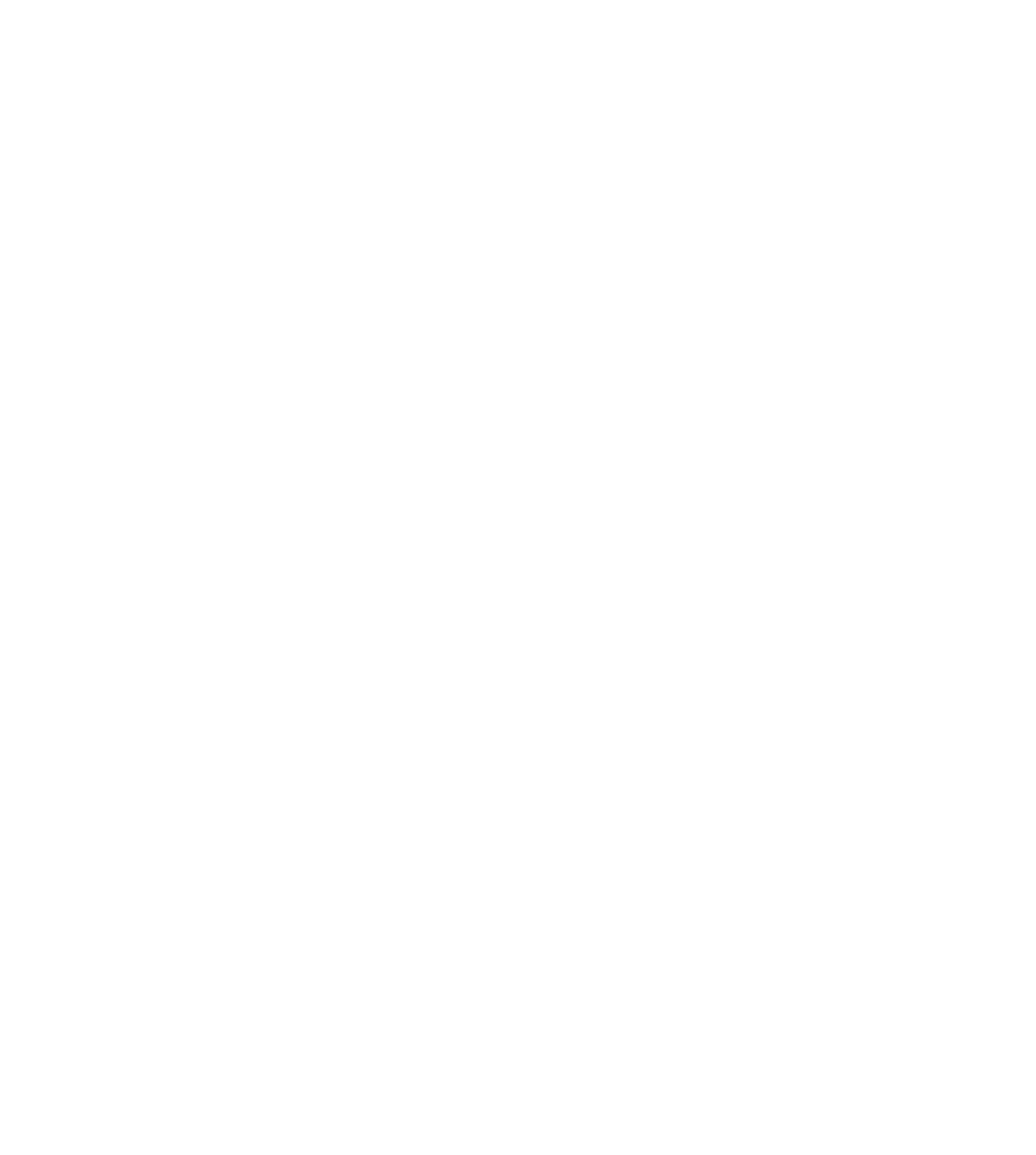




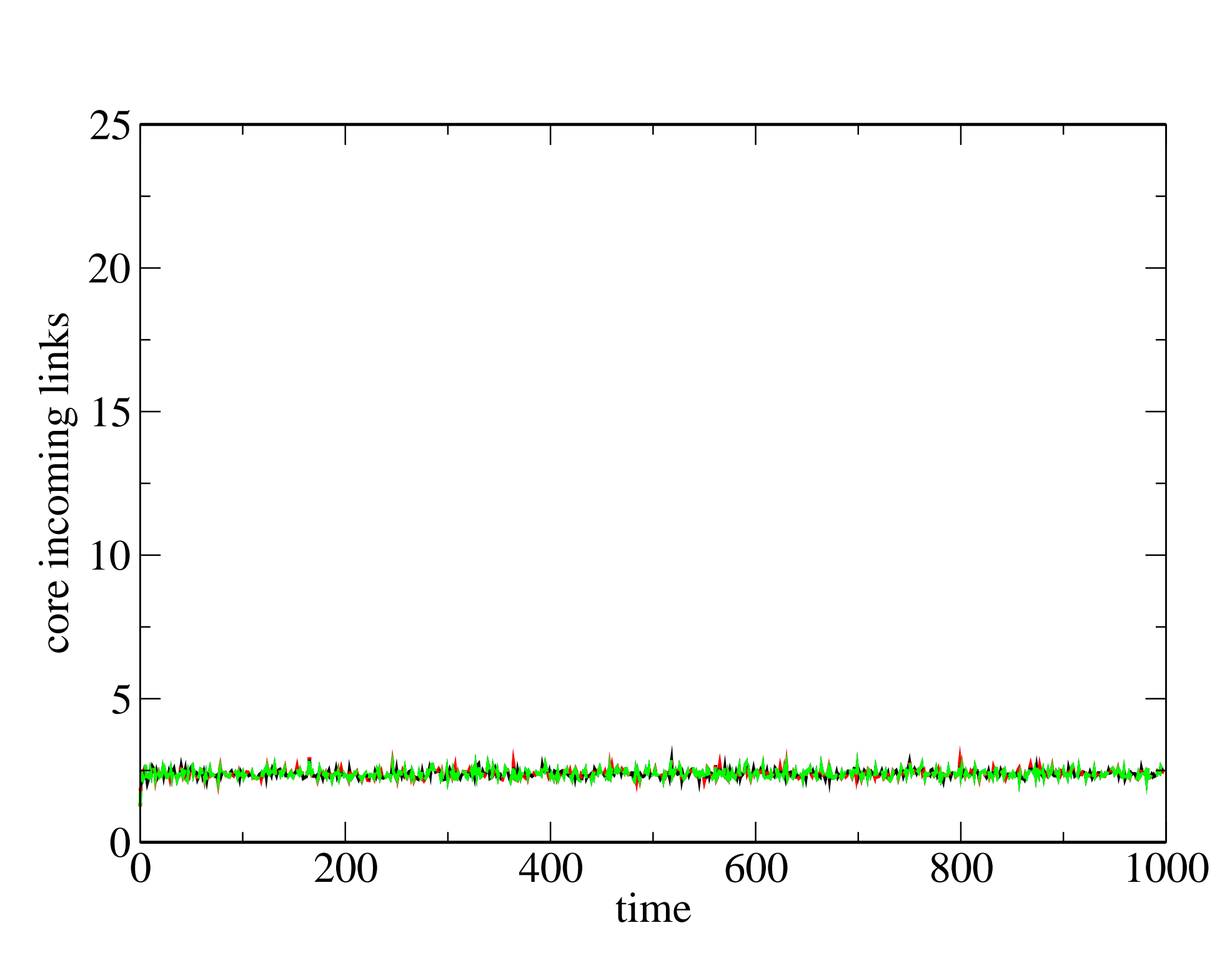

Figure

.




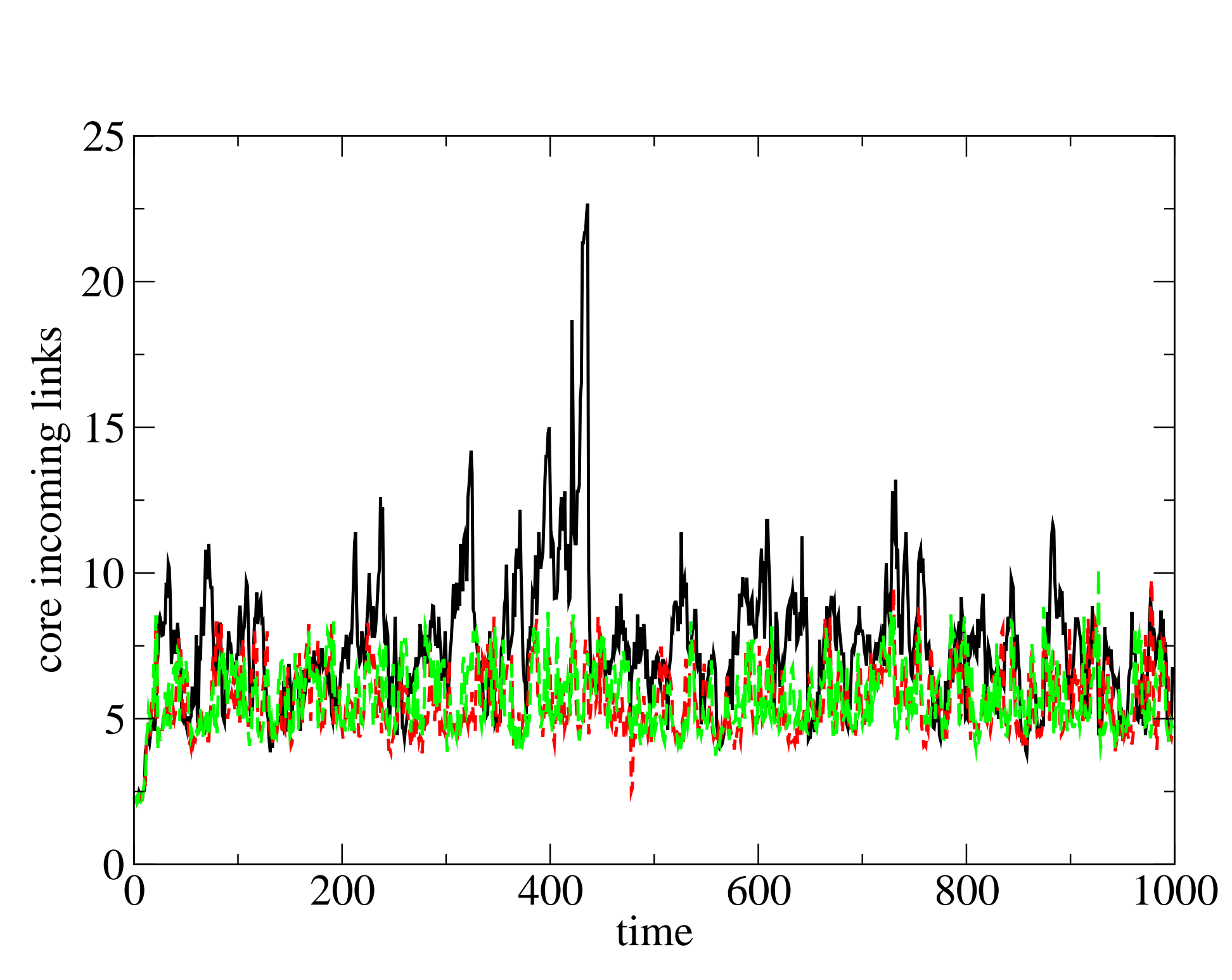

Figure

\section{.}

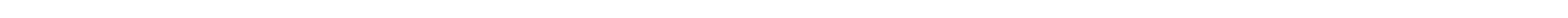


Figure

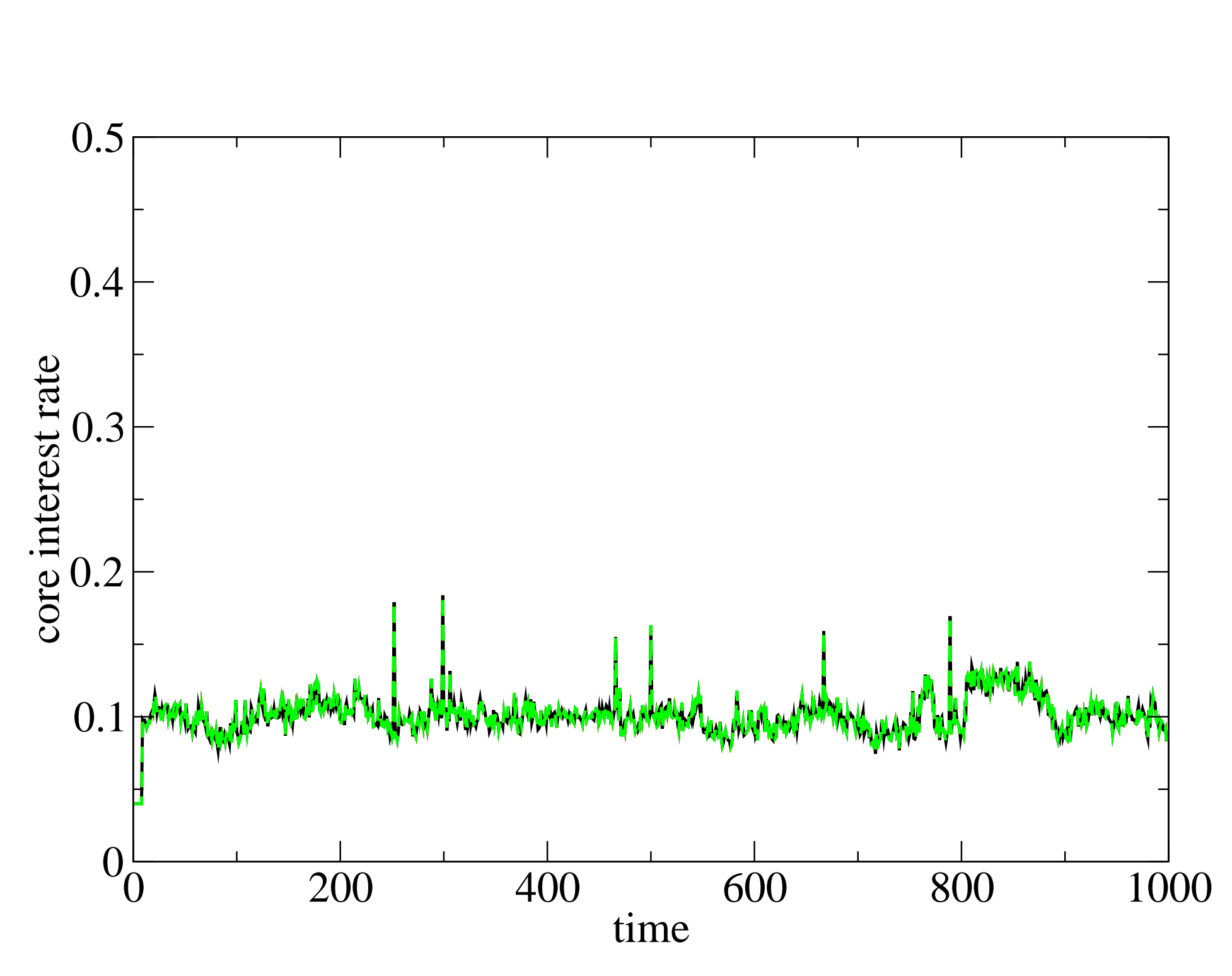

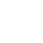

.

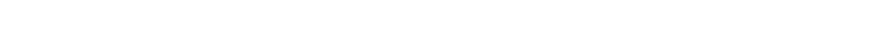

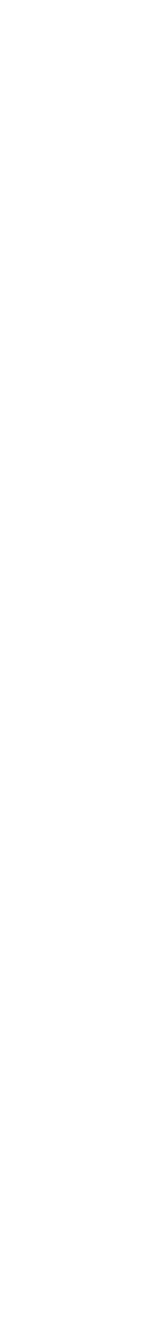




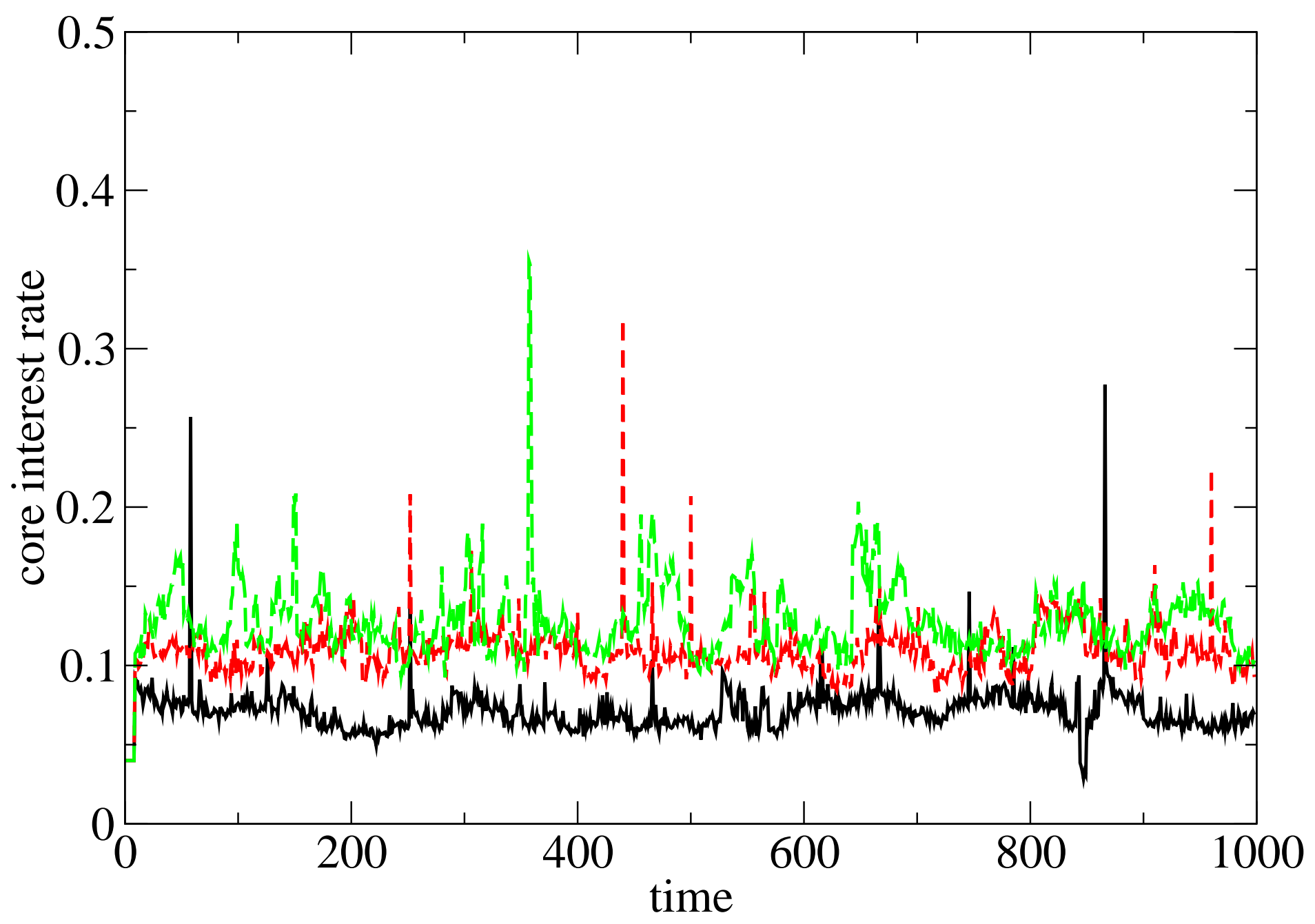




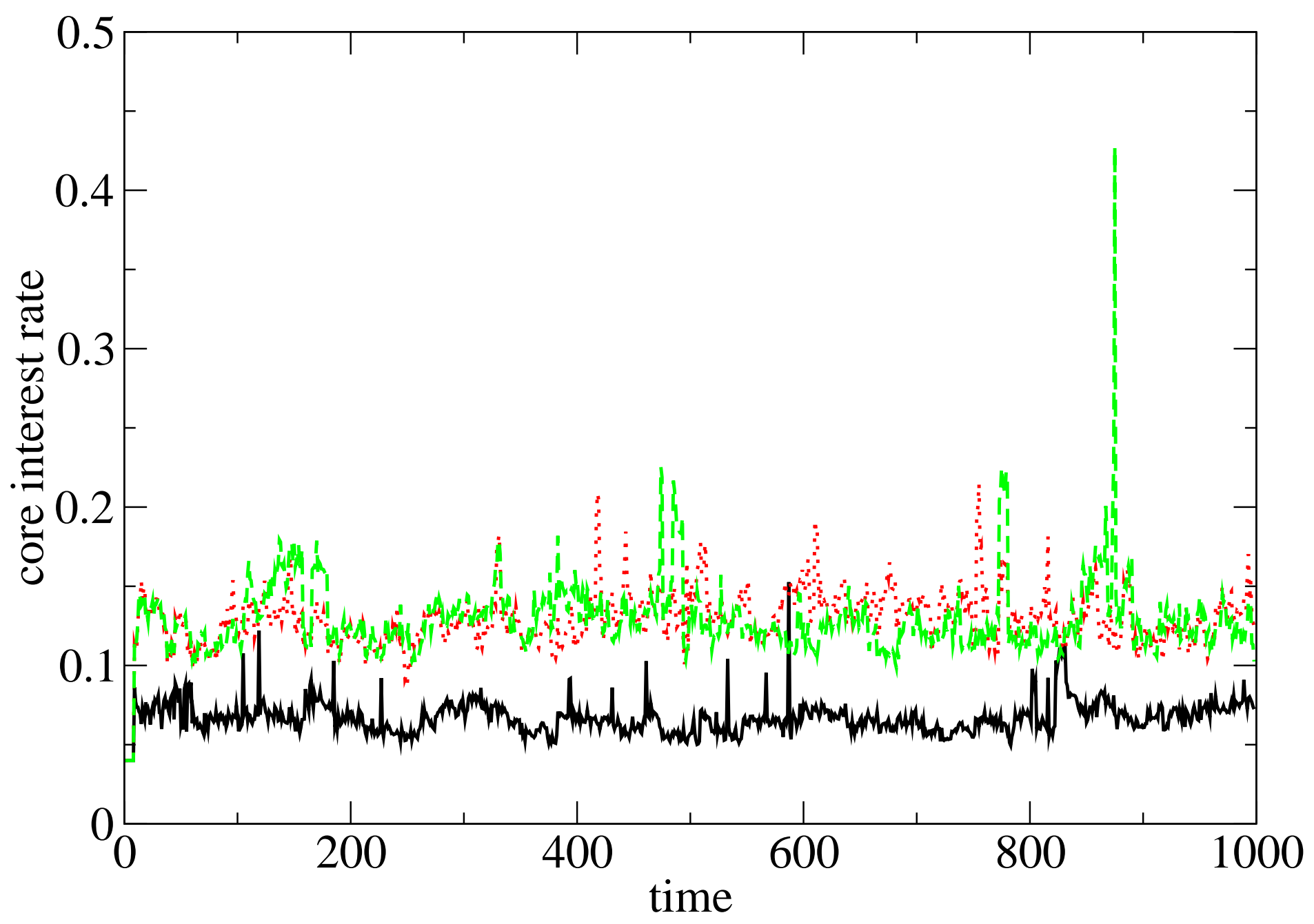


LaTeX Source Files
Click here to download LaTeX Source Files: Interbank_REV3.tex

LaTeX Source Files
Click here to download LaTeX Source Files: Interbank_REV3.tex Click here to download LaTeX Source Files: Interbank REV3.tex

$\sqrt{2}$

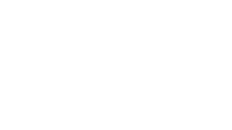

(n)

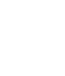

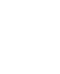

(1)

(1)

(1)

(1)

$\sqrt{3}$

